University of South Carolina

Scholar Commons

Theses and Dissertations

2016

More Than One Voice: Utilizing Students' Home Languages And Cultural Experiences In Reading Recovery

Sarah Catto

University of South Carolina

Follow this and additional works at: https://scholarcommons.sc.edu/etd

Part of the Language and Literacy Education Commons

Recommended Citation

Catto, S.(2016). More Than One Voice: Utilizing Students' Home Languages And Cultural Experiences In Reading Recovery. (Doctoral dissertation). Retrieved from https://scholarcommons.sc.edu/etd/3917

This Open Access Dissertation is brought to you by Scholar Commons. It has been accepted for inclusion in Theses and Dissertations by an authorized administrator of Scholar Commons. For more information, please contact digres@mailbox.sc.edu. 


\title{
MORE THAN ONE VOICE: UTILIZING STUDENTS' HOME LANGUAGES AND CULTURAL EXPERIENCES IN READING RECOVERY
}

\author{
by \\ Sarah Catto \\ Bachelor of Science \\ Presbyterian College, 2003 \\ Master of Education \\ University of South Carolina, 2008
}

Submitted in Partial Fulfillment of the Requirements

For the Degree of Doctor of Philosophyin

Language and Literacy

College of Education

University of South Carolina

2016

Accepted by:

Diane DeFord, Major Professor

Lucy Spence, Committee Member

Yang Wang, Committee Member

Robert Johnson, Committee Member

Cheryl L. Addy, Vice Provost and Dean of the Graduate School 
(C) Copyright by Sarah Catto, 2016

All Rights Reserved. 


\section{DEDICATION}

I dedicate this work to my loving, supportive parents, who never wavered in their encouragement from the day I decided to begin this journey. I also dedicate this to my husband and son. My love for both of you is boundless. Nick, I could always trust that you would take care of everything as I spent days and nights in Columbia and writing. Nicholas, I hope this work is proof to you that anything is possible when you have the initiative to do it and support from others. Finally, I dedicate this work to the three students who made it possible. You taught me more than I ever thought I would learn, and I still have very far to go. Thank you. 


\section{ACKNOWLEDGEMENTS}

This journey began six years ago when I broached the idea of pursuing my Ph.D. to my husband and parents. Their overwhelming support is just as strong now as it was then, and I will be forever grateful. My success in this program would not have been possible without the assistance of a variety of people who guided me along the way. I was fortunate enough to have the expertise of Dr. Diane DeFord throughout my journey in this program. Her invaluable knowledge and advice have always propelled me forward. Whether learning in her class, analyzing data together, or discussing my own research, I never took for granted the privilege it was to work alongside her. Thank you to Dr. Lucy Spence, Dr. Yang Wang, and Dr. Robert Johnson, who provided their feedback throughout this process. Their comments and viewpoints improved not only my writing, but also my knowledge as a practitioner and researcher. Finally, thank you to Andrew Corley and Melissa Wells, two members of my learning community at two different times in this journey. Thank you for providing a listening ear and an encouraging back slap when I needed it. 


\begin{abstract}
This dissertation examines the experiences of three Latino emergent bilingual children and their Reading Recovery teacher as they engaged in Reading Recovery lessons offered in English with the support of Spanish. The negative impact of cultural bias and expectations of assimilation into English has implications for needed innovations in classroom literacy practices,as well as ways to address teachers' inexperience in teaching culturally and linguistically different students. This case study sought to gain a better understanding of the impact of students' native languages and aspects of cultural diversity that influenced reading and writing instruction, as well as the instructional methods and materials that could be used in the lessons that would best support these students' emerging bilingualism. It also explored how the involvement of students' families contributed to students' use of home and school languages and cultural experiences within school. Both quantitative and qualitative data were collected over a period of eight months. The students' confidence and motivation within the reading and writing instruction improved greatly with the encouragement of the use of their home languages and cultural experiences within Reading Recovery lessons. All three students showed gains in speaking, reading, and writing in both their home and school languages. They made solid and useful connections between the languages and the texts, and drew upon their cultural experiences, which strengthened their reading and writing strategies in both languages. The support of their languages and instructional methods motivated the students to read and write more within lessons, in their classrooms, and at home.
\end{abstract}


Involving the children's families in lessons and in activities at school, and supporting their use of reading and writing at home helped build relationships among the participants, families, and school faculty. This contributed to the beginnings of new understandings on the part of the school's teachers and administration. This study suggested the need for students to have the space to use their home languages and cultural experiences in school. In addition, the results suggested ways that teachers and administrators could include the knowledge of emergent bilingual families within the life of the school to further expand all students' learning and promote social justice in the classroom setting. 


\section{TABLE OF CONTENTS}

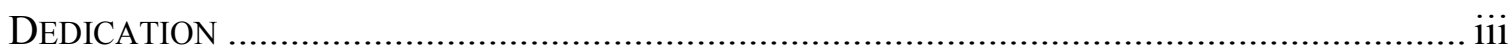

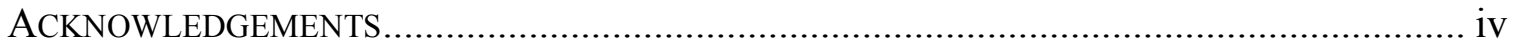

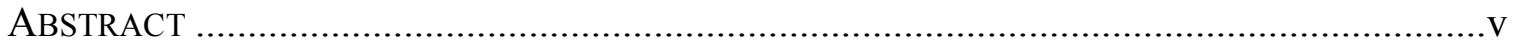

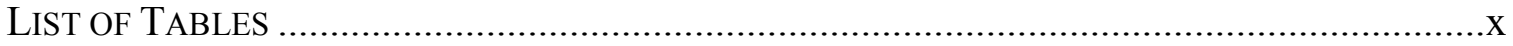

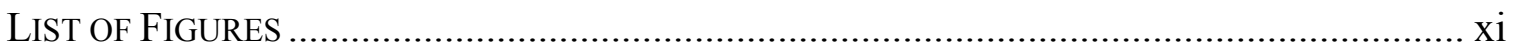

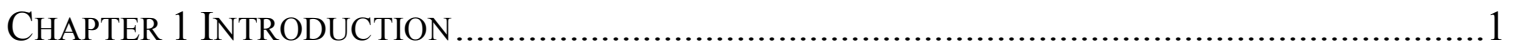

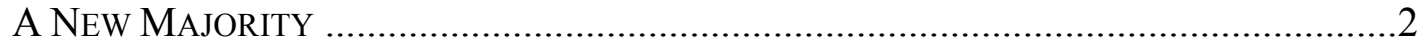

STATEMENT OF THE Problem …......................................................................

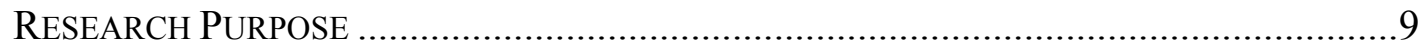

RESEARCH QUESTIONS, TyPE OF STUDY, RESEARCHER's RoLE ...............................10

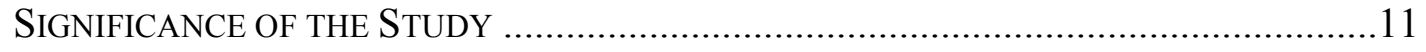

DEFINITION OF TERMS ...................................................................................... 12

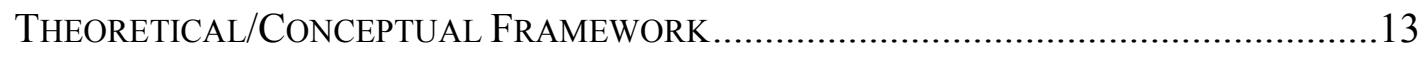

SiTUATED KNOWLEDGE AND RELATED ASSUMPTIONS ........................................16

CHAPTER 2 REVIEW OF RELATEd RESEARCH.............................................................21

ASPECTS OF LITERACY AS INTERRELATED AND DEVELOPING CONCURRENTLY .........21

LITERACY LEARNING IS SITUATED IN SOCIAL AND CULTURAL CONTEXTS ................26

Culturally Relevant Pedagogy and CRitical Literacy...............................29 
Literacy EduCATION CAN Fully Support Both Native AND NonNATIVE

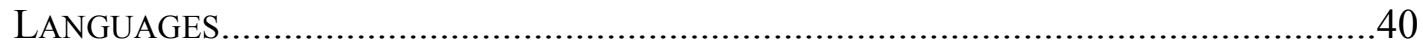

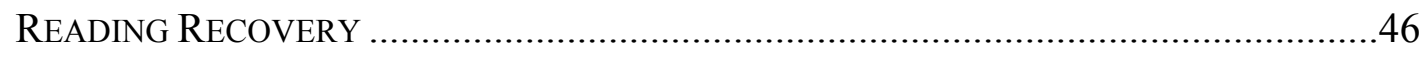

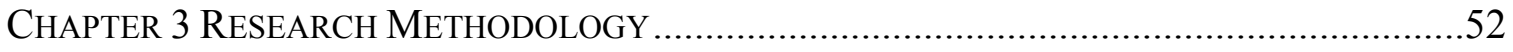

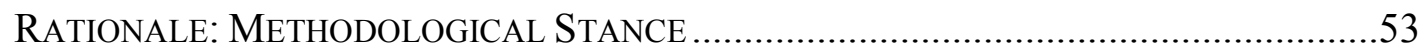

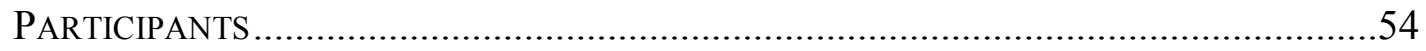

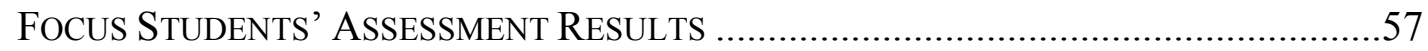

OBTAINING HuMAN SUBJECTS APPROVAL (IRB) ...............................................61

Site SElECtion, CRITERIA, AND JustifiCATION ..............................................61

DATA COLLECTION METHODS .......................................................................... 70

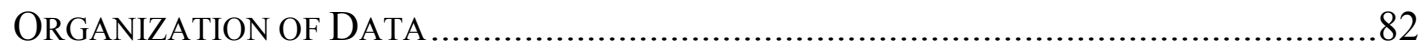

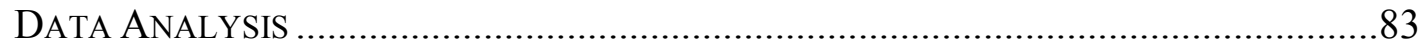

Trustworthiness, Triangulation, And Member Checking.............................83

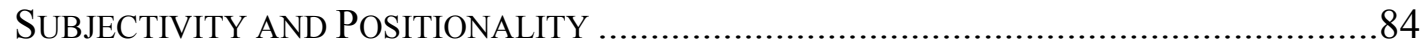

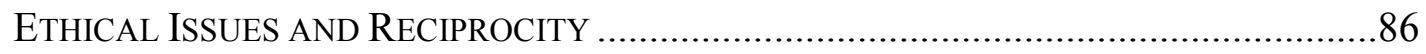

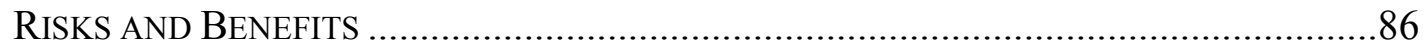

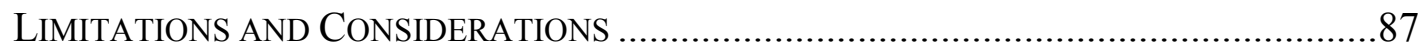

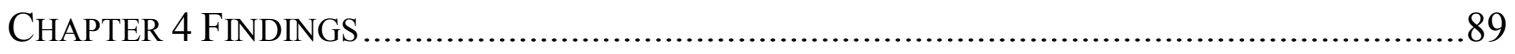

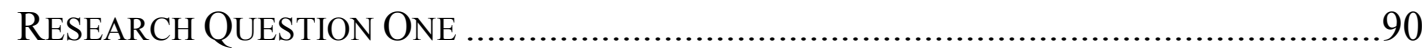

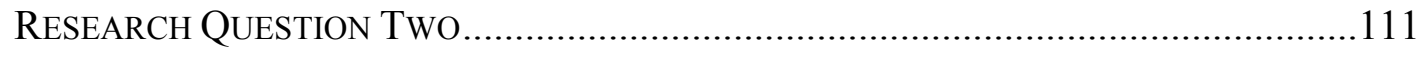

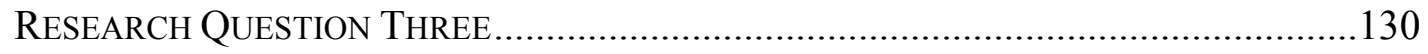

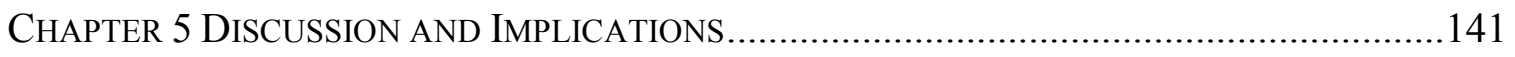

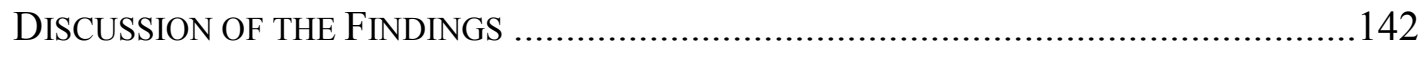

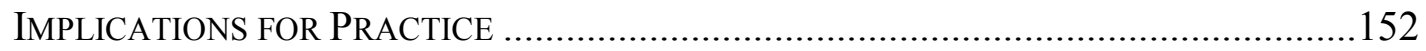


IMPLICATIONS FOR FUTURE RESEARCH...................................................... 155

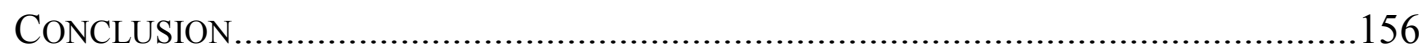

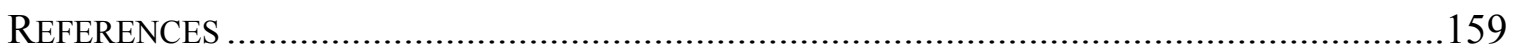

APPENDIX A - INVITATION FORM AND PERMISSION FORM (ENGLISH) ............................173

APPENDIX B - INVITATION FoRM AND PERMISSION FORM (SPANISH) .............................175 


\section{LIST OF TABLES}

Table 3.1 Fall Literacy Assessment Results ...............................................................58

Table 3.2 Fall Assessment Results- OLAI-2 ……………………...........................59

Table 3.3 Fall Assessment Results- Observation Survey Tasks ........................................60

Table 3.4 Fall Assessment Results- Dominie Show Me and Text Level Tasks ................61

Table 3.5 School District 8 Student Ethnic Composition ..................................................66

Table 3.6 Reliability of Dominie Tasks (Grades K-3)........................................................74

Table 3.7 Concepts About Print (CAP) Reliability Coefficients ........................................77

Table 4.1 OLAI-2 Assessment Data (Beginning of Year).............................................105

Table 4.2 OLAI-2 Assessment Data (End of Year) .........................................................105

Table 4.3 Observation Survey Assessment Data .............................................................107

Table 4.4 Benchmark Assessment System Independent Reading Levels........................108

Table 4.5 Benchmark Assessment System Reading Levels (Comparison Group)..........109

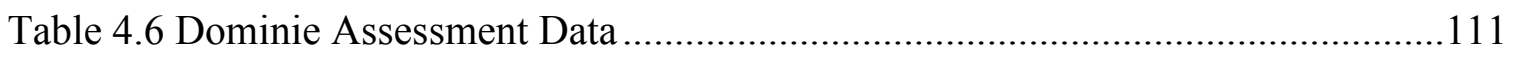




\section{LIST OF FIGURES}

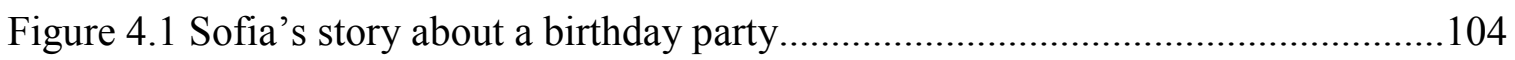

Figure 4.2 The first page of Isabel's book about her trip to Mexico .............................127

Figure 4.3 Using Spanish and English, Isabel describes the food she will eat ..............127

Figure 4.4 Sofia writes about her brother, Dylan, playing with his food ......................128

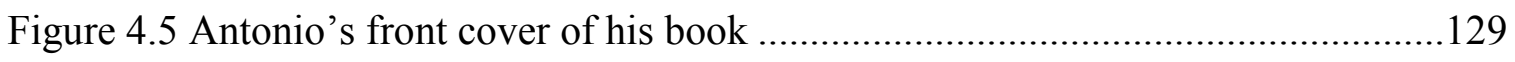

Figure 4.6 Antonio writes about the foods he and his mother eat for breakfast ..............129 


\section{CHAPTER 1}

\section{INTRODUCTION}

This is me, the teacher and researcher: I am a White, middle-aged, upper middle class, female educator.When I was in school, reading and writing were my favorite subjects and I easilyexcelled in them. My first language is English and when I started learning Spanish in kindergarten, it was an option provided to my parents as an additional skill I could use in the future. I could choose whether I wanted to speak Spanish or English. I can now speak, read, and write in Spanish.

This is Antonio, one of my Reading Recovery students and one of the participants in this study: He is a six-year-old, Latino boy in the first grade, and he is from Guatemala. Reading and writing are subjects that make him feel frustrated. His first language is Spanish. Antonio is not only expected to learn how to speak English, he is also expected to read and write in English at the same grade-level proficiency as his English-speaking peers. Antonio became a candidate for Reading Recovery, and this is where our story began.

This study examined the experiences of three Latino emergent bilingual children

and their Reading Recovery teacher as they engaged in Reading Recovery lessons offered in English with the support of Spanish. The changing demographics of America, as well as teachers' inexperience in teaching culturally and linguistically different students, are important aspects of the national context around English Language Learner (ELL) students that illustrate the need for studies such as this one. 


\section{A New Majority}

Society is changing as ethnicities and racial groups that were once considered "minorities" are becoming the "new diverse majority" (Southern Education Foundation, 2010). In fact, "the number of students of color has grown more rapidly in public schools in the South than in any other region" (Southern Education Foundation, 2010, p. 12). The rise in the number of students of color in the South is in part a result of the growing Latino population. The current trend of Latino population growth affects the demographic composition of students in the Southern United States, and in particular its schools. The students who now constitute the largest groups in the South's public schools are the students who are scoring the lowest on both state and national standardized tests.According to data from the National Assessment of Educational Progress (NAEP), only a very small percentage of limited English proficient (LEP) students in the eighth grade are proficient in reading (4\%) and in math (6\%) (Batalova, Fix, \& Murray, 2007). Nieto (1992) referred to the United States as a "living nation of immigrants" (p. 333 ) and the nation's diverse demographics are changing rapidly. By 2050, it is expected that the Latino population will make up to $25 \%$ of the U.S. population, outnumbering the African American population as the nation's largest minority (Nieto, 2009). As the diversity in the student population grows, the teaching workforce remains mostly homogeneous. In 2006, the Schools and Staffing Survey from the National Center for Education Statistics (NCES) reported public teachers are predominately female $(75 \%)$ and from non-Hispanic White backgrounds (83\%). In addition to this demographic data, the majority of teachers feel unprepared to meet the needs of this new diverse student population. A 2001 NCES survey revealed only $32 \%$ of teachers felt well prepared to 
"address the needs of students from diverse cultural backgrounds" (p. 6), and only $27 \%$ felt they were adequately prepared to teach students with limited English proficiency. Furthermore, the surveyed teachers were most likely to participate in professional development that focused on state and district curriculum and standards $(80 \%)$, educational technology integration (74\%), and new methods of teaching (72\%) and assessment (62\%), topics that may directly impact teachers' jobs in today's high stakes testing environment (in terms of teacher evaluation and teacher effectiveness).

Interestingly, the professional development topics in which teachers were least likely to attend were those addressing the needs of students from diverse cultural backgrounds (41\%) and those students with limited English proficiency (26\%) (NCES, 2001), even though two thirds of the teachers who were surveyed felt unprepared to address these students' needs.

With the rapid increase in the number of bilingual children entering local schools, as well as the lack of preparation for the teachers of these children, there is a need for major changes in education in order to meet the needs of this new majority of students. In order to bring about a change in reading achievement for this Latino population, one of the first steps is focusing on emergent bilingual children in primary classrooms and the connection between their native and non-native language growth and their cultural experiences as they impact their literacy lives and achievement.

\section{Statement of the Problem}

The negative impact of cultural bias and expectations of assimilation into English, without a well-prepared teaching force to accommodate children's linguistic and literacy education needs, has particular implications in four areas: 1) U.S. legislation that affects 
language education; 2) needed innovations in classroom literacy practices; 3) ways to address teachers' inexperience in teaching culturally and linguistically different students; and 4) particular intervention services that may be needed to accelerate culturally and linguistically diverse children's literacy performance. These topics define the current and historical contexts of education as we grapple with the issues surrounding increasing numbers of bilingual children taught by teachers who are uncertain how to best meet these students' needs.

Language education legislation versus research. Historically, communities of people speaking different languages have lived side by side for hundreds of years. This diversity of language stemmed from the immigration of people from all over the world over time, with different local, state and federal programs offered to ameliorate some of the factors that impact immigrants' educational success. For example, during the $20^{\text {th }}$ and $21^{\text {st }}$ centuries, language legislation in education has been a battleground between groups who extol the restriction or exclusion of bilingual education and those who believe in the inclusion of bilingual education programs for the beneficial effects of utilizing students' home languageas part of the educational enterprise.

In the Nationality Act in Texas in 1906, English was officially established as the only language to be taught in schools (Nieto, 2009). Sixty-two years later, the Bilingual Education Act passed in 1968. The Bilingual Education Act is considered the "most important law in recognizing linguistic minority rights in the history of the United States" (Nieto, 2009, p. 63), offering federal funding to districts that provided special programs or services to students whose English level was not considered proficient. However, even with the passing of that legislation, the past 48 years have included numerous laws 
that undermine the utilization of bilingual education, including 1998's Proposition 227, which ended bilingual education programs throughout California, and the No Child Left Behind Act of 2002, whose testing system promoted the adoption and implementation of English-only instruction (Crawford, 2004). Arizona's Proposition 203 required that all public school instruction be conducted in English. Proposition 203 also maintained that children not fluent in English should be placed in an intensive English immersion program for one year to "teach them the language as quickly as possible." The legislation dismantled most bilingual education programs in the state of Arizona.

Throughout these legislative battles, researchers have continued toinvestigate bilingual education programs. Greene (1998) found that limited English proficiency (LEP) students who were taught utilizing at least some of their home language outperformed their peers who were taught in an exclusively English setting. Other studies also illustrated how the instruction in students' native languages supports their acquisition of English while bolstering their content knowledge as well (Cummins, 2000; Krashen, 2004). Research studies have illustrated the positive outcomes from the same bilingual programs that legislative actions have restricted or altogether eliminated.

The need for culturally relevant classroom practices. While the battles surrounding the inclusion or exclusion of bilingual education in schools in the United States will continue to rage, the issues that impact the effectiveness of language and literacy education must be addressed. At the core of these issues are teachers in classrooms, trying to support children's language learning and literacy development. Multiple researchers agree that creating curriculum content for learners must involve meaningful content that takes into account students' cultures (Gay, 2010; Goodman, 
1997; Gregory, Long, \& Volk, 2004; Nieto, 2009; Rogoff, 2003; Wells, 1999). This can be accomplished with two jointly implemented goals: 1) Teachers can begin by ensuring that their instructional practices authenticate students' cultural heritages; and 2) they must simultaneously introduce content in a way that is accessible to all students (ComptonLilly, 2004; García \& Kleifgen, 2010; Gay, 2010; Ladson-Billings, 2009; Taylor, 1997). These joint goals are accomplished in what is known as culturally relevant pedagogy (Compton-Lilly, 2004; Gay, 2010; Ladson-Billings, 2009).

Culturally relevant practices support students' home languages, cultural knowledge, and personal experiences while simultaneously developing literacy knowledge and skills needed for academic achievement (Compton-Lilly, 2004; Gay, 2010; Ladson-Billings, 2009; Taylor, 1997). Gloria Ladson-Billings (2009) describes teachers with culturally relevant practices as people who believe all students can succeed and who will help those students work collectively to utilize their innate knowledge in order to achieve success. Critical literacy projects are another part of culturally relevant pedagogy utilized by many teachers and researchers (Compton-Lilly, 2004; Kinloch, 2009). Compton-Lilly's (2004) critical literacy projects addressed an issue selected by the students that was commonly relevant to them, required use of their developing literacy skills, and could promote change in the children's community. Examples from ComptonLilly's (2004) work include students discussing the violence surrounding their homes and school or the levels of lead discovered in their community. Culturally relevant practices contribute to the achievement of all cultures in a classroom. Just as "typical" classroom practices contribute to the achievement of students from the dominant, White culture, using the experiences of other cultures facilitates the success of ethnically and culturally 
diverse students (Gay, 2010). These practices focus on caring classroom communities where teachers are actively engaged in positively affecting the academic success of her students (Gay, 2010; Ladson-Billings, 2009). Gay (2010) summarized the objective of culturally relevant pedagogy, "The fundamental aim of culturally responsive pedagogy is to empower ethnically diverse students through academic success, cultural affiliation, and personal efficacy" (p. 127).

Gay (2010) concluded we do not see evidence of culturally relevant teaching because teachers do not have enough knowledge about how current teaching practices manifest the European American culture. Gay attributed this lack of culturally relevant teaching to the belief that if teachers treat students differently because of their culture, race, or ethnicity, it is equivalent to racial discrimination. However, a large body of research points out that just the opposite is the case: Teachers must understand and appreciate the cultural practices of marginalized groups, and use this new knowledge to transform their classroom practices into culturally relevant pedagogy (Chasnoff \& Cohen, 1996; Compton-Lilly \& Green, 2010; Gay, 2010).

Armed with a wealth of curriculum guides, teachers' editions, and standards, educators might inaccurately assume students, especially those from marginalized cultures, are empty vessels waiting to be filled with the knowledge teachers have. Compton-Lilly (2004) believed, "We must strive to reach beyond the assumptions society has taught us throughout our lives" (p. 52). These assumptions could include beliefs about parents in poverty as incompetent, bilingual students as inadequate in terms of their general learning ability, or children from impoverished homes as having limited or no literacy experience (Compton-Lilly, 2004; Hankins, 2003; Valdés, 1996). Once these 
assumptions are recognized and resolved, definitions of literacy and what it means to be literate can change so that educators canappreciate children's home knowledge, language, and experiencesand begin to offer instruction that supports and extends their language and literacy.

Teacher inexperience. Not all people view an elementary child's bilingualism as a strong point, especially if that person does not speak or understand the child's native language or their cultural practices. Emergent bilingual students need more, not fewer, interactions with their teachers and with their peers. Despite any feelings of discomfort, teachers must persevere and interact with emergent bilinguals as often as possible, encouraging them to use their native language. Calkins (2003) stated,

We simply can't let the fact that we feel helpless or awkward prevent us from interacting with our English language learners more than we interact with our other students. We needn't speak the child's language nor be skilled communicators. What is most important is our presence at the child's side and our attentiveness to the child. (p. 71)

If teachers expect that their emergent bilingual students have the ability to speak, read, and write English and their native language, then their interactions with those students must demonstrate those beliefs. Consequently, their instructional practices effectively expand the students' language and literacy as emergent bilinguals.

Reading Recovery. Reading Recovery's success with emergent bilingual children is one promising example of the kinds of instructional practices these students need to grow in their language and literacy. Reading Recovery is a short-term, one-onone intervention for first grade students having difficulty with early reading and writing 
development. It is an early literacy intervention service that is offered on average for 12 weeks, but services can continue up to 20 weeks. When students have reached the average of their class, the one-on-one tutorial is discontinued. Researchers (Ashdown \&Simic, 2000; Hobsbaum, 1995; Neal \& Kelly, 1999) have shown the benefits Reading Recovery provides for emergent bilingual children whether the instruction is offered in Spanish, or in English. The researchers concluded that emergent bilingual children are as likely as their monolingual, English-speaking peers to successfully discontinue from Reading Recovery, thus well able to successfully reach the average of their class in literacy achievement within 20 weeks of instruction or less.

\section{Research Purpose}

Given the restriction or outright exclusion of students' home languages and cultural experiences in their education, and teachers' uncertainty of the best ways to implement literacy instruction for emergent bilingual students, the purpose of this research was to first explore how students' native languages and cultural experiences affected reading and writing instruction and achievement in a literacy intervention setting, specifically in Reading Recovery lessons. These children received literacy instruction in English in their classrooms, while I offered Reading Recovery lessons in English with the support of Spanish to increase their opportunities for growth in both languages. The support of Spanish took on a variety of forms, including: reading bilingual and Spanish texts, writing in both Spanish and English, writing student-made books about their cultural experiences in both Spanish and English, and encouraging the use of Spanish in our daily conversations (further discussion of these examples can be found in Chapter 4). I hoped to gain a better understanding of the impact of students' 
native languages and aspects of cultural diversity that influence reading and writing instruction. I also explored the instructional methods and materials used in the intervention lessons that best supported these students' emerging bilingualism. I focused on gaining insights about three emergent bilingual children's ways of using their home languages and experiences in conversation, reading, and writing during their instruction. Throughout our interactions, it is important to note that I have limited proficiency in Spanish speaking and writing. I can maintain basic conversations about daily life and current events, which I felt was sufficient for me to explore culturally relevant pedagogy by supporting their cultural heritage and their language learning as emerging bilingual students, and to introduce content in a way that was more accessible to them in our intervention sessions.

\section{Research Questions, Type of Study, and Researcher's Role}

To contribute to the body of work that addresses improving literacy instruction for students who are emergent bilinguals, this study used a qualitative design to ask:

1. How does the utilization of students' home languages and cultural experiencesaffect their reading and writing instruction and achievement in a literacy intervention setting offered in English with the support of Spanish at Goodman Elementary School?

2. What is the nature of the methods and materials used in the instructional intervention that best support the students' emerging bilingualism?

3. How can the involvement of students' families contribute to the utilization of students' home languages and cultural experiencesin school?

In order to address these questions, I utilized a case study methodology in this 
research. According to Glesne (2011), case study research refers to "the intensive study of a case" (p. 22). Case studies tend to involve "in-depth and often longitudinal examination with data gathered through participant observation, in-depth interviewing, and document collection and analysis" (Glesne, 2011, p. 22). The "case" I studied was the process of the participants' utilization of home languages and experiences within the literacy intervention setting. As Schram (2006) asserted, “The case study’s strategic value lies in its ability to draw attention to what can be learned from the single case" ( $\mathrm{p}$. 107). I believed a case study methodology provided the opportunity to pursue in-depth analysis with three students' experiences with their home languages and cultural experiences in a literacy intervention setting. Within this case study, I had two roles: interventionist and researcher. I was one of two reading interventionists at Goodman Elementary School. In this role, I worked with 16 students on a daily basis in small group or one-on-one sessions.

\section{Significance of the Study}

So often, teachers are preoccupied with the need to impart all the knowledge to their students, that they disregard the considerable expertise their students have to share (Donaldson, 1978).In order to create a supportive curriculum, it is important for teachers to know their students and the expertise and knowledge they bring to literacy interventions. Clay (2010) believed literacy instruction should begin with each child's “own set of understandings- his 'known"” (p. 9). A teacher cannot assume that all students have similar knowledge since children's literacy opportunities are unique to each situation and background. Martens (1996) stated, "It becomes the role of the teacher to help children recognize the many ways in which they are already literate when they come 
to school" (p. xii).

This case study had significance regarding the treatment of languages other than English in the literacy intervention setting. The research could be utilized to show teachers how children used their home language and cultural experiences in a literacy intervention setting, which could be transferred to classroom instruction as well. Moreover, this case study provided examples of the kinds of methods and materials that best supported emergent bilingual students' literacy development in this setting.

\section{Definition of Terms}

Bilingual- using "complex language and cultural practices that are fluid and changing depending on the particular situation and the local practice. Typically, one language is considered the powerful majority language, and the other minoritized." (García, 2012, p. 3)

Biliteracy- the ability to effectively communicate or understand written thoughts and ideas through the grammatical systems, vocabularies, and written symbols of two different languages (Butvilofsky \& Sparrow, 2012)

Emergent bilingualism- the ability to "speak another language at home while also learning English and, in so doing, becoming bilingual" (García, Kleifgen, \& Falchi, 2008, p. 6)

Monolingualism- the ability to speak only one language while still utilizing varieties of that language and adapting it to specific needs (Horner, Lu, Royster, \&Trimbur, 2011) Sociocultural approach- based on the idea that society and culture help shape people's identity and reality

Translanguaging- "the ability of multilingual speakers to shuttle between languages, 
treating the diverse languages that form their repertoire as an integrated system" (Canagarajah, 2011, p. 401)

In addition to the terms listed above, I refer to students as "emergent bilinguals" rather than "English language learners" in this study, except in the case of direct quotations from authors. I use this term to define students by the abilities they encompass rather than a skill they lack.

\section{Theoretical/Conceptual Framework}

My personal, professional, and academic experiences form my belief system about teaching and learning. I believe that learning is a sociocultural process; reading and writing are socially constructed, meaning-making learning tools; and culturally relevant practices support the needs of all students. These beliefs were particularly important to this study that addressed the problem of the prohibitive treatment of students' home languages and cultural experiences in schools. The following sections outline these beliefs about teaching and learning and how they informed my research process as I examined the research problem, the methods I used to examine the problem, and the formulation of research questions.

Learning is a sociocultural process. I adhere to the belief that learning takes place in cultural contexts and relies on the interdependence of individual and social processes in the construction of knowledge (Vygotsyky, 1978). According to Vygotsky (1978), "Learning awakens a variety of internal developmental processes that are able to operate only when the child is interacting with people in his environment and in cooperation with his peers" (p. 86). Therefore, the social context of a learner is the foundation for understanding the child's development and learning. I also align with 
Nieto's (2009) belief that "learning develops within a culture and community and learning and thinking are always situated in a cultural setting and always dependent upon the utilization of cultural resources" (p. 49). Culture plays a role not only in communicating and receiving information in the learning process, but also in shaping the thinking process of learners.

This belief was critical in my examination of the research problem in this study. First, since I believe learning is a sociocultural process, I believe a child's beliefs, language, and cultural norms affect that child's reality and cognition. Because of this belief, this study's research problem centered on how a child's use of language and cultural experiences affected that child's reality in reading and writing. When the child reads or writes, those processes are intertwined with the child's languages and cultural experiences. These pieces are not separate and must be treated as a functioning whole. To better understand a child's reality in reading and writing, the child's languages and cultural experiences are part of that process.

Reading and writing are socially constructed, meaning-making tools. Within the sociocultural contexts inside and outside of school, students use reading and writing to learn. Both are socially constructed, meaning-making processes. In families' home lives, I believe literacy experiences are cultural activities that are successful if they achieve their authentic, meaningful purposes. Families utilize reading and writing to complete routines at home, which shows children how literacy is relevant to their everyday lives (Taylor, 1997). Reading and writing are preserved as a meaningful whole.

Children are constantly in a state of learning alongside their classmates, their family members, and other peers in their life. I believe these more knowledgeable people 
are not always the teacher of the classroom. The child has an opportunity to learn a skill that is out of his independent reach with the help of a more experienced person. Fellow students can be part of the scaffolding process, as can family members and people in the community. Martens (1996) described the impact of the community on her daughter, Sarah's, literacy development: "The literacy interwoven into her social community shaped who she was as a reader and a writer" (p. 2). For Sarah, her social life and literacy life were one and the same. Ideally, within these sociocultural contexts of home and school, I believe children come to understand that reading and writing are meaningful and that they are processes, rather than products.

My belief in reading and writing as socially constructed, meaning-making learning tools affected the research methods and materials in this study. The research methods included ways in which I directly observed and actively explored their language and cultural experiences as the student participated in reading, writing, and conversation. I recorded our daily lessons and reflected on our interactions daily. These reflections informed both the next steps in their literacy lessons and my next steps in my support of their learning. The materials in our lessons also reflected my belief in reading and writing as authentic and meaningful practices. I purposefully chose texts that would fit each child's literacy needs, as well as their personal interests. The children chose their writing topics and crafted their own stories every day, maintaining meaningful ownership of the messages they created.

\section{Culturally relevant practices support the needs of marginalized students.}

Thirdly, I believe that instruction should be culturally relevant. Ladson-Billings (2009) describes teachers with culturally relevant practices as people who believe all students 
can succeed and who will help those students work collectively to utilize their innate knowledge in order to achieve success. Traditional teaching practices are culturally relevant for students who belong to the norm, which is currently defined by ways of being in White middle-class, Christian, heterosexual, English-speaking homes (ComptonLilly, 2004; Goodman, 1997; Moll, Amanti, \& Gonzalez, 2005; Taylor\& Dorsey-Gaines, 1988). Culturally relevant practices, which treat language and literacy as social practices instead of separating cognitive processes and social development, support a more meaningful kind of learning for all students (Gregory et al., 2004; Nieto, 2009; Taylor\& Dorsey-Gaines, 1988; Vygotsky, 1978; Wertsch, 1985). When students feel they have a safe place to celebrate and promote their unique ethnic, cultural, economic, or religious attributes, they are more likely to feel successful in their academic endeavors.

My belief that culturally relevant pedagogy supports the needs of all learners affected this study's research questions. I believe the utilization of students' home languages and cultural experiences are components of culturally relevant pedagogy. Therefore, all of my research questions reflected this belief. I wanted to examine how these culturally relevant practices affected the literacy instruction and achievement of the participants, the kinds of methods and materials that would support these students' emerging bilingualism, and how their families' involvement contributed to these culturally relevant practices.

\section{Situated Knowledge and Related Assumptions}

My personal, professional, and academic experiences formed my current belief system and assumptions regarding this problem. When reviewing my previously stated beliefs, I found it interesting that the first two beliefs focus on the importance of 
individuality, while the third assumption generalizes and disregards individuality altogether.

First, I believe in the importance of each student's individuality affecting how we approach education. Accepting each child for who he or she is and creating an individual learning path from that point provides multiple pathways to the common goal of student success. Therefore, I assume each child has a different way of learning that is unique to the child's personality, experiences, likes, and dislikes. For example, the ways in which I learn best differ drastically from the ways my husband and preschool son learn best. Both my husband and son are the type of learners who immerse themselves in the new topic of interest by trial and error. Without knowing if he will succeed or fail, my son throws himself into the new learning with a "sink or swim" mentality. My husband's pathway to new learning involves a lot of experimentation until he meets success. Alternatively, I am more cautious. I learn best when I observe what others have tried before I attempt something new. Although our learning styles differ, we can still reach the same learning goals. Therefore, I believe goals and instruction must begin with where learners are and progress from that starting point.

This idea extended my thinking as I worked on the curriculum for my school. Oftentimes, we compare what children achieve to what other children can do through norm studies and percentile rankings. The shortcomings of these developmental expectations refined my own thinking on this subject. Morally, I realized I was being unfair to these students. Now I view the percentile rankings and growth norms as one part of that child, instead of considering those developmental expectations as the most important indicators of the child's learning. This assumption can be justified through 
researchers such as Marie Clay. Clay (1998) helped me define my ideological stance regarding the value of truly differentiated paths of learning for individual children.

Another assumption I hold is that each child has something special to bring to language and literacy experiences. Therefore, I assume that the best education a child can receive involves educators drawing on students' special knowledge and experiences to provide culturally appropriate and meaningful classroom activities that are relevant to children's lives. This assumption is grounded in critical sociocultural perspectives that consider disparities in power as voices that dominate the educational process and those voices that are never heard (Gay, 2010; Compton-Lilly, 2004). From this perspective, at the heart of my beliefs and assumptions is a commitment to valuing the knowledge available in students' homes (Moll et al., 2005) and acknowledging their home literacy experiences as "legitimate roads to learning" (Goodman, 1997, p. 57). The inclusion of the home knowledge, languages, and cultural experiences is not typical practice for marginalized students at Goodman Elementary, who are similar to the participants for this study. Marginalized groups are those people that remain separated from dominant groups along race, class, gender, language or ethnicity lines, resulting in less power, advantage, and importance for those who are marginalized (Delpit, 1988). In the context of the setting of Goodman Elementary School, these participants are marginalized as students of low socioeconomic status from families whose cultural and linguistic backgrounds differ from that of their White, middle-class, English-speaking peers. Nevertheless, I assume these students' diverse reservoirs of knowledge, languages, and cultural experiences are essential to their education. 
Because of these assumptions, I am a proponent of culturally relevant pedagogy and I align with progressive thought. I believe curriculum begins with the learner and validates the different ways of knowing and learning, even if this knowledge differs from the norm. To bring all of these diverse needs together in one classroom, students need to feel they have a safe place to celebrate and utilize their differences. In my experience as a classroom teacher, students feel safe in a classroom that values their differences and they are more likely to feel successful in their academic endeavors as well. Successful teachers create these safe spaces in their classrooms to support every child in their academic undertakings.

Lastly, even as I near the end of my program in language and literacy, I still make assumptions about the definition of literacy, especially when discussing marginalized families. The conventional descriptions of literate homes include plentiful amounts of children's books, regular conversations between adults and children about books, and consistent parent attendance at school functions. Unless I am being vigilant about my thoughts, I still tend to lean towards standard definitions, although I want to investigate the unrecognized literacies that can be found as well. I believe part of the reason for this assumption on my part is the fact that I am a White, middle class, female educator. Because of this background, my traditionally defined literacy followed those conventional descriptions. I never thought about the unrecognized literacies in a child's home before I began this doctoral program. Stories from families like Antonio's and others can help me understand more about these unacknowledged literacies in those families' home lives. 
My awareness of some of my assumptions concerning the definition of literacies affected my research process. I needed ways to monitor the impact of my assumptions. As I reviewed and transcribed the daily recorded lessons, I made notes of when I might have reverted to my standard ways of viewing and responding to students' unconventional literacies. When I reviewed my field journal notes, I noted when I felt frustrated or fearful and wrote about what assumptions or subjectivity might be accountable for those feelings. I also asked two of my professional colleagues who are from different backgrounds and belief systems than my own to monitor how my assumptions could be affecting the research process. Our conversations helped broaden my view when I felt like I was reverting to my previously narrow lens of situated assumptions. 


\section{CHAPTER 2 \\ REVIEW OF RELATED RESEARCH}

This review of literature encompasses key works organized around theoretical concepts that inform this studyof effective instructional practices that support emergent bilingual students' language and literacy development within an early intervention program: (a) reading, writing, speaking, and listening are interrelated and develop concurrently, (b) literacy learning is situated in cultural and social contexts, (c) critical literacy theories have implications in pedagogy and learning, and (d) literacy education can fully support both native and nonnative languages. These bodies of research inform this study and establish the importance of the research that has been completed in the areas of literacy and language development, culturally relevant pedagogy, critical literacy and linguistic diversity in classroomstowards improving literacy instruction for emerging bilingual students.

\section{Aspects of Literacy as Interrelated and Developing Concurrently}

The emergent literacy perspective, which became prominent in the 1980's, differed significantly from the dominant "readiness perspective" of the early 1900's. Emergent Literacy research established that all of a child's interactions with texts, print, reading, writing, and language encountered in the home and community were foundational in developing key understandingsas steps to becoming independent readers and writers prior to school entry (Teale \&Sulzby, 1986). According to Clay (1966), 
literacy has much in common with oral language development and writing. Instead of limiting children to a predetermined scope and sequence of acquired abilities in school,previously believed to be the case within the readiness perspective, emergent literacy research illustrated the complex relationship between learning to read, write, and talk as developing simultaneously as a result of interactions with other language users, readers and writers.

Several parents, teachers, and other researchers detailed that very young children do write prior to school entry, and that writing is connected with key abilities they are developing in oral language and reading. Clay (2010) addressed the importance of the interrelatedness of writing, reading, and speaking, "As they write their earliest messages, children gradually begin to make links between speaking, reading, and writing. They may discover that: What I can say, I can write. And, what I can write, I can read” (p. 7). Cushla exemplified this relationship (Butler, 1980). Cushla was a girl born with significant developmental challengesthat prompted her physicians to say she would likely never develop normally in terms of oral language development. Her parents ignored these predictions and provided extensive experiences through book reading, opportunities to write, and conversations they had with her while assisting her in talking with them. Cushla began to exhibit an increase in oral language that resulted from the extensive literature experiences provided by her parents (Butler, 1980). This was not random repetition of words from her books, but correct usage of complex words, phrases, and sentences in her everyday language.

In a similar way, the process of writing supports children in discovering various concepts about written language that reciprocally impact knowledge needed in reading, 
such as left to right directionality, the concept of letters as different from words, and even the relationship between the letters they see on the page and the sounds those letters represent. Smith (2013) echoed this reciprocal relationship between reading and writing, "The development of composition in writing cannot reside in writing alone, but requires reading and being read to. Only from the written language of others can beginning writers observe and understand convention and idea together" (p. 207). Moreover, Ferreiro and Teberosky (1982) proposed a common abstract system of principles that children learn from the beginning of their progression as readers and writers. She suggested that reading and writing are both influenced by a single abstract understanding of the system of written language, a kind of universal understanding of the relationships in language learning.

Multiple researchers have examined how language, reading, and writing are closely related. Clay (1975) illustrated how a child's perception of print is related to early reading, while Bissex (1980) detailed the progression of her son's writing ability and how it is closely connected to his reading development. In her son's own words, "Once you know how to spell something, you know how to read it" (p. 42). In her research on emergent bilingual Spanish-speaking children, Ferreiro and Teberosky (1982) referred to the matching of oral words or syllables with written marks as the syllabic hypothesis, or the guess children create to relate the language they speak and hear with the language they read and write. In addition, Read's $(1971,1986)$ examination of the similarities between different children's spellings demonstrated that learning to spell is a linguistic process where children's articulation of speech sounds affected their understandings of sound-letter correspondences. For example, a child may write JRAGIN for dragon, 
NUBRS for numbers, or LETL for little because the place of articulation for key sounds like $/ \mathrm{dr} /$ and $/ \mathrm{jr} /$ and $/ \check{\mathrm{e}} /$ and $/ \tilde{\mathbf{1}} / \mathrm{cause}$ these letter combinations to commonly be substituted by young children when they write. Also, certain letters can be dropped, like the M in numbers, because they are not articulated due to their letter placement within the word. According to Martens (1996), these kinds of hypotheses "mark the beginning of children's understanding of phonics, of the relationship between oral and written language" (p. 34).

Heath's (1983) ethnography conducted in Piedmont Carolina is another example of research connecting language, experiences in the home, and knowledge ofliteracy. Heath (1983) explored how the environment and social interactions also play a larger, critical part in the acquisition of language, as can be seen in the diverse cultures she studied, Trackton and Roadville. Children's social interactions in their home environments directly influenced their language acquisition and usage. In both Trackton and Roadville, children's understanding of how to define a story, for example, was influenced by norms for story telling in their respective communities, which differed greatly from what their school teachers valued. However, once teachers learned how to connect with and use their students' previous knowledge and capabilities, they saw a change in children's learning. When considering how to build upon children's strengths, teachers must notice the varied competencies children bring from different cultural communities. Children from linguistically diverse homes have strengths that must be recognized, respected, and further developed in the classroom setting.

Teachers must encourage the connection between all components of literacy (reading, writing, hearing, and speaking) in their instruction. Explicitly demonstrating 
this relationship supports children's literacy development. Clay (2001) believed, "Children can be made aware that reading and writing contribute reciprocally to early progress when teachers prompt for such reciprocity" (p. 19). Many teachers may be aware of the reciprocity between reading and writing but do not necessarily prompt children for it, or help them notice these aspects of print as they read and write. For example, teachers may pick books for students to read by selecting texts that have vocabulary the children have used as writers. Reminding children that they can read a word by remembering how they wrote it in a previous story or vice versa is important in early literacy interventions. Children's own writing gives them the opportunity to read a wider variety of words:

When encouraged to invent spellings as best they can, children will pull from the thousands of words they know orally to help them compose their texts, and many of the words they'll use are ones they wouldn't recognize yet if they encountered them spelled conventionally while reading. It follows that if teachers know how to support children's early writing, this support may actually give children access to richer texts - their ownduring their independent reading (Ray \& Glover, 2008, p. 14). As children participate in independent writing, they are presented with the chance to create a message that will be read and interpreted by an audience of readers. This opportunity to make meaning directly correlates with the kind of strategies children need when independently reading. It is essential for young children's literacy learning for them to understand the fact that a written message that they read must also convey meaning, so that they do not focus only on decoding individual words as a reader, a practice that impedes comprehension (Smith, 2005). 


\section{Literacy Learning is Situated in Social and Cultural Contexts}

The concept of reading, writing, speaking, and listening as necessary, interrelated components of literacy and, as a result, supporting emergent bilingual students in their literacy, connects to literacy learning being situated in cultural and social contexts. Dyson (1991) raised the issue of whether educators are guilty of viewing literacy in an acultural way, without any recognition of sociocultural influences. Nieto (2009) believed that "learning develops within a culture and community and learning and thinking are always situated in a cultural setting and always dependent upon the utilization of cultural resources" (p. 49). Multiple researchers found that creating curriculum content for learners should involve more than standards and state guidelines and should instead involve meaningful content that takes into account students' cultures (Gay, 2010; Gregory, Long, \& Volk, 2004; Goodman, 1997; Wells, 1999; Nieto, 2009; Rogoff, 2003). This curriculum content should not only authenticate students' cultural heritages, but also introduce new content in a way that is easy for a group of ethnically or culturally diverse students to understand (Gay, 2010). Respecting the diversity of cultural identities in a classroom provides students the opportunity to learn in a caring and supportive environment (Nieto, 2009). Rogoff (2003) believed that students' literacy needs are as diverse as their cultures, and one student's uses and purposes for literacy can be very different from those of classmates.

Social contexts. Readers and writers utilize connections to support deeper and more meaningful engagement with texts. These connections may be constructed between their personal experiences and the particular literacy experience they may be engaged in,or the connections may be with their peers or classmates in the socially situated 
context of learning. Martens (1996) explained how Sarah, an eight-year-old girl and her brother, Matthew, a four-year-old boy, participated in reading and writing events together. Sarah and Matthew sat and read and wrote together in their home:

The children were, and are, models and resources for each other, catalysts stimulating and facilitating each other's learning, actively and reactively shaping literacy experiences for each other. It happened naturally as she [Sarah] witnessed and experienced functional, meaningful transactions between written language, others, and herself. (p. 10)

As children take turns supporting the literacy learning of another, literacy learning becomes a "social process through which meaning is negotiated when learners are engaged with more knowledgeable others in meaningful transactions with text" (Gregory, Long \& Volk, 2004, p. 14). Wells (1999) noted the importance of this kind of social engagement to support learning in the zone of proximal development: "Not so much a more capable other is required as a willingness on the part of all participants to learn with and from each other" (p. 324).

In school, small groups of children working together in a lesson provide a social context for their learning as they converse and work through the processes of reading and writing. Talking with the children while listening and responding to their remarks supports an educator's value of the importance of conversation as part of the social process of literacy. Offering invitations for children to talk more and extend the conversation instead of a large amount of teacher "telling" (Clay, 2010) will make the literacy task more engaging and support a more meaningful kind of learning for the children. 
Children are constantly in a state of learning alongside their classmates, their family members, and other peers in their life. They have an opportunity to learn a skill that is out of their independent reach with the help of a more experienced person. These more knowledgeable people are not always the teachers of the classrooms. Fellow students can be part of the scaffolding process, as can family members and people in the community. Martens (1996) described the impact of the community on her daughter, Sarah's, literacy development: "The literacy interwoven into her social community shaped who she was as a reader and a writer" (p. 2). For Sarah, her social life and literacy life were one and the same. Ideally, within these sociocultural contexts of home and school, children come to understand that reading and writing are meaningful and that they are processes, rather than products. They view literacy as an integral piece of daily life as they interact with and learn from other people at home and school, rather than seeing literacy as culturally bound and specific to a given setting. Reading and writing are purposeful, relevant, and necessary for life when immersed within a social context.

Cultural contexts. Along with regarding language and literacy as social practices, respecting the cultural context of literacy learning is also crucial. Writing and reading, as socially-constructed, meaning-making processes, are influenced and supported by writers' cultural and social experiences. Samway (2006) challenged the view that writing is just a simple process of transcribing thoughts. In contrast, she believed we can explore and articulate our thoughts through writing as a recursive, not linear, process. This aligns with Smith (2005), who described writing as "an active, personal, theory-building, theory-testing process that facilitates the making of meaning" (p. 45). Therefore, the act of writing is accessible to all writers, regardless of their 
relative proficiency in English. According to Samway (2006), educators must "focus on the individual writer and his or her development and needs while recognizing how cognitive and sociocultural factors intersect with writing” (p. 20).

\section{Culturally Relevant Pedagogy and Critical Literacy}

Understanding literacy as part of cultural and social contexts is an element of culturally relevant pedagogy that supports all students. Culturally relevant practices support students' home languages and home knowledge while simultaneously developing literacy knowledge and skills needed for academic achievement (Compton-Lilly, 2004; García \& Kleifgen, 2010; Gay, 2010; Ladson-Billings, 2009; Taylor, 1997). LadsonBillings (2009) described teachers with culturally relevant practices as people who believe all students can succeed and who will help those students work collectively to utilize their innate knowledge in order to achieve success. Guitierez (1995) discussed the creation of a third space in the classroom where home and school interests combine to create a meaningful learning environment. Creating this third space involves "using both the children's home languages and classroom language(s), using student cultural knowledge as a resource, and using everyday classroom literacy practices as resources for student learning" (Compton-Lilly, 2004, p. 54-55). When students' home and school interests intersect in an environment of respect and consideration, school learning does not seem as disconnected from students' real lives, and teachers simultaneously enhance and enrich the classroom curriculum with students' home languages, cultures and knowledge. When students feel they have a safe place to celebrate and utilize their ethnic, cultural, economic, religious or sexual differences, they are more likely to feel successful in their academic endeavors as well (Nieto, 2009). 
Role of critical theory in culturally relevant pedagogy. Critical theory plays a significant role in the practice of culturally relevant pedagogy. The view of literacy as power is a central tenet of critical theory. Literacy as power is a transformative tool for changing existing social structures of oppression (Freire, 1970). For example, Freire (1970) promoted the idea of teachers teaching students how to think and question, rather than simply teaching isolated skills. In a culturally relevant classroom, this perspective suggests that students should have a safe space in which to begin to question why their homeculture is not privileged in the school setting, reflecting a disparity within the larger context of society. Similarly, critical literacy involves imagining multiple perspectives and possibilitiesas legitimate and valuable, rather than enforcing alignment with a single perspective.

Multiple perspectives in reading. Researchers in early childhood classrooms have explored the use of texts encouraging multiple perspectives. For example, Clark and Whitney (2009) intentionally chose books that presented different viewpoints, such as Voices in the Park (Browne, 2001), which tells the story of a play date at the park from the perspectives of four different characters. In the story, each perspective has its own unique set of concerns and interpretations. Engaging children in these kinds of texts and discussions around those texts supports the idea of the reality of multiple viewpoints, not only in texts, but also in institutions and social structures surrounding that classroom. Souto-Manning (2009) also explored the use of multiple perspectives within her first grade classroom. The children began by exploring different versions of the same story of The Three Little Pigs, engaging in discussions about how different perspectives present a different story. Then, Souto-Manning (2009) explored multiple texts and versions of the 
civil rights movement and instances of racism with her students, creating a curriculum that "emerges from social issues exposed in multicultural children's books and is developed through dialogue" (p. 57). Battling the dangers of the single story (Adichie, 2009), these children explored texts representing multiple perspectives to engage in critical literacy.

Analysis of texts. The need to make the learning process and material relevant and culturally specific to students was a major tenet of Freire's (1970) work. Lankshear and McLaren (1993) explored the general practice of simplifying a complex act such as literacy into the more traditionally defined skills of reading and writing. This process promotes normative structures that alsoexploit marginalized groups of people. Similarly, in culturally relevant pedagogy, it is important for students to have the space and ability to relate their academic knowledge to their immediate environment, as opposed to learning decontextualized, isolated skills that have nothing to do with their views, cultures, or identities. For example, Jones (2013) worked with second-grade students who were marginalized by mainstream texts. She argued that marginalized readers must feel a sense of entitlement before they can begin to analyzeand question mainstream texts that do not include their working-class lives (Jones, 2013). She noted her students constantly tried to make connections between their lives and the texts, even to the point of lying about their life experiences so that they can "fit" into their early reading texts. Jones's (2013) students' critical reading of the Henry and Mudge series included questioning why this mainstream text (and others like it) did not include lives similar to the children's working-class realities. This critical reading to uncover thedisconnect (Jones, 2013) within normalized texts empowered those children to "critically reposition 
themselves as readers...to better imagine challenging, changing, and critiquing practices and structures represented by those very texts" (Jones, 2013, p. 199). Jones (2013) calls for teachers to engage students in critiquing these early reader texts in this way, instead of only using them for traditional guided reading instruction.

The critical literacy perspective also recognizes languages other than English and cultures other than the privileged norm as valuable literacy resources (Ruiz, 1984). Native language literacy is seen as a way to break cultures of silence (Edelsky, 1991) for those language minorities who are not literate in English. For students who are bi-literate (literate in more than one language), each language provides another expression of student voice and potentially different perspectives.

Supporting home languages. Culturally relevant pedagogy includes valuing students' home languages, regardless of whether the teacher can speak or understand that language. Cummins (2000) advocated the use of two languages in the classroom "to affirm the experiences and cultures of the students and communities who speak those languages and challenge the discourse of superiority" (p. 10). All children of different language backgrounds deserve the opportunity to develop bilingual abilities to be productive citizens of a 21 st century society. Educators may consider students who can speak Spanish and know only a little English as emergent bilinguals. However, educators must also consider students who are speakers of English only as potential emergent bilinguals themselves (García \& Kleifgen, 2010). If educators view English-speaking students in this manner, they can utilize their students' bilingualism to enhance their curriculum and provide a meaningful education for all students. For example, DeNicolo (2010) used classroom ethnography to examine the ways that the use of Spanish and 
English impacted participation in three fourth-grade classrooms' literature discussion groups. The author found the use of both languages enabled students to take risks in using their language of lesser proficiency and promoted a higher level of engagement.

Classroom practices can support home languages in the classroom even if the teacher is not literate or fluent in the students' home languages. Students can write bilingual books and read them with peers, expanding their understanding of language and how it works. Students can decide what languages they want to use when reading and writing about topics. When students are using a language the teacher does not understand, a more advanced emergent bilingual student can be a translator. For independent reading, teachers can provide leveled reading material in students' home languages. Students' parents, former students, or even other students in the classroom can author these books (García\&Kleifgen, 2010).

Valuing home knowledge. Since literacy is related to the social and cultural contexts in which it is learned, valuing the knowledge of students' homes and communities is important, even if the knowledge or cultural practicediffers from the norm which is currently defined by ways of being in White, middle-class, Christian, heterosexual, English-speaking homes(Compton-Lilly, 2004; Goodman, 1997; Moll, Amanti, \& Gonzalez, 2005; Taylor\& Dorsey-Gaines, 1988). There are commonly accepted assumptions about poor and diverse parents that affect educators' treatment of these families and the children in their classroom (Compton-Lilly, 2004; Taylor\& Dorsey-Gaines, 1988). These assumptions include the notions that parents cannot or do not read, and that they do not help their children with reading. However, building relationships with families can help dispel these myths, realizing that "simplistic 
explanations that focus on negligence and incompetence are generally inaccurate and incomplete" (Compton-Lilly, 2004, p. 10).

Acknowledging the literacies found in the home environment is an essential part of developing literacy knowledge and skills. Many families do not even realize the power behind many of their literacy practices at home, until someone in the education world acknowledges these actions as "legitimate roads to learning" (Goodman, 1997, p. 57). Families use literacy for a wide range of purposes in their everyday lives, and educators must make the effort to leave the comfort zone of their classrooms and enter students' homes to learn from the expertise of families (Taylor \& Dorsey-Gaines, 1988; Long et al., 2004; Gonzalez et al., 2005). After their learning experiences in students' homes, Long et al. (2004) discovered, "The deepest learning occurs when we shift our role from teacher-as-expert to teacher-as-learner" (p. 266). Brock, McVee, ShogreenDowner, and Duenas (1998) provided just such an opportunity for a "teacher-as-learner" experience in their case study research. Focusing on the literacy learning opportunities of one child, Adriana, an immigrant child who only spoke Spanish, the researchers used qualitative methods to assess the impact of a six-week summer school program. The program included Adriana in classroom activities with a peer translator and encouraged her use of Spanish in conversation, reading, and writing. While Adriana's use of English was still sparse, her use of a peer translator helped show her English-speaking teacher how advanced she was in her Spanish reading and writing. Knowing Adriana was so advanced in Spanish reading and writing affected how the teacher viewed Adriana, her achievement, and even her family (Brock et al., 1998).

Since learning and assessment are embedded in social and cultural contexts, 
valuing the knowledge of students' homes and communities is important, even if this knowledge differs from the educators' home experiences. If teachers embrace culturally relevant pedagogy, regardless of existing differences, then students should be expected to take an active role in the learning process as they construct their knowledge about literacy alongside teachers and peers (Gregory et al., 2004; Nieto, 2009; Rogoff, 2003).

Compton-Lilly (2004) illustrates this point. She developed an example of using home knowledge in school activities by supporting her students in a project that explored the jobs held by their family members. This project not only illustrated the important contributions the students' families made, but also dismissed the notion that urban families are all on welfare or are content to be unemployed. Murillo (2012) presented literacy activities for monolingual teachers to help them learn from the family literacies of their bilingual students. One example from Murillo's (2012) work involved students interviewing their parents about how they use reading and writing in their daily lives. The students wrote in notebooks to record these daily family literacy practices. Murillo (2012) also suggested a food literacy project, where students created a booklet containing the labels of the products they eat most often at home and explained how they are prepared. Using this student-made booklet, students wrote about these foods and asked if there were favorite foods from their home countries that are difficult or expensive to buy or grow in the United States. These projects treated language and literacy as social practices, instead of separating cognitive processes and social development, which supported a more meaningful kind of learning for students (Gregory et al., 2004; Nieto, 2009; Taylor\& Dorsey-Gaines, 1988; Vygotsky, 1978; Wertsch, 1985).

Parental involvement. Multiple researchers have identified factors that influence 
why parents need to be involved in their children's schools and the nuances of parentschool relations. The involvement of emergent bilingual parents in their child's classroom also supports the development of their families' home knowledge, cultural experiences, and languages (Hoover-Dempsey, Bassler, \& Brissie, 1995; GonzalesDeHass \& Willems, 2003; Mapp, 2003). Hoover-Dempsey et al. (2005) included five levels in their parent involvement model: (a) parent motivations and perceptions regarding involvement and school responsiveness; (b) learning mechanisms that parents used during involvement; (c) their children's perceptions of parents' involvement; (d) students' attributes; and (e) student outcomes. The first level, parent motivations and perceptions, is essential to this study and includes parents' motivational beliefs, including their sense of efficacy, the impact of invitations of involvement from others, and the school's responsiveness to the life context of the family (Hoover-Dempsey et al., 2005). Parents need to believe that their involvement in their child's school is an important part of their parenting roles. In addition, parents must believe their involvement will make a positive contribution to their children's success in school (Hoover-Dempsey et al, 2005). Parents must also believe their children and the schools both welcome and expect their involvement. Hoover-Dempsey et al. (2005) emphasized that invitations needed to include both general invitations from the school and specific ones from teachers. When considering the life context issues of families, low socioeconomic status, parents' knowledge, skills, time, and energy, and family culture are all factors (Hoover-Dempsey et al., 2005).

Latino parent involvement. Multiple researchers have examined these components of parental involvement as they relate to Latino families (Delgado Gaitan, 
1992; Gillanders \& Jimenez, 2004; Goldenberg, Gallimore, Reese, \& Garnier, 2001; Green et al., 2007, Marinez-Lora \& Quintana, 2009; Walker et al., 2011). Green et al.'s (2007) study of predictors of parental participation included Latino parents as $25 \%$ of the sample. The researchers found that parental role construction, parental efficacy, and invitations from the school, teachers, and their own children were significant predictors of Latino parental involvement at home and school (Green et al., 2007).

Goldenberg et al.’s (2001) study of Latino immigrant parents' expectations suggested a kind of dual nature when examining the parents' beliefs about their role in their children's academics. Although these parents emphasized the importance of education and respect for teachers, monitored the completion of homework, and held conversations with their children about school, they also believed it was the school's job to educate their children (Goldenberg et al., 2001). In an effort to maintain respect for their children's teachers, these parents refrained from assuming a teaching role related to their children's learning in school. On the contrary, other researchers found Latino parents who were eager to ask their children's teachers for advice on how to best support their learning at home (Delgado Gaitan, 1992; Gillanders \& Jimenez, 2004) and who were actively involved and provided massive amounts of support of their children's academic learning in the home environment (Trevino, 2004).

When examining the effect of school and teacher invitations of Latino parental involvement, Marinez-Lora and Quintana (2009) and Walker, Ice, Hoover-Dempsey, and Sandler (2011) clarified the importance of both types of requests. While school invitations were significant predictors of Latino parents' involvement in their children's schools, specific invitations from teachers overrode parents' discomfort due to their 
race/ethnicity or family income (Marinez-Lora \& Quintana, 2009; Walker et al., 2011).

Hoover-Dempsey et al. (2005) found that invitations from schools and teachers were more influential in Latino parental involvement than the parents' beliefs in their own roles or competence. Additionally, Latino parents were more likely to be involved when schools consistently used the parents' home language to communicate with them and invite them to the school (Garcia Coll et al., 2002).

\section{Obstacles and improvements in Latino parent involvement. Even if Latino} parents wish to become more involved in their children's schools, they encounter many obstacles. Some of these problems reside within the nature of the school activities themselves whereby "schools facilitate the exclusion of parents by (consciously or unconsciously) establishing activities that require specific majority culturally based knowledge and behaviors about the school as an institution" (Delgado Gaitan, 1991, p. 21). Other barriers could be lack of transportation, childcare concerns, time and energy as related to job and home responsibilities or lack of school personnel who speak the parents' languages.

In response to these problems, Delgado Gaitan (2004) emphasized three conditions of increased Latino parental involvement: connecting to families, sharing information with parents, and supporting continued parental involvement. Trumbull, Rothstein-Fisch, and Hernandez (2003) provided these conditions in their action research project with seven elementary school teachers working with Latino students and families. The project addressed the gaps in teachers' knowledge of the Latino families' cultures and supported the teachers in increased interactions with families, visits to the communities for social events, and new approaches to parent-teacher conferences and 
engagement of parent volunteers (Trumbull et al, 2003). Trumbull et al. (2003) stated, Increasing parent involvement is not just about teaching parent skills or getting parents into the school to participate in predetermined ways. Success with parents from these Latino immigrant communities is predicated on cross-cultural understanding and openness to hearing how parents wants to participate. (p. 68) De Gaetano (2007) involved parents, teachers, and administrators of two elementary schools in a three-year project, The Cross Cultural Demonstration Project. The goal was to develop and maintain a bilingual and culturally responsive approach to teaching in those schools to improve the academic outcomes of their English language learners (De Gaetano, 2007). Through monthly staff development for all three groups (parents, teachers, and administrators) and classroom coaching, the project focused on strategies to support children's bilingualism and "the use of culture as a mediator of learning" (De Gaetano, 2007, p. 147). The project resulted in a group of Latino parents who were empowered in their abilities to support their children's academics while strengthening their children's home language. Moreover, by the end of the project, the parents' scope of influence spread outside of the immediate school environment to the larger social concerns of their community as a whole.García and Kleifgen (2010) illustrated another example of connecting families through a multilingual awareness program where mothers who spoke different languages came into their children's classrooms so all students could become familiar with the child's language in a classroom context. The students learned greetings and songs in the different languages and the mothers read stories and brought in artifacts and foods that represented their cultural identity. 
Culturally relevant practices contribute to the achievement of all cultures in a classroom. Just as "typical" classroom practices contribute to the achievement of students from the dominant, White culture, using the experiences of other cultures facilitates the success of ethnically and culturally diverse students (Gay, 2010). These practices focus on caring classroom communities where teachers are actively engaged in positively affecting the academic success of her students (Gay, 2010; Ladson-Billings, 2009). Gay (2010) summarized the objective of culturally relevant pedagogy, "The fundamental aim of culturally responsive pedagogy is to empower ethnically diverse students through academic success, cultural affiliation, and personal efficacy” (p. 127).

\section{Literacy Education Can Fully Support Both Native and Nonnative Languages}

Culturally relevant practices include respecting the cultures of all students in a classroom, including their native languages. Unfortunately, when encountering emergent bilingual students in a classroom, some teachers feel unprepared to support those children in their literacy development. Instead of welcoming the children's use of their native language in the classroom, a teacher may restrict the children to using only English. Samway (2006) noted:

Many myths surround the teaching of ELLs, including the notion that teaching them in their native language will impede their development in English. Illinformed policies have often made it difficult to educate children bilingually, that is, teach them in their strongest language (their native language), while also teaching them English. (p. 163)

However, the research indicates that developing literacy in the native language (L1) is a very important resource to students when reading and writing in English (Calkins, 2003; 
Cummins, 2000; Fu, 2009; García\&Kleifgen, 2010; Hudelson, 1989; Samway, 2006).

Supporting both native and nonnative languages. Within the educational setting, instructional times can be focused on developing students' literacy skills in their primary language without adverse effects on the development of their literacy skills in English (Samway, 2006; Fu, 2009). Cummins (2000) referred to this as "additive bilingualism" (p. 37), which requires both the development of a student's L1 while simultaneously adding a second language.

One way to support this additive bilingualism stemmed from Newkirk's (1989) emphasis on the importance of the relationship of a child's drawing to their written text. Calling attention to the fact that many adults deemphasize the importance of children's drawings, Newkirk (1989) called for educators to consider a child's writing as the entire piece, both text and drawing. Teachers who are perceptive when analyzing their emergent bilingual students' drawings can support them in labeling those drawings with words in both English and their L1: "For many young children and newcomers to English, drawing provides a valuable rehearsal for writing. ELLs often need time to draw as this is sometimes the most effective way for them to express meaning" (Samway, 2006, p. 77). Ray and Glover (2008) described the use of student-made picture books as part of a classroom context that is supportive of all writers, including emergent bilingual students. Students went through their own process to create picture books, working on writing for longer and longer stretches of time as they built stamina. The finished books became part of the classroom culture, read multiple times by teacher and students alike. These self-selected and self-created texts "help ELL students figure out how written English works, and allows them to express themselves in writing in meaningful ways" 
(Samway, 2006, p. 38). Samway (2006) introduced Pedro as a student who struggled with writing tasks, which were usually decontextualized skill worksheets that he completed alone, with no interactions or opportunities to talk with peers or his teacher. The teacher then introduced bookmaking and Pedro's writing came alive with the prospect of crafting an authentic text that told his story in both Spanish and English.

Supporting additive bilingualism resulted in students with more developed awareness of language, which enhanced the academic resources of those students, helped them communicate with their families, and had advantages in learning additional languages (Cummins, 2000). Supporting students' additive bilingualism also contributes to their achievement in all academic areas, since it typically takes immigrant children "at least five years (often more) to catch up academically to native-speakers of English" (Cummins, 2000, p. 36). The academic benchmarks are constantly adjusting in difficulty as emergent bilingual students attempt to catch up with a moving target.

A school program that supports both students' native and nonnative languages can "affirm the experiences and cultures of the students and communities who speak those languages" (Cummins, 2000, p. 10). A bilingual school program that is fully bilingual has a strong English reading and writing program with a strong L1 language arts program. There are significant advantages in the goal of children reading and writing in bothlanguages. According to Samway (2006), "Children's bilingualism enhanced their options for making meaning, rather than reducing or limiting it" (p. 49). RodriguezVallas (2011) studied 100 families whose children were enrolled in an elementary school where teachers, parents, and children read bilingual books in a dialogic fashion. Through interviews, observations, and surveys, the author found that reading and analyzing 
bilingual books showed the participants how the skills used in a first language can be applied to learning a second language. Similarly, Soltero-Gonzalez's (2008) qualitative case study examined the literacy practices of an emerging bilingual child during one school year in a preschool classroom filled with Mexican immigrants. Data collection included recordings of students' literacy practices, field notes, work samples, and interviews. Although all of the classroom's instruction in literacy practices was in English, the researcher found that emerging bilingual children used their bilingualism and biliteracy in peer conversations and literacy practices. Manyak (2002) discovered the same phenomenon in his analysis of the literacy practices in a primary-grade class of 20 native Spanish-speaking students. Across the 10-month school year, the author collected data via participant observation, individual and focus group interviews, and samples of student reading and writing. Manyak (2002) found that even in an English-only instruction classroom, children blended Spanish and English in their reading and writing activities.

Utilizing native languages in reading and writing. Multiple researchers (Butvilofky \& Sparrow, 2012; Escamilla \& Coady, 2001; Cuero, 2010; De la Luz Reyes, 2012; Escamilla, 2007; Vaughn, Linan-Thompson, Mathes, Cirino, Carlson, PollardDurodola, Cardenas-Hagen \& Francis, 2006) explored the use of native language in students' reading or writing experiences and assessments. As students progress in their learning, continuously learning about both languages in conversation and formal reading and writing, they may switch from English to their L1 and back throughout their literacy experiences. Instead of regarding this occurrence as a disadvantage, teachers should consider it a benefit, "as it indicates that students are active learners. They are using what 
they already know about print to construct and refine understandings about how written language works in another language" (Samway, 2006, p. 58).

Researchers have explored what happens when students read and write in both their native language and English. De la Luz Reyes (2012) examined reading and writing samples from two students from their kindergarten through third grade years. After giving the students the freedom to use their native language as they wanted, De la Luz Reyes (2012) found the students used their bilingualism and biliteracy to improve their academic success in reading and writing. Vaughn et al. (2006) examined the effectiveness of an explicit, systematic reading intervention for 69 first grade students who were at risk for reading difficulties. The treatment group's interventions were in Spanish as was their reading program. English was used for the comparison group's classroom reading instruction and intervention. The researchers used English and Spanish measures of reading skills to assess the impact of each intervention program. After meeting daily for 50 minutes for the duration of the school year, the researchers found that that the Spanish intervention students outscored their English intervention counterparts in letter-sound identification, phonological awareness, passage comprehension, and reading fluency.

Similarly, in many emergent bilingual students' writing pieces, it is not uncommon to find influences from that child's L1 (Samway, 2006; Fu, 2009). Encouraging students to use their L1 in their writing may increase their amount of writing as well. According to Hudelson (1989), “Allowing the native languages may make children feel more comfortable and give them access to more input than they would have otherwise, thus contributing to, rather than retarding, their growth as users of English" (p. 45). Fu (2009) 
described that as an adult, literate speaker, reader, and writer of English, she still writes in her native language of Chinese when she feels at her most comfortable. Many emergent bilingual students maintain that it is easier for them to express complicated feelings or complex thoughts in their native language (Fu, 2009).

Cuero's (2010) study focused on Jeniffer, one of 15 bilingual Latino fifth grade students. For six months, her teacher encouraged Jeniffer to use her native language in a dialogue journal to write about her transnational experiences. Cuero (2010) concluded that Jeniffer's use of Spanish made it possible for her to vividly articulate experiences that could not have been as artfully communicated using English only. Gort (2006) drew similar conclusions as he investigated the writing process of 32 emergent bilingual first grade children as they composed stories in two languages during Writing Workshop. Gort (2012) then examined code-switching patterns in the writing of six emergent bilingual first grade children. Code-switching is the ability to switch between two or more languages in conversation or writing. In both studies, he found students transferred linguistic skills from one language to another and at times used strategic code-switching to express themselves more clearly in their writing.

Hernandez (2001) compared the writing proficiencies of first and second language learners to examine their teachers' beliefs about the writing students produced. This case study involved eight fifth-grade students, three of whom were native speakers of English, five of whom were non-native speakers of English, and all of whom had attended the school since kindergarten or first grade. Their fifth-grade teachers had specifically identified each of the students as either a "strong" or "weak" writer. The data included interviews, field notes, and writing samples collected over a two-year period. The results 
of the study suggested that the writing skills of strong second-language children writers were "virtually indistinguishable" (Hernandez, 2001, p. 24) from those of strong firstlanguage children. However, Hernandez (2001) also found that second-language students' poor spelling and punctuation sometimes led teachers to miss the fact that some of these children had good ideas and organizational skills, and that they also used complex sentence variety as often as first-language writers.

\section{Reading Recovery}

These studies illustrated the importance of using students' language strengths for writing and reading instruction. However, even with these strengths, some emergent bilingual students experience reading difficulties in first grade. Reading Recovery is one intervention that can be used with these students. Reading Recovery is a short-term intervention for first grade students having difficulty with early reading and writing development. Trained teachers work with students individually for daily 30 -minute lessons lasting 12 to 20 weeks. The goal of this early intervention is to prevent need of further "remedial" education by providing excellent instruction to bring about accelerated progress at a point in time when the existing literacy achievement gap is easiest to overcome. Teachers create opportunities for the child to problem-solve and provide enough support to help the child develop strategic processing in both reading and writing activities. When students have reached the average of their class, the one-on-one tutorial is discontinued. Each lesson incorporates the reading of continuous text, writing stories, and letter work within a lesson framework that includes reading familiar books, reading the new book introduced the previous day while the teacher takes a running record, working with letters and/or words using magnetic letters, writing a story, re-assembling a 
cut-up version of that story, and, finally, reading a new book. Typically, the Reading Recovery teacher has ten minutes for each major component of the lesson. However, DeFord (1994) found that teachers of students who had the highest outcomes gave more time to writing early in lessons than the teachers of children who had lower outcomes. In addition, the teachers of students with the highest outcomes generally used less time for writing toward the end of the students' programs as the children became more independent and fluent as writers. Clay (2005) indicated that with children learning English, that amount of time might vary even more.

As long as a student has adequate English language proficiency to complete the one-on-one assessment tasks in An Observation Survey of Early Literacy Achievement (Clay, 1993), the child is eligible for selection into Reading Recovery. Clay (2005) maintained,

Children who come to school speaking any language will have a preparation for literacy learning that is to be valued, whatever that prior language is. Research is clear that most children can add a second language at this age with relative ease, and, although it does not happen overnight, it does not take them long. We need to see them as competent children who speak and problem-solve well in their first culture and who are lucky to be learning a second language while they are young and active language learners. It is surprising how rapid their progress can be. (p. 6)

It is important to use emergent bilingual children's competency in their home language to further expand their reading and writing abilities in English. The use of students' home languages in this way can be an effective tool to propel their progress forward in reading 
and writing.

Multiple researchers have investigated the success of emergent bilingual children in Reading Recovery. Ashdown and Simic (2000) studied six years of Reading Recovery data. Studying over 25,000 children in Reading Recovery, Ashdown and Simic (2000) also collected data on two other groups of children in first grade, one of which was a random sample of children who performed at an average level, and the other a comparison group of low-performing students who did not participate in Reading Recovery. The researchers identified three subgroups: native English speakers $(\mathrm{N}=15,673)$, fluent non-native speakers $(\mathrm{N}=6,388)$, and limited English-proficient speakers $(\mathrm{N}=3,540)$. Equivalent percentages of each group of children were successfully discontinued from Reading Recovery: $62.2 \%$ of native English speakers, $66.3 \%$ of fluent non-native speakers, and $61.7 \%$ of limited English-proficient speakers. Based on their findings, the researchers concluded that "both native speakers and English language learners are equally likely to be successful"' (Ashdown \&Simic, 2000, p. 38).

Neal and Kelly (1999) also studied multiple years of data for all children in California's Reading Recovery program $(\mathrm{N}=2,366)$. Analyzing three years of data, the researchers examined data for emergent bilingual children, monolingual Englishspeaking children, and a random sample of first-grade students who were not in Reading Recovery. The data revealed that $72 \%$ of emergent bilingual children and $75.2 \%$ of English-speaking children discontinued from the program. Additionally, the emergent bilingual children in Reading Recovery earned scores at the end of the year that surpassed those of the random sample students. Neal and Kelly (1999) upheld the authentic and intense learning context of Reading Recovery for these learners: 
That children are enabled to accelerate their literacy learning in a daily regimen of authentic reading and writing activities whether they are proficient in the language of instruction or still acquiring academic-level competency in their second language should not be a surprising finding. (p. 103)

Hobsbaum (1995) evaluated the United Kingdom's Reading Recovery program in terms of the outcomes for both monolingual (English-speaking) and bilingual children. The monolingual children's discontinuing rate was $66 \%$ and the bilingual children's discontinuing rate was $63 \%$. Hobsbaum (1995) noted the bilingual children's entry scores on the Observation Survey were lower than those of their monolingual peers; however, "by the end of the programme, there are no differences between them" (p. 32-33).

Descubriendo la Lectura. Reflecting Marie Clay's recommendation that, "The least complicated entry into literacy learning is to begin to read and write the language that children already know and speak" (Escamilla, Andrade, Basurto, \& Ruiz, 1996, p. 25), Descubriendo la Lectura (DLL) is the reconstruction of Reading Recovery for those first grade students who are learning how to read and write in their regular classroom setting in Spanish. With the same theoretical foundation as Reading Recovery, Descubriendo la Lectura differs in its procedural and training issues because of inherent differences in the English and Spanish languages (Rodriguez, 2001). Teachers of Descubriendo la Lectura must be certified bilingual educators with experience teaching in a primary bilingual classroom (Rodriguez, 2001). Escamilla, Andrade, Basurto, and Ruiz (1996) explained part of the theoretical foundation for Descubriendo la Lectura: The best preparation for literacy learning is learning to talk and having many opportunities to talk. For Spanish-speaking students, learning to talk has meant 
learning to talk in Spanish, and it makes sense for schools to continue to speak and develop Spanish and to use Spanish as their springboard to literacy. (p. 26) Escamilla (1994/1997) investigated whether use of the DLL program accelerated a group of first-grade, Spanish-speaking students $(\mathrm{N}=23)$ from struggling to average. These students received their initial literacy instruction in Spanish. Using the Spanish Observation Survey (Andrade, Basurto, Clay, Ruiz \& Escamilla, 1995) and the Aprenda Spanish Achievement Test (Harcourt Brace, 1994) as measurements, the data revealed the DLL program resulted in acceleration for these 23 Spanish-speaking students. The gains made were significant when compared to the control group of children who were struggling to read in Spanish, but were not receiving instruction through DLL. Differences between the Fall and Spring data between the two groups of students were significant on all assessment measures $(p<.05)$ (Escamilla, 1994/1997). In addition, spring assessment results revealed DLL students reached the average band of progress or higher on all measurements.

Escamilla, Loera, Ruiz, and Rodriguez (1998/2003) explored the effects of Descubriendo la Lectura on Spanish-speaking students in the second and third grades. Dividing the participants $(\mathrm{N}=264)$ into two groups, students formerly in the DLL program $(\mathrm{N}=132)$ and a random sample group of same-age peers $(\mathrm{N}=132)$, the data revealed the DLL students sustained the gains they made from first grade as they progressed into second and third grades (Escamilla, Loera, Ruiz, and Rodriguez, 1998/2003). When compared to the random sample participants, the DLL students scored the same or higher on both quantitative and qualitative assessments.

My case study utilized Reading Recovery instead of Descubriendo la Lectura 
because my students received initial literacy instruction in English. Therefore, looking across the studies that utilized Reading Recovery with Spanish-speaking emergent bilingual students, none of them explicitly investigated the use of students' home languages and cultural experiences within that setting. My case study about the impact of three students' native languages and cultural experiences in their literacy intervention helps fill this gap in the literature. Furthermore, although this study addresses the impact of utilizing students' home languages and cultural experiences in a literacy intervention setting, the methods, materials, and practices could be applied in regular classroom settings as well. Therefore, this study adds to the literature on culturally relevant methods that support emergent bilingual students in all academic settings. Finally, the research on Latino parent involvement included its effects on students' academic achievement and bilingualism, communication between schools and families, and teachers' understanding of the families' cultures. This case study contributes to this literature through the examination of parental involvement and its effect on students' use of home languages and cultural experiences in a literacy intervention setting. 


\section{CHAPTER 3}

\section{RESEARCH METHODOLOGY}

In order to better understand the impact of native language and cultural experiences in reading and writing, this study focused on gaining insights about three emergent bilingual children's ways of using their home languages and cultural experiences in conversation, reading, and writing during Reading Recovery lessons. These children received literacy instruction in English in their classrooms, while I offered Reading Recovery lessons in English with the support of Spanish to increase their opportunities for growth in both languages. I sought to understand:

1. How does the utilization of students' home languages and cultural experiencesaffect their reading and writing instruction and achievement in a literacy intervention setting offered in English with the support of Spanishat Goodman Elementary School?

2. What is the nature of methods and materials used in the instructional intervention that best support their emerging bilingualism?

3. How can the involvement of students' families contribute to the utilization of students' home languages and cultural experiencesin school?

In the following sections, I describe the qualitative methodology I used to collect and analyze the data. 


\section{Rationale: Methodological Stance}

I utilized a case study methodology in this research. Case studies involve "indepth and often longitudinal examination with data gathered through participant observation, in-depth interviewing, and document collection and analysis" (Glesne, 2011, p. 22). According to Yin (2014), a case study design should be considered when:

(a) the focus of the study is to answer "how" and "why" questions; (b) the researcher cannot manipulate the behavior of those involved in the study; (c) the researcher wants to cover contextual conditions because she believes they are relevant to the phenomenon under study; or (d) the boundaries are not clear between the phenomenon and context. (p. 72)

The case I studied was the process of the participants' utilization of home language and cultural experiences within the literacy intervention setting. The students received literacy instruction in English in their classroom settings. Then, I provided Reading Recovery lessons in English with the support of Spanish to advance the students' abilities to develop their languages and literacies as emergent bilingual children. The support of Spanish in our lessons included multiple layers: reading bilingual and Spanish texts, writing in both Spanish and English, writing student-made books about students' cultural experiences in both Spanish and English, and encouraging the use of Spanish in our daily conversations. This study centered on questions that explored how students' home languages, cultural experiences, and family involvement contributed to their literacy and language growth. Furthermore, I believed the setting of literacy intervention was relevant to the study of students' utilization of their home languages and cultural experiences in reading and writing. I believed a case study methodology would enable me to use in- 
depth analysis of our experiences and conversations in literacy interventions. It is important to note that throughout this study, I acted as both an interventionist/teacher and a researcher.

\section{Participants}

Given the topic I explored, the participants were elementary-aged children who were non-native English speakers enrolled in a school literacy intervention program. I used criterion sampling and intensity sampling (Patton, 2002) as my selected strategies for choosing participants for this study. Criterion sampling explores all cases that meet some kind of criterion, such as all emergent bilingual students who exhibit difficulties in literacy. Intensity sampling involves "information-rich cases that manifest the phenomenon of interest intensely" (Patton, 2002, p. 234). I decided to use these two strategies for two reasons. First, criterion sampling enabled me to explore all the possible participants who are emergent bilingual students at the school enrolled in the literacy intervention program. With such a large student population, this sampling strategy helped me narrow down the possible participants. Next, I used intensity sampling to identify those students who had the most information-rich cases to clearly illustrate the phenomenon I was studying. The specific criteria I used for selection purposes included students who were emergent bilingual students who were still growing in English proficiency and participated in the school's literacy intervention program for reading or writing difficulties. Using these criteria, the list of participants narrowed to three students. I utilized a case study methodology in this research, which involved exploring multiple participants that fit my specified criteria. I believe including three participants afforded the opportunity of exploring multiple experiences, behaviors, personalities, and 
situations when utilizing native languages and cultural experiences in literacy interventions. All names of people and places are pseudonyms.

\section{Sofia}

With sparkling eyes and a ready smile, Sofia transferred to Goodman Elementary as a first grade student in August 2015. She turned seven years old in January 2016 and has three older sisters, two older brothers, and one younger brother. She lives with her siblings, her mother, her father, and a family friend. Sofia has lived in the United States for her entire life, but her mother, father, and older sister were born in Guatemala. Sofia received literacy intervention services in the form of daily Reading Recovery lessons for a total of 20 weeks, beginning in September 2015. Having reached the average of her class, her program in Reading Recovery was discontinued in January 2016. Sofia also received services from Goodman Elementary's ESOL program for 30 minutes every day. In April 2016, after a request from her parents and teachers, Sofia underwent a hearing evaluation, the results of which showed a mild to moderate sensorineural bilateral hearing loss. After following up with an ENT appointment, Sofia received fittings for hearing aids in both ears in June 2016. Sofia enjoyed talking about animals, especially dogs, and the fun antics of her newest baby brother, Dylan. Sofia was a very inquisitive and perceptive child, who asked questions to understand more about what she was seeing in texts and the world around her.

\section{Isabel}

Isabel started at Goodman Elementary as a student in the CD (Child Development) program as a four-year-old child. Her parents submitted an application to the CD program, and Isabel enrolled in 2013. In the CD program for District 8 (all 
names are pseudonyms), priority is given to children who demonstrate an academic or developmental need, or socioeconomic factors that could characterize them as at-risk students. Isabel entered first grade as a spirited and talkative six-year-old child. She has two older brothers, one older sister, one younger sister and one younger brother. Isabel lives with all five of her siblings, as well as her mother. Her father still lives in Mexico, which is the family's home country. They moved to the United States before Isabel was born. Isabel received literacy intervention services with daily Reading Recovery lessons for 20 weeks, starting in September 2015. Her program in Reading Recovery was also discontinued after 20 weeks, the point at which she had reached the average of her class. Isabel also received services from Goodman Elementary's ESOL program for 30 minutes three days per week. Enjoying the role as older sister and "mother hen," Isabel enjoyed talking about her siblings, especially how she helped her mother take care of the younger children. She also talked about her family in Mexico very often and about trips she planned on taking to Mexico. Isabel took on every challenge with a determined spirit, and was quick to offer help to others in need of support.

\section{Antonio}

Like Isabel, Antonio started at Goodman Elementary three years ago in the $4 \mathrm{~K}$ program. Now in the first grade, he has one older brother who lives with him and his parents. He also has one younger brother who still lives in Guatemala with his grandmother. Antonio received literacy intervention services in the form of daily Reading Recovery lessons for 12 weeks, beginning in February and ending in May 2016. At the end of those 12 weeks, his program in Reading Recovery was discontinued as a result of assessment data documenting his reading was at the end-of-year average of his 
class. Antonio also received services from the school's ESOL program for 30 minutes three days per week. Antonio could be quite shy and reserved in groups, but when conversing in a one-on-one scenario, he came alive with fun stories to tell and a contagious laugh. Antonio's favorite topics were the cartoons he loved to watch at home: Batman, Spiderman, SpongeBob, and Curious George. He looked up to his older brother, Juan, who was a senior in high school, and many of the hopes and aspirationshe shared with me were modeled after his older brother. Antonio constantly made connections between texts and between his life experiences and texts, as if he was always searching for how themes, places, and people fit together in some kind of pattern.

\section{Focus Students' Assessment Results}

In the fall, all first grade students completed three literacy assessments: MAP Reading, DRA, and AIMSWeb. MAP Reading is a standardized, computer adaptive assessment administered three times during the academic year in September, January, and April. DRA is a teacher-administered criterion-referenced assessment administered at least three times during the year (fall, winter, and spring); however, Goodman Elementary teachers can administer the assessment more often as needed. AIMSWeb is a standardized universal screening and progress monitoring system. AIMSWeb is used as a benchmark assessment at three points during the academic year in August, December, and May. In addition, AIMSWeb is used as a weekly progress monitoring system for students receiving intervention services. The scores from these literacy assessments are used to determine whether students qualify for intervention services. Table 3.1 shows the initial results of the three participants' literacy assessments from fall 2015, compared with the grade-level expectations for each assessment. 
Table 3.1

Fall Literacy Assessment Results

\begin{tabular}{|c|c|c|c|c|c|c|}
\hline Student & $\begin{array}{c}\text { MAP } \\
\text { Reading }\end{array}$ & DRA & $\begin{array}{l}\text { AIMSWeb } \\
\text { Letter } \\
\text { Naming } \\
\text { Fluency }\end{array}$ & $\begin{array}{l}\text { AIMSWeb } \\
\text { Letter } \\
\text { Sound } \\
\text { Fluency }\end{array}$ & $\begin{array}{c}\text { AIMSWeb } \\
\text { Phonemic } \\
\text { Segmentation }\end{array}$ & $\begin{array}{c}\text { AIMSWeb } \\
\text { Nonsense } \\
\text { Word } \\
\text { Fluency }\end{array}$ \\
\hline Sofia & $\begin{array}{c}137 \\
\left(3^{\text {rd }} \% \text { ile }\right)\end{array}$ & $\mathrm{A}$ & 34 & 29 & 19 & 28 \\
\hline Isabel & $\begin{array}{c}142 \\
\left(7^{\text {th }} \% \text { ile }\right)\end{array}$ & A & 30 & 21 & 2 & 16 \\
\hline Antonio & $\begin{array}{c}149 \\
\left(10^{\text {th }} \% \text { ile }\right)\end{array}$ & A & 28 & 18 & 5 & 14 \\
\hline
\end{tabular}

Note. First grade Fall 2015 on grade level scores:

MAP Reading: $160\left(50^{\text {th }}\right.$ percentile $)$

DRA: 4 (Beginning levels progress as A, 1, 2, 3, 4)

AIMSWeb LNF: 36

AIMSWeb LSF: 21

AIMSWeb PSF: 29

AIMSWeb NWF: 22

Since these students receive ESOL services, the ESOL teacher administers the Assessing Comprehension and Communication in English State-to-State (ACCESS)

assessment(World-Class Instructional Design and Assessment, 2013). This test addresses

English language development standards in four language domains: listening, speaking, reading, and writing. The assessment provides scale scores between 1 and 6 as an indicator of the student's English language proficiency level. Each scale score is interpreted in an ELP (English Language Proficiency) level, which is illustrated as a whole number and a decimal. The whole number specifies the student's ELP level as 
based on the WIDA ELD standards: 1-Entering, 2-Emerging, 3-Developing, 4Expanding, 5-Briding, and 6-Reaching (WIDA, 2012). The decimal "indicates the proportion within the proficiency level range that the student's scale score represents, rounded to the nearest tenth" (WIDA, 2012, p. 6). For example, Sofia's ACCESS score from fall 2015 was 1.3, which indicates her ELP level is slightly above the Entering stage. Isabel's score was 2.1 and Antonio's was 1.5.

While these assessments provided some data, I wanted more information about these students' strengths and needs in the areas of concepts about print in Spanish and English, oral language, as well as reading and writing in Spanish. Therefore, I also administered the Oral Language Assessment Inventory, Second Edition (OLAI-2, Gentile, 2011), the Observation Survey, including the Concepts About Print assessment (Clay, 2000), and text level and Show Me tasks from the Dominie Reading and Writing Assessment Portfolio in Spanish (DeFord, 2004). The data collection section of this proposal includes descriptions of these assessments and the tasks associated with each. Tables 3.2, 3.3, and 3.4 show the fall 2015 assessments results for the OLAI-2, the Observation Survey, including CAP, and Dominie.

Table 3.2

Fall Assessment Results- OLAI-2

\begin{tabular}{lcccc} 
Student & Phonemic Awareness & $\begin{array}{c}\text { Print } \\
\text { Concepts }\end{array}$ & $\begin{array}{c}\text { Repeated } \\
\text { Sentences }\end{array}$ & $\begin{array}{c}\text { Story Retelling } \\
\text { and } \\
\text { Comprehension }\end{array}$ \\
\hline Sofia & Stage I & Stage I & Stage I & Stage I \\
Isabel & Stage II & Stage I & Stage II & Stage II \\
Antonio & Stage II & Stage II & Stage I & Stage I \\
\hline
\end{tabular}


Stage I (Least Experienced) includes students who use single words or phrases and some simple sentences, struggle to comprehend or retell a story read aloud to them, and whose retelling lacks sequence and essential story elements. Stage II (Basic) describes students who understand and use complete sentences, most prepositional phrases, and conjunctions and show the ability to listen to and read a simple story with a basic retelling. The basic retelling has one or more missing story elements. Stage III (Most Experienced) includes students who understand and use complete and complex sentences with prepositions, conjunctions, pronouns, and adverbs. These students also listen to and read a longer story with a complete retelling including details and all story elements.

Table 3.3

Fall Assessment Results- Observation Survey Tasks

\begin{tabular}{|c|c|c|c|c|c|}
\hline & Letter ID & CAP & $\begin{array}{c}\text { Word } \\
\text { Reading }\end{array}$ & $\begin{array}{c}\text { Writing } \\
\text { Vocabulary }\end{array}$ & $\begin{array}{c}\text { Hearing / } \\
\text { Recording Sounds } \\
\text { in Words }\end{array}$ \\
\hline Sofia & $\begin{array}{c}49 \\
\text { (Stanine 3) }\end{array}$ & $\begin{array}{c}9 \\
\text { (Stanine 2) }\end{array}$ & $\begin{array}{c}1 \\
\text { (Stanine 2) }\end{array}$ & $\begin{array}{c}4 \\
\text { (Stanine 2) }\end{array}$ & $\begin{array}{c}8 \\
(\text { Stanine 1) }\end{array}$ \\
\hline Isabel & $\begin{array}{c}47 \\
\text { (Stanine 2) }\end{array}$ & $\begin{array}{c}9 \\
\text { (Stanine 2) }\end{array}$ & $\begin{array}{c}1 \\
\text { (Stanine 2) }\end{array}$ & $\begin{array}{c}8 \\
\text { (Stanine 3) }\end{array}$ & $\begin{array}{c}19 \\
\text { (Stanine 3) }\end{array}$ \\
\hline Antonio & $\begin{array}{c}48 \\
\text { (Stanine 3) }\end{array}$ & $\begin{array}{c}8 \\
\text { (Stanine 2) }\end{array}$ & $\begin{array}{c}1 \\
\text { (Stanine 2) }\end{array}$ & $\begin{array}{c}3 \\
\text { (Stanine 1) }\end{array}$ & $\begin{array}{c}12 \\
\text { (Stanine 2) }\end{array}$ \\
\hline
\end{tabular}


Table 3.4

Fall Assessment Results- Dominie Show Me and Text Level Tasks (Spanish Version)

\begin{tabular}{lcc} 
Student & Show Me & Text Level \\
\hline Sofia & $6 / 17$ & 1 \\
& $($ Stanine 1$)$ & (Stanine 3) \\
Isabel & $8 / 17$ & 1 \\
& $($ Stanine 2) & (Stanine 3) \\
Antonio & $8 / 17$ & 1 \\
& $($ Stanine 2) & (Stanine 3) \\
\hline
\end{tabular}

\section{Obtaining Human Subjects Approval (IRB)}

I obtained informed consent by first creating an invitation letter that outlined everything both the participants and their parents or legal guardians needed to know about the study and their involvement in it. I created copies in both English and their home language. I ensured the information sheet was written in a clear and concise manner that both the children and the families could understand. I called the parents or legal guardians to explain the invitation letter and the study before I sent the paper home. I also created a consent form that matched the design of the invitation letter in both language and style. Since the children were under the age of 16, their parents or legal guardians were asked to provide informed consent. However, the children themselves were also asked to provide assent to the study. Copies of the information sheet and the consent forms can be found in Appendix A and B.

\section{Contexts}

\section{Site Selection, Criteria, and Justification}

Prior to my current position as a Master Reading Teacher at Goodman Elementary, I was an instructional coach at Goodman Elementary for two years. In my 
interactions with parents, students, and faculty, I started to notice a trend of fear and ignorance when faculty members referred to or discussed Latino students and their families. My concern grew as I completed an inquiry project about the lack of access for Spanish-speaking families in the Head Start CD classrooms at the school. I investigated the perceived ways of access the school and its faculty members believed they presented to Spanish-speaking families, and the reality of that accessibility for the Spanish-speaking parents. I found that while faculty and staff believed there were numerous entry points for Spanish-speaking parents to participate in school activities or meet with teachers in support of their children's academic progress at Goodman Elementary, the parents did not perceive all of these as ways to access the school or their children's classrooms to support their children's educational experiences.

The findings of that project illustrated the rift between the perceptions of effective ways of access for Spanish-speaking parents, and the reality of those entry points when the parents needed to access the school, the teachers, or communicate with school personnel about their children's educational needs. For English-speaking parents at Goodman, there were unspoken expectations that they received papers home in a language they could understand, and that the front office staff did speak their language so the staff was able to meet English-speaking parents needs throughout the day. Additionally, parent-teacher conferences were offered in English as they discussed their children's academic and social progress. For the Spanish-speaking parents in my inquiry project, the lack of Spanish translations made it difficult for parents to attend or understand the information being presented. The papers sent home were not consistently translated well. There was one person in the front office staff who spoke Spanish, and 
she was only available for one hour every morning. The parent-teacher conferences may have included a translator, but usually only when the child was struggling with academics or behavior. Some parents tried to improve their English by taking classes or learning from their English-speaking friends, but they still experienced a high level of difficulty in communicating with their children's school about their children's progress and needs.

The next semester, I chose to complete another inquiry project centered around what happens when a teacher and first grade students engage in the sharing of personal stories through artifacts and digital storytelling (Pahl\&Rowsell, 2010). Three teachers participated in the project, and the majority of the students in their classes were Latino children. We invited children to bring in artifacts that reflected something special, unique, or important to their lives, their families, or their cultures. We engaged the children in sharing their artifacts with us and with one another, sharing why their artifactswere special. Then, we asked the children to create narratives about their artifacts, using digital media as one choice to record their stories.

Students' discussions during their artifact sharing time were rich and meaningful. Both children and teacher began to understandmore about each other, their families, and their traditions. The project opened the door for communication around what was similar, different, or altogether interesting about their artifacts and, consequently, their lives. In addition, the students improved the length and content of their writing and showed more confidence when writing and reading their stories. The teacher who participated in the study, Mrs. Strickland, stated this would be something she would continue with this class and her future classes: "I just learned so much about the kids and their families and their lives, not just what I thought I knew. Which I'm kinda ashamed to 
say, you know? It took this project to get me to do that" (A. Strickland, personal communication, April 15, 2015).

As a literacy coach at Goodman Elementary, one of my responsibilities included observing regularly in all classrooms. Throughout these observations, most teachers displayed a similar lack of understanding and support of Spanish-speaking children, their families, and their backgrounds. This inquiry study provided the opportunity to examine if, as an instructional leader, I could influence one teacher's understanding of her emergent bilingual students. The results of this project propelled plans forward as both Mrs. Strickland and I shared the outcomes with other classroom teachers. Two additional teachers implemented similar plans of student artifact sharing in their classrooms.

When I accepted the position of Master Reading Teacher in August 2015, these inquiry projects and the resulting discussions were sparking some changes at Goodman Elementary. The administration at Goodman began to explore other avenues for translation services for parents. Another translator joined the staff in January 2015 and she was present for the entire day 3 days per week. No Spanish-speaking family members were on the School Improvement Council, Parent Teacher Association, or school Leadership Team. The administration sent home a simple survey that was correctly translated into Spanish for those families, asking if they would be willing to serve on any or all of these councils and asking for their input in including Spanishspeaking families' viewpoints and opinions more consistently. The same survey was provided in person at parent nights in March 2015 and April 2015, as well as a digital version on iPads to help with a translator provided for parents for the evening. In addition to the small changes in classroom practice by the few first grade teachers, I felt 
like these events were good first steps towards the forging of productive relationships between Goodman Elementary faculty and staff and Latino families.

However, on my first day of my new position, my coworkers and I reviewed the school's reading data over the past two years, including DRA (Beaver, 2006) scores and MAP assessment results. Much of the conversation revolved around how "low" the Spanish-speaking students were, and how frustrating it was for classroom teachers and interventionists to work with those students. During that discussion, I broached the ideas of utilizing their home languages and cultural experiences more often. I was told multiple times that the students needed to learn in English only and that we did not have the time to try to "fit in one more thing" by trying to include more of their home and cultural experiences. These discussions and the feelings of fear and caution I still noted in many interactions throughout the school influenced my decision to complete research using my own intervention groups at my school.

In addition, I believe my choice of an elementary school in South Carolina helped illustrate how the utilization of students' native languages and cultural experiences could be part of this major change in Southern education. It was a site with a large population of emergent bilingual students, which forged the connection between this research and other sites with similar student populations. Since the site's instructional practices solely focused on English in the regular classroom, I hoped to offer a different kind of instruction by providing Reading Recovery lessons in English with support of Spanish to scaffold these emergent bilingual students' growth. Finally, Goodman Elementary was a site with some kind of program in place, which supported my work with emergent bilingual students and their struggles in reading and writing. In the following sections, I 
describe my site, as well as each setting in which I collected data.

School District 8. School District 8 (all names are pseudonyms) represents a unique blend of urban, suburban, and rural schools that span 1,000 square miles of coastal lands. The district serves more than 49,000 students in 140 schools and several specialized programs. School District 8 offers neighborhood, charter, magnet, IB (International Baccalaureate), and Montessori schools and is divided into elementary, middle, and secondary learning communities, each led by an associate or assistant associate superintendent. With approximately 6,000 employees district-wide, School District 8 is the fourth largest employer in the region. As of May 20, 2016, 3,524 students in School District 8 were English Language Learners, according to the 20152016 School District 8 Facts Sheet. The student ethnic composition of District 8 is shown in Table 3.5 .

Table 3.5

School District 8 Student Ethnic Composition

\begin{tabular}{lcc} 
& Ethnicity & Number of Students \\
\hline Asian & 737 & $1.5 \%$ \\
African-American & 19,895 & $40.1 \%$ \\
Hispanic & 4,264 & $8.6 \%$ \\
White & 23,077 & $46.6 \%$ \\
Other & 1,591 & $3.2 \%$ \\
\hline
\end{tabular}

Goodman Elementary school. Goodman Elementary School, situated in a large city in South Carolina, currently serves over 700 young learners from ages three to twelve. The children attending Goodman Elementary School come from diverse backgrounds. The racial/ethnic composition of students consists of $65 \%$ African 
American, 35\% Hispanic, and 5\% White. Of the 700 students, 170 were identified as emergent bilingual or bilingual on a school survey sent out by the ESOL teacher in August 2015. The poverty rate, which is based on subsidized meals and Medicaid eligibility, has increased over the past four years from $72 \%$ to $95 \%$. Approximately $98 \%$ of students receive free lunch. The school receives Title I assistance to provide support for struggling students.

The school currently houses two three-year-old classes, three CD (Child Development) classes, four kindergarten classes, five first grades, five second grades, five third grades, five fourth grades, and four fifth grade classes. Each CD and kindergarten teacher has one full-time assistant. Two ESOL teachers serve 130 students in CD through fifth grades with limited English proficiency, as identified by the ACCESS assessment. Goodman Elementary has maintained an Average Absolute rating on the State School Report Card for the past five years.

Literacy Academy. Goodman Elementary School is in its sixth year of utilizing Literacy Academy, a tiered Response to Intervention (RTI) model for struggling students in reading and writing. At the beginning of each academic year, the teachers analyze student data from several sources. They utilize kindergarten students' AIMSWeb scores on letter identification, letter sounds, and phonemic segmentation and scores on the Developmental Reading Assessment (DRA-2) (Beaver, 2006) tasks. First grade students' scores on AIMSWeb and Measures of Academic Progress (MAP), as well as their text levels as determined by Fountas and Pinnell's (2010) Benchmark Assessment System determine their interventions. Interventionists identify second through third grade students for interventions based on their percentile rankings on MAP (Measures of 
Academic Progress) as well as their scores on AIMSWeb and text level. Data from students' writing assessments and running records also inform interventions. Students in kindergarten through third grade are placed in Literacy Academy for literacy interventions if their scores from these assessments place them in Tier II or Tier III of the RTI model. The descriptions of each tier are below.

Tier II interventions. Students scoring at the $11^{\text {th }}$ to 25 th percentile on MAP, who are at least two levels below grade level on text level, and scores of Strategic or Intensive on AIMSWeb assessments, are placed on a Tier II intervention plan. Students in Tier II interventions leave the classroom for 30 minutes every day to work in a small group consisting of a maximum of three children. The children in this group work with a trained adult utilizing Fountas and Pinnell's (2009) Leveled Literacy Intervention (LLI) System.

The LLI system (Fountas \& Pinnell, 2009) is a second guided reading group in addition to the guided reading instruction the student receives in the classroom. The lesson also focuses on writing, phonics skills, and high frequency words that relate to the guided reading segment of the lesson. Interventionists administer a weekly progress monitoring assessment using AIMSWeb as well as reading records of texts students have read that week.

Tier III interventions. Students scoring below the $11^{\text {th }}$ percentiles on MAP, with at least two levels below grade level on text level, and scores of Intensive on AIMSWeb assessments are placed on a Tier III intervention plan. Tier III students' intervention plans involve one of two programs: instruction in Reading Recovery lessons for 12-20 weeks, or instruction in LLI (Fountas \& Pinnell, 2009) with additional individual 
instruction for 30 minutes at another time during the day.

Reading Recovery is a short-term intervention for first grade students having extreme difficulty with early reading and writing skills. Trained teachers work with students individually for daily 30 -minute lessons lasting 12 to 20 weeks. Teachers create opportunities for the child to problem-solve and provide enough support to help the child develop strategic behaviors to use in both reading and writing activities. Each lesson incorporates learning about letter/sound relationships and consists of reading familiar books, reading the new book from the previous day while taking a running record, working with letters and/or words using magnetic letters, writing a story, assembling a cut-up story, and reading a new book.

For Tier III students who are not served in Reading Recovery, other districtapproved curricula include: Wilson Foundations (Wilson, 2012), Six-Minute Solution (Adams and Brown, 2007) and Read Well ${ }^{\circledR}$ (Sprick, 2007). The strategies used in Tier III are supposed to be based on the specific skills or strategies that were problematic for a given student served in other interventions.

Importance of connections in Reading Recovery lessons. When I reflected on the Reading Recovery lesson framework, I noted the importance of connections between all the components. For example, the running record of the new book from the previous day provides the student the opportunity to practice the reading strategies from the prior day's lesson. Working with letters or words using magnetic letters connects to reading and writing strategies the child may use in other parts of the lesson. Physically moving magnetic letters to "break" a word into parts provides practice for the child to use that strategy when encountering an unknown word in continuous text. As a child writes in 
their writing book, they connect the components of their meaningful message to the idea of reading for meaning in books. Additionally, Reading Recovery uses continuous texts in both reading and writing, emphasizes the importance of students' independence in utilizing reading and writing strategies, and begins with each child's strengths and knowledge and builds upon them. These program qualities are essential for any struggling reader, and I viewed them as especially important for emergent bilingual children who are still learning about the English language.

Furthermore, I believed I could support the children's home language of Spanish and their cultural experiences in any of the components of the Reading Recovery lesson framework. Because of my basic fluency in Spanish, the students and I could participate in conversations in their home language at any time, broadening the range of topics and complexity of thoughts the students could express. I also included some emergent level Spanish texts with the English books we read every day. These simple texts reinforced the spoken to written language connection and emphasized the importance of reading as a way of expressing a meaningful message. In addition to writing about the books we read, the students also had the choice to write about their backgrounds, their families, and their cultural experiences. In my role as an interventionist/teacher, I offered Reading Recovery lessons in English while I supported the students' use of Spanish and their cultural experiences in our conversations, reading, and writing.

\section{Data Collection Methods}

I collected both quantitative and qualitative data over a period of eight months. Quantitative data included scores from the Oral Language Assessment Inventory, Second Edition (OLAI-2, Gentile, 2011), the Observation Survey, including the Concepts About 
Print assessment (CAP) (Clay, 2000), and text level and Show Me tasks from the Dominie Reading and Writing Assessment Portfolio in Spanish (DeFord, 2004). Qualitative data included a researcher's journal, transcriptions of video recordings of lessons, informal interviews, focus group interviews, inventories, lesson records and student work samples. Each form of data collection was important as I explored the three research questions. The scores from the OLAI-2 (Gentile, 2011), Dominie (DeFord, 2004), and Observation Survey (Clay, 2000), as well as transcriptions of lessons and student work samples, provided data to explore how the utilization of students' home languages and cultural experiencesaffected their reading and writing instruction and achievement in a literacy intervention setting at Goodman Elementary School. The transcription of lessons, my field notes in my researcher's journal, and the lesson records provided some insight into the nature of the methods and materials used that best supported the students' emerging bilingualism. Finally, the informal interviews, focus group interviews, and inventories improved my beginning understanding of these students' families and their contributions to their children's utilization of their home languages and cultural experiences in school.

OLAI-2. The OLAI-2 (Gentile, 2011) is an assessment that uses criterionreferenced tasks to provide information related to the most common language structures children control in their expressive speech. Identifying stages of linguistic development, the assessment's results can be used to link language and literacy instruction and provide a baseline for measuring progress. The OLAI-2 is a value-added assessment. The assessment is one way to evaluate student growth, in contrast to a standardized achievement test traditionally used to compare and rank students to an absolute level of 
achievement (Gentile, 2011). The OLAI-2 evaluates progress over short intervals and compares the results of a student's performance with the student's performance on a previous form of the assessment (Gentile, 2011). The assessment includes five sections: phonemic awareness, print concepts, repeated sentences, story retelling and comprehension, and learning behavior. For the purpose of this study, I used the repeated sentences and story retelling/comprehension components.

Component I (Repeated Sentences) consists of 29 sentences organized by five grammatical structures and four sentence transformations. The sentences vary from simple sentences to sentences containing conjunctions, adverbs, relative pronouns, and prepositional phrases. These sentences were randomly selected by the author after analyzing the writing samples of students in early intervention programs and regular classrooms (Gentile, 2011). The analysis included identifying the most common English sentence structures in both the orallanguage used and the writing journals of students reading at grade level, as well as those reading above and below grade level (Gentile, 2001, 2004). Component II (Story Retelling) includes four stories (Forms A, B, C, and D) written by the author based on the five most common grammatical structures and four most common sentence transformations identified in his previous research (Gentile, 2004). The validity of the OLAI-2 content was researched using the triangulation of the original OLAI data, current quantitative and qualitative literature, and professional interviews and observations of students and teachers utilizing the OLAI (Gentile, 2011). Goldenberg and Rutherford (2009) examined the relationship between the OLAI and another assessment, the California English Language Development Text (CELDT). The students' scores on the CELDT were compared to the Repeated Sentences and Story 
Retelling components of the OLAI. The overall OLAI score yielded the greatest agreement with CELDT scores, ranging from $43.8 \%$ exact agreement and $88.3 \%$ within 1 score point in a five-point range. These findings suggested the OLAI and CELDT measured comparable constructs (Goldenberg \& Rutherford, 2009).

Romeo, Gentile, and Bernhardt (2008) explored whether the Repeated Sentences and Story Retelling components were reliable indicators of young students' English language proficiency by comparing the components to the CELDT and Standardized Testing and Reporting (STAR) assessment. Using a sample of 117 first, second, and third grade Hispanic bilingual students, the researchers found a statistically significant correlation between the OLAI Repeated Sentences and Story Retelling scores and the CELDT listening and speaking tests and STAR. Romeo et al. (2008) concluded that both components correlated with standardized measures of language proficiency.

Scoring of the tasks includes a percentage correct and an assessment of learning behavior which are then aligned to the appropriate stage of language, literacy, and learning behavior for each section and for the total performance.I administered the OLAI2 (Gentile, 2011) at three points throughout the study: Week 1 of intervention services, Week 10 and Week 20. I recorded these data by making copies of the students' completed assessments from the OLAI-2 (Gentile, 2011) and recording the audio of the assessment session.

Dominie (Spanish version). Dominie (DeFord, 2004) can be administered in either English or Spanish. Since all other assessments were administered in English, I selected the Spanish version of Dominie, which provided data on the students' literacy development in their home language. The Kindergarten through grade 3 assessments 
include the Show Me Book, in which students write their own names and demonstrate their knowledge of basic print conventions, such as identifying a letter and a word.

Students' oral reading and comprehension are assessed as well. The phonemic awareness component of the assessment asks children to identify sounds they hear in words, as well as tomatch phonemes and letters. Sight words, letter knowledge, and word and sentence writing and spelling are other components of the assessment. For the purposes of this study, I utilized the Show Me Book task and the Text Reading task. The tools utilized in this portfolio assessment are closely linked to instructional activities, which illustrates their content validity as performance assessments (DeFord, 2004). Reliability was calculated on data from the beginning, middle, and end of the year for the Sentence Writing and Spelling and Core Vocabulary tasks. Fall and spring data were used for computing the reliability for the Phonics Inventory and Phonemic Awareness task. Table 3.6 illustrates the reliability of the tasks for grades K-3 for all three forms of the tasks (A, $\mathrm{B}$, and $\mathrm{C})$.

Table 3.6

Reliability of Dominie Tasks (Grades K-3)

\begin{tabular}{|c|c|c|c|c|c|}
\hline Task & Test & Grade Levels & Form A & Form B & Form C \\
\hline \multirow[t]{4}{*}{ SWS } & $\mathrm{A}: \mathrm{B}, \mathrm{B}: \mathrm{C}, \mathrm{C}: \mathrm{A}$ & $\mathrm{K}, 1,2,3$ & K .74 & K .79 & K .82 \\
\hline & & & 1.78 & 1.74 & $1 \quad .80$ \\
\hline & & & 2.80 & 2.83 & 2.87 \\
\hline & & & $3 \quad .82$ & $\begin{array}{ll}3 & .83\end{array}$ & $\begin{array}{ll}3 & .85\end{array}$ \\
\hline \multirow[t]{2}{*}{ Core Vocabulary } & $A: B, B: C, C: A$ & $\mathrm{~K}, 1$ & K . .85 & K .89 & K . .59 \\
\hline & & & $1 \quad .92$ & $1 \quad .97$ & 1.92 \\
\hline \multirow[t]{3}{*}{ Phonics } & Test/retest & $1,2,3$ & 1.68 & & $1 \quad .74$ \\
\hline & & & 2.71 & & 2.74 \\
\hline & & & 3.68 & & $3 \quad .75$ \\
\hline & Test/retest & $\mathrm{K}, 1$ & K. . .43 & & K .45 \\
\hline \multirow[t]{2}{*}{ Awareness } & & & $1 \quad .48$ & & 1.47 \\
\hline & & & K. .75 & & K. .78 \\
\hline Show Me Book & Test/retest & $\mathrm{K}, 1$ & 1.85 & & 1.80 \\
\hline
\end{tabular}


Content validity was investigated through comparisons between the Dominie benchmark books and student results on texts utilized in Reading Recovery, including Scott Foresman Reading texts and books leveled by Fountas and Pinnell (1999). In addition to these comparisons, content validity was also studied through a second grade classroom pilot of the Dominie text reading materials. The data compared student results on accuracy, fluency, and comprehension with both the Dominie benchmark texts and leveled guided reading texts. Concurrent validity was also studied by investigating the relationship between the tasks in the Dominie Reading and Writing Assessment Portfolio and the text reading assessment alone. A correlation above .40 is considered a somewhat high correlation, and the inter-correlations between text level and each task were between 0.514 and 0.745 . The Phonemic Segmentation and Deletion tasks were also compared at the grades $\mathrm{K}$ and 1 , as well as to the other subtasks of Letter Knowledge, Core Words, and Phonics Inventory. Student results in both grades were similar across the tasks, and there was high correlation among phonemic segmentation in the Sentence Writing and Spelling phonemic segmentation and Letter Knowledge $(r=.43, \mathrm{p}<.05)$, the phonics task for first grade Onset \& rime $(\mathrm{r}=.50, \mathrm{p}<.01)$, and rime $(\mathrm{r}=.46, \mathrm{p}<.05)$, and the three core reading lists $(\mathrm{r}=.53, .67, .59, \mathrm{p}<.01)($ DeFord, 2004). This evidence illustrates the validity and reliability of the different tasks within the Dominie Reading and Writing Assessment Portfolio.I administered Dominie (DeFord, 2004) at two points during the study: Week 2 and Week 20. I recorded these data by making copies of the students' completed assessments and recordedvideos of the assessment sessions.

Concepts about Print (CAP). CAP (Clay, 2000) is an assessment of a child's emergent literacy concepts, including book orientation, directional arrangement of print 
in a text, knowing the meaning of reading terms such as word versus a letter, and basic punctuation marks (period, question mark, etc.). The examiner asks the child to help with the task of reading a book together as the examiner asks the child to point out different components in the text. CAP has evidence to support its validity and reliability, and it is one of the tasks of the Observation Survey (Clay, 2013). These tasks were developed from common literacy behaviors observed by Clay (1982). The content of CAP represents what is actually taught in the classroom. To investigate construct validity, researchers examined interrelationships among the Observation Survey tasks, including CAP, and correlations between task scores and external measures (Clay, 2013). The New Zealand Ministry of Education correlated four sub-scores with the total score on CAP. The correlations were high for knowing how reading is executed $(\mathrm{r}=.93)$, punctuation $(\mathrm{r}$ $=.68)$, concepts about print $(\mathrm{r}=.84)$. However, attention to sequences of letters in words was low $(r=.33)($ Clay, 2013). Clay (1979) reported the predictive validity of CAP through a longitudinal study of the original sample of 83 children who remained in the same schools. Scores on two standardized reading tests at age seven and eight years were correlated with the scores from the Observation Survey tasks. The predictive correlations for CAP ranged from .64 at age eight to .73 at age nine.

Over the past 48 years, reliability coefficients for CAP, as well as the other tasks from the Observation Survey, have been reported for internal consistency, test-retest reliability, and inter-rater correlations. Clay (2013) included a sample of reliability coefficients for each task. Table 3.7 illustrates the reliability coefficients for CAP. 
Table 3.7

Concepts about Print (CAP) Reliability Coefficients

\begin{tabular}{cccc} 
Date & Number of children & Type of reliability & Reliability \\
\hline 1966 & 100 & Split half & .95 \\
1968 & 40 & KR-20 & .85 \\
1978 & & Test-retest & $.73-.89$ \\
1980 & 56 & Split half & $.84-.88$ \\
1998 & & Alpha & .87 \\
1990 & 106 & Alpha & .78 \\
2009 & 128 & Test-retest & .91 \\
2009 & 112 & Alpha & .83 \\
2008 & 326 & Alpha & .69 \\
\hline
\end{tabular}

In addition to these reliability coefficients, CAP includes alternate forms for retesting for reliability. I administered CAP (Clay, 2000) at two points during the study: Week 1 and Week 20. I recorded these data by making copies of the students' completed assessments from the CAP (Clay, 2000) and recording videos of the assessment sessions.

Researcher's journal. All interventionists at Goodman Elementary keep a daily lesson record with any observations about successes or struggles with the specific reading or writing strategy focus. While I also recorded this information on the lesson record every day, I also kept a researcher's journal of observations and reflections after each of my sessions with the participants. I used a physical paper notebook for this purpose and kept it directly next to the table where the students and I worked. I also used my iPhone 
and iPad to record voice or video recordings to document anything throughout the day that I might not have the time to record in writing. This helped me record my observations about connections the participants made between their languages and cultural experiences and reading and writing. I documented specific phrases in students' home languages that were used in conversation, reading, and writing and the contexts within which those phrases were used. I noted the kinds of cultural and home experiences the students mentioned or used in our lessons together. Keeping in mind my role as a researcher, I recorded my analysis of my lesson records and how those records informed my thinking and planning for the following lessons. I also documented my thoughts about my part in the research process, struggles and successes I personally encountered as an interventionist/teacher and researcher, and questions I needed to work through as the research progressed. The researcher's journal was a place to record both theoretical notes that I explored within specific researchers' work, as well as my personal notes as I interpreted what was occurring in the lessons. The questions guiding my observations and reflections were:

1. What went well during the lesson today? What did not go well? How can I use this knowledge to inform the next lesson?

2. Were there times during the lesson that we used the participant's home language? If so, when and what words were used? What was the context in which we used the home language?

3. What kind of home experiences did the participant mention today? How did the participant use the experience in the reading and writing work?

4. What connections are being made between oral language, reading and 
writing by the participants and by the researcher? What are my

personal responses to those connections and how do those responses inform my thinking and planning?

Transcriptions of video recordings. I video recorded every lesson with each participant and transcribed the conversations. I also made notes about participants' body language, overall attitudes, and other ways they participated in the lessons. I recorded what I noticed about my own participation in the lesson as well.

Informal interviews. Three times during the study, in Week 2, Week 10, and Week 20, I engaged the participants in informal interviews. I wanted the participants to be comfortable and unguarded during this time in order to gather the most honest feedback and information from them. Therefore, I did not use a formal list of interview questions that I asked them. Instead, I used our daily conversations as a way to ask them the questions that I needed in the most authentic context possible. Immediately after our three conversations, I recorded as much of the participants' answers and my reflections on our conversations as I could remember. I did not use an audio or video recorder or attempt to take notes throughout the interview unless I felt doing so would not inhibit their responses. These interviews helped me gather information in a comfortable, relaxed manner about the participants' home lives, classroom experiences, and feelings regarding reading and writing. The questions guiding my informal interviews were:

1. When do the participants feel comfortable using their home languages? When do they not feel as comfortable? Why?

2. When do the participants feel they can use what they know from their home experiences in the school day? How do they use those 


\section{experiences?}

3. How do the participants feel about reading and writing when they are at home and when they are at school? Why?

4. What experiences have the participants had regarding their use of home languages in different contexts: at home, at school, in the community?

Focus group interviews. In order to explore the participants' families' experiences throughout the study, I conducted two focus group interviews. The first focus group interview occurred during October 2015, approximately three weeks after their child started working with me. I invited the participants' family members to meet either before school, during my planning time, or after school, providing the choice for parents who had other obligations at different times of the day. The first focus group discussion concentrated on the families' use of their native language and cultural experiences at home and in the community. I asked families to share their experiences at home and at school with their native language and what they observed concerning their children's experiences as well. We explored what was available as support for the participants in the home and community environments. Throughout the study, I invited the participants' parents to observe a lesson with their child. All three participants' parents attended at least one lesson. After all of the parents had the opportunity to watch a lesson, I conducted the second focus group interview. The second focus group occurred in December 2015 and concentrated on the families' thoughts and feelings regarding their children's lessons, as well as any experiences they could share from their home lives concerning their children's use of language and cultural experiences.

Reading interest inventories. I conducted a reading interest inventory with each 
participant during Week 1 and Week 10 of the study. The reading interest inventories not only addressed what a student may find interesting to read, but also provided insight into attitudes and values reflected in reading experiences. I kept copies of the participants' inventories and recorded my observations and reflections on the inventory process and responses afterwards. A copy of the reading interest inventory I used can be found in Appendix C.

Lesson records. I kept lesson records of what occurred throughout each session. These lesson records included titles of the books chosen by me or the students to read, and whether the text was English or Spanish. The lesson records also included observed strategic actions utilized by the participants in their reading and writing, as well as the kinds of teacher prompts I used to introduce, support, or reinforce strategic actions. I recorded the written message the child wrote for each lesson and any letter or word work we did. Finally, I wrote summarizing comments about each lesson in preparation for the following lesson's instructional decisions.

Student work samples. I gathered examples of the participants' reading and writing through reading records and writing samples from their writing journals. I also collected samples of student-created books we made together. Analyzing the reading records helped me identify struggles in their reading processes, as well as their strengths as readers. The participants' writing samples illustrated their use of English and their home languages as a writer, as well as their writing process. The writing samples also depicted any cultural experiences or home knowledge the participants brought to their writing. I collected work samples every day of our lessons together. 


\section{Organization of Data}

To organize and store my data, I used both paper and digital storage. I used a paper binder for each participant to store copies of their assessments, work samples, and notes specific to that participant. I also used a digital folder in NVivo for each participant to store scanned copies of the assessments, work samples, notes, and transcribed lessons. I used a paper notebook for my researcher's log, and I also used NVivo to pair my written notes with any audio or video files of reflections and observations throughout the study. For transcription purposes, I set aside two to three days per week to transcribe any interviews or audio and video files. I stored those transcriptions in NVivo and added a backup copy of each audio and video file and accompanying transcription on Google Drive.

\section{Data Analysis}

Both quantitative and qualitative data were collected in this study; therefore, the data analysis methodologies varied based on the type of data.

Inductive analysis of qualitative data. The analysis of interview transcripts, reading interest inventories, and observations and reflections were based on an inductive analysis by identifying patterns in the data using thematic codes. According to Patton (1980), "Inductive analysis means that the patterns, themes, and categories of analysis come from the data; they emerge out of the data rather than being imposed on them prior to data collection and analysis" (p. 306). Throughout the data collection, I used the three research questions as my first a priori codes, and I narrowedsome of the codes to be more specific as I transcribed. After data collection, I read and re-read all of the observations, reflections, transcripts, and inventories and then began noting the inductive codes 
emerging from the data. I brought all the codes together in a master list and then began to organize them in NVivo, noting which codes were similar and grouping them together in a broader category. After I organized the codes into categories, I looked across all the categories to see if they represented themes or patterns in the data. I involved the participants and their parents in the analysis as we participated in member checking sessions, sometimes over the phone and sometimes in person, examining the data and evaluating their meaning in the context of the study's research questions and purpose.

Quantitative data. After all the data were collected from the DRA (Beaver, 2006), Observation Survey (Clay, 2000), OLAI-2 (Gentile, 2011), and Dominie (DeFord, 2004), I analyzed the progress of each student. The different assessments represented student data in varied forms, including numbered levels, numbered stages, percentages, total points, and rubric scores. I created tables to analyze individual participants' data across different administrations and across assessments. I also analyzed the data across the participants.

\section{Trustworthiness, Triangulation, and Member Checking}

Multiple data collection sources maintained the integrity of the rigor of this study. I collected data through a variety of strategies and in several contexts. I also used a researcher's log to reflect on my observations and experiences and record my thoughts. Writing in my log helped me reflect on my interpretation of the data throughout the study and how I affected the overall analysis of the data. Since I was the creator of the content for the literacy intervention with the participants, as well as the initial interpreter of the data, I needed to consistently self-reflect on how I was affecting the research process in this way. Member checking occurred as I asked the participants and their families 
clarifying questions about my transcripts and even shared some of my thoughts from my journal so I could obtain their feedback.

\section{Subjectivity and Positionality}

I approached this study with an identifiable relationship and theoretical perspective to what I am studying. I believe that learning is a sociocultural process; reading and writing are socially constructed, meaning-making learning tools; and culturally relevant practices support the needs of all students. I also approached this study with differences between the participants and myself. When I compared myself to my participants, we were as different as two individuals could be. I am a White, middle-aged, upper middle class, female educator. The participants were first grade Latino students from families of a lower socioeconomic status. When I was in school, reading and writing came easily to me. Reading and writing are not as easy for these children. My first language is English and when I started learning Spanish in kindergarten, it was an option provided to my parents as an additional skill I could use in the future. I enjoyed learning Spanish so much through my elementary and into my high school years that I then earned a minor in Spanish during my undergraduate career. The participants, on the other hand, were expected to learn English as a requirement in their education. It was not instructed to them in a separate English language class, like the Spanish classes I was in throughout my academic career.

As a White female educator, it is also important to recognize that I was in a position of power and privilege in relation to the participants. There was a clear difference between our cultural, ethnic, and linguistic identities in terms of power differentials in society. Being a White, upper middle class female placed me in a position 
of power in relation to them. As an instructional coach in the school system and the instructor for literacy interventions, the participants regarded me as someone with power in the academic world.

Another component of my positionality was my involvement in two roles throughout this study: an interventionist/teacher and a researcher. In these dual roles, I was attentive to the instructional methods I utilized and why I chose to use them with the participants. I was aware of the participants' varying levels of engagement and interaction with these approaches, and kept in mind that my position as a researcher was part of the motivation behind those chosen methods. The use of a researcher's journal to document these decisions, the motivations behind them, and the students' reactions to them helped me keep my positionality at the forefront as I tried to balance both of these roles.

The participants likely participated and followed what I encouraged because of my position of power as their intervention instructor and prior instructional coach at their school. There is an unspoken understanding between teachers and students that communicates the expectation that students will do what is asked by the teachers. Since the participants and I all spoke Spanish, this similarity may have made the participants feel more at ease with using the home language in an academic setting with me. However, the level of comfort we had could be used to interpret what Iobserved throughout the study in a biased way. When I asked the participants to share their beliefs, opinions, or feelings with me, they may have refrained from fully sharing everything they thought out of fear of what I thought or how I would respond. Overall, the weaknesses within my positionality with the participants were balanced as much as possible with the 
strengths in my beliefs surrounding the utilization of home language and cultural experiences in literacy intervention settings.

\section{Ethical Issues and Reciprocity}

There was one ethical issue I encountered during this study. One of the member checking sessions with a participant's parent resulted in sharing some discussions she had with other Latino parents about the lack of access and understanding they experienced at the school. She told me this in confidence, and I asked her to encourage the parents to speak with me or the principal. She refused and begged me to keep her confidence out of fear of repercussions from those parents. I decided not to press the matter any further and hoped those parents would one day feel comfortable enough to share their concerns. This was an ethical issue for me because I knew the identities of those parents and could have reached out to them for more data for the study. I chose not to do so out of respect for the confidentiality between me and the parent.

Issues of reciprocity included explaining to the parents of the participants the benefits of their participation in the study, for both the students and the parents. I explained what would be included in the lessons because of their participation, and all of the parents expressed excitement that their child would be using their home language and experiences in a school setting. When I invited the parents to the focus groups, I tried to compensate some of their time by offering food and drinks, and a teacher friend of mine volunteered to watch their children in her classroom throughout the duration of the interviews as free childcare.

\section{Risks and Benefits}

One risk to the participants as they participated in the study included some 
resistance and misunderstanding from other teachers. As the participants began to use their home languages more often in our literacy intervention setting, they also started using those languages in other settings more often, including their homerooms. One homeroom teacher expressed discomfort with a participant's increased use of her home language in the classroom, and the teacher came to me to speak about it. Even after our discussion, she told the student not to speak in Spanish in her classroom, even though the child could continue to speak Spanish when she was with me. It was difficult for that child to understand why she could not speak the language she wanted, especially when she witnessed the other two participants' teachers gradually encouraging the use of their home languages in their classrooms.

Benefits for the participants included increased confidence in their utilization of their home languages and cultural experiences, and increased motivation and achievement in the historically difficult academic areas of reading and writing. Also, the participants became examples to other emergent bilingual children who initially felt uncomfortable with using their home languages or experiences at school. They also became examples to their teachers. I had many students approach me and ask if I was the "lady who let Isabel talk Spanish." The participants' increased confidence and motivation led to conversations with my coworkers about what I was doing that made such a difference. The participants were the impetus to many enlightening and exciting discussions among the faculty of Goodman Elementary.

\section{Limitations and Considerations}

My conversational fluency in Spanish was one limitation in this case study. Since I could mostly understand what was spoken and written in Spanish, I felt more confident 
in a participant's use of that language in our interactions. However, if another teacher who was monolingual was in the same situation, that person may not have felt as comfortable. This study had limitations in regards to setting and participants as a case study. I conducted the study in only one school and with three student participants. More time to explore the use of home languages and cultural experiences with more participants across more school settings would have proven beneficial to the purposes of this study. 


\section{CHAPTER 4}

\section{FINDINGS}

This study explored three emergent bilingual children's ways of using their home languages and experiences in a literacy intervention setting, specifically in Reading Recovery lessons. Specifically, I sought to understand:

1. How does the utilization of students' home languages and cultural experiences affect their reading and writing instruction and achievement in a literacy intervention setting offered in English with the support of Spanish at Goodman Elementary School?

2. What is the nature of the methods and materials used in the instructional intervention that best support the students' emerging bilingualism?

3. How can the involvement of students' families contribute to the utilization of students' home languages and cultural experiencesin school?

In the discussion of these findings, I believe it is important to state that serving in the dual role as teacher and researcher, I am the interpreter of these findings. Glesne (2011) noted qualitative researchers are "interpreters who draw on their own experiences, knowledge, theoretical dispositions, and collected data to present their understanding [emphasis added] of the other's world" (p. 157). My experiences and beliefs filtered my collection of data across multiple data sources, resulting in my unique understanding of the realities of Sofia, Isabel, Antonio and their families. 


\section{Research Question One}

How does the utilization of students' home languages and cultural experiences affect their reading and writing instruction and achievement in a literacy intervention setting offered in English with the support of Spanish at Goodman Elementary School?

The students' use of their home languages and cultural experiences affected their reading and writing instruction and achievement in two ways. First, the students' confidence and motivation within the reading and writing instruction improved greatly when I encouraged them to use their home languages and cultural experiences. Secondly, all three students showed gains in speaking, reading, and writing in both their home and school languages. These specific areas emerged as dominant themes throughout my analysis of video transcriptions of lessons as well as the analysis of the formative and summative assessments utilized throughout our lessons.

Confidence and motivation. After their weeks of instruction in Reading Recovery, all three students were confident, motivated, and engaged readers and writers. At the end of our lessons in May, Antonio confided in me, "I am a real reader now." Even Antonio's classroom teacher, who was skeptical of using home language in Reading Recovery, noted the change in March after two weeks of lessons, "He is so confident now. Like a different kid! What a huge difference" (L. Richland, Personal Communication, March 13, 2016). At Isabel's end of the year conference with her mother, she announced, "Me encanta leer. Yo leyendo los libros de español y tambien los libros muy difícil. I love to read. I read the Spanish books and also the hard books." Sophia told me in December 2015, "I can do this by myself! Look at this! I know how to 
read all the books!" However, these children did not begin their lessons as confident readers, writers, or even speakers, especially of their home language. I believe in order to see a more complete picture of these students as self-assured readers, writers, and speakers of both school and home languages, it is important to first see the uncertain and somewhat fearful children they were when we first began our lessons together. The following section describes the issues of permission and fear that permeated our beginning lessons before the students discovered their confident literacy selves within.

The issues of permission and fear. Which language are we supposed to speak? Allowed to speak? Afraid to speak, but only in certain places or with certain people? These questions seemed to be the foundation of my beginning weeks with the three participants. In my data analysis, within the first 3 weeks of our lessons, there were 29 instances of the students expressing fear in using their home language or occasions when they asked permission to use Spanish in our conversations or their reading and writing experiences. Isabel expressed fear around the use of her home languages five times; Sofia mentioned the same fear in three different instances, and Antonio made statements that asked permission to use Spanish or showed fear 21 times in our first three weeks together. In our first informal interview in September, Antonio explained his beliefs about languages and where they are accepted.

Antonio: And you um, talk a lotta English and your Spanish and you talk at your home, like, you talk in Spanish over there and you have to talk in Spanish at your house. You have to talk a lot of Spanish, if you don't talk a lotta Spanish and you talk in English, you're not gonna.... like you're gonna get confused. 
Sarah: So you're saying you speak a lot of Spanish at home but you speak English at home-

Antonio: No. Look, I talk in Spanish over there in my house.

Sarah: And you speak English in school.

Antonio: Uh huh, and I have to speak English here at school. You gonna start confusing and you only gonna know a lot English and not a lotta Spanish.

Sarah: Oh I see. You want to make sure that you keep your Spanish?

Antonio: Sí. Yes.

Both Isabel and Sofia also expressed similar sentiments when I asked them about speaking Spanish in different settings. In our first informal interview in September, Isabel explained that speaking her home language in the classroom was a punishable offense with a written discipline referral to the assistant principal.

Isabel: I talk with Brenda, Sarai and Sayri, English in the classroom and Spanish in the park (playground).

Sarah: You don't speak Spanish inside the classroom?

Isabel: No. Because our teacher don't let us. Because if we talk in Spanish...she doesn't talk in Spanish and she doesn't know. And if we talk in Spanish, she makes us a referral. But you let me talk in Spanish. No referral here.

Sofia explained a similar situation in the same classroom in our initial informal interview:

Sofia: I can't talk in Spanish. She (the teacher) can't talk it or read it.

Sarah: Who else in class can speak Spanish? 
Sofia: $\quad$ Brenda, Sayri, Jennifer...

Sarah: Do you ever talk in Spanish in the classroom?

Sofia: No, outside we talk each other...the Spanish.

Sarah: Just outside?

Sofia: Just outside because our teacher don't want us to talk in Spanish. She told us no. I like to talk in the Spanish because that is my favorite to talk.

The students' statements matched my prior experiences, observations, and conversations within the school regarding students' use of Spanish. If I spoke Spanish with a child I saw in the hallway within earshot of some teachers, I was reminded by those educators that they were trying to teach English, not Spanish, in the school environment. At one point, a colleague even suggested my conversations with students in Spanish were hurting the children's academic progress in her classroom. She stated, "I don't tell them [the students] to tell me things in Spanish a lot, or they won't want to learn English."

I explained to each participant that we would use their home language, as well as English, in our conversations, reading, and writing experiences. As we began our first ten lessons "roaming around the known" (Clay, 2005, p. 32), including their home languages and cultural experiences helped me follow the participants as we stayed with what the children already knew in both languages. According to Clay (2005), "the teaching should not start where the teacher is but where the child is! Confidence, ease, flexibility, and, with luck, discovery are the keynotes of this period" (p. 32). This was my goal for the first ten lessons. I wanted to use what the children already knew in order to promote their confidence and flexibility with reading and writing. At first, all three 
children reacted with surprise and caution. Even after I showed the children my limited ability in using their language, they were still unsure about the idea. According to my personal notes and transcriptions from February 3, 2016, Antonio continued to ask my permission to speak Spanish when we were talking: "Antonio consistently asks, 'In Spanish?' now that I've told him he's free to speak in his native language. Lots more conversation now than before though." Another example came from my transcription of a lesson a few weeks later:

Antonio: My brother came walking and my brother has a key to open it and I do my homework and my brother does his homework and we...um...Spanish?

Sarah: Spanish? Yeah, go ahead. Te puedes hablar en español. You can speak in Spanish.

Antonio: Y vayamos y leo con mi mama y nosotros comemos. And we went and I read with my mom and we eat.

Sarah: No tienes que pedir permiso para hablar en español conmigo. You don't have to ask permission to speak in Spanish with me. You can just do it whenever you want to. OK? (Antonio nods)

Sofia and Isabel also expressed concern with the idea of punishment by their homeroom teacher while they were speaking, reading, and writing Spanish with me. Especially in those first few weeks, our building of trust was crucial to the belief that my classroom was a safe space for both oftheir languages and cultures.

Confidence in home language and English. As time progressed, the students started to show evidence of building confidence in their use of both languages in 
speaking, reading, and writing. In the data analysis, I coded instances of student confidence 118 times within our lessons, as compared to 31 instances of student uncertainty. While I coded 29 total instances of fear and permission around the use of their home language in September, by October, that number dropped to zero. Once given the choice, the students used Spanish confidently in their speech, reading, and writing. Their increased confidence in their home language transferred to their use and knowledge of the English language in their reading and writing.

Confidence in speaking. When I first met the three participants, their levels of confidence in speaking English and Spanish varied. Isabel was a very confident speaker in Spanish, but only once she knew that speaking Spanish was not prohibited. For example, on October 30, 2015, I noted in my research journal, "As soon as she knew Spanish was an accepted language in the space of my room, she wanted to tell me everything in Spanish. She especially likes to translate English texts into Spanish as she reads." That note stemmed from an experience reading the English book, Cats and Kittens that day. Below is the conversation between me and Isabel.

Sarah: $\quad$ Alright, Cats and Kittens.

Isabel: $\quad$ I can read it in Spanish.

Sarah: Well, the book is in English.

Isabel: I can read it in English and then say it in Spanish.

Sarah: That sounds like a great idea. Go ahead.

Isabel: (reading) Cats play. Kittens play too.

Sarah: OK. Spanish?

Isabel: Los gatos juegan, gatitos juegan también. Cats like milk. Kittens like 
milk too. Gatos le gustan leche, gatitos les gusta leche también.

Isabel was confident enough in her home language to translate the book as she read it for the first time. That confidence would extend to her reading and writing experiences as well. She was also very confident in her use of English. She explained that her cousin spoke English very well, and she spent a lot of time with her cousin growing up. So Isabel had more experience using English than Antonio or Sofia.

Sofia's confidence in using English was very low when we first met. I noted in my October 13, 2015 field notes:

Sofia told me today, "I can't talk good," when she struggled to find the word she wanted to say in English. I replied that she could just use Spanish instead and off she went to tell me exactly what she wanted to say. Her confidence in the two languages is so very different. Most of the time, when I would invite Sofia to use Spanish when she was stuck on an unknown English word, the English would quickly come immediately after "her use of Spanish loosened her tongue" (October 15, 2015 Field Notes). An example from October 14 is below:

Sarah: What could we write about shopping with your family today?

Sofia: I bought a...I can say in Spanish?

Sarah: ¡Por supuesto! Of course!

Sofia: $\quad$ Vestido. Dress.

Sarah: Oh, a dress? De qué color? What color?

Sofia: Blue! ¡Azul! I bought a blue dress at the store and I wear it to my sister's birthday!

I noted the look of relief and excitement that flooded Sofia's face once the words she 
desperately wanted to write came out. Once she worked through the mental block of the unknown English word, I was impressed with the complexity and clarity of the resulting sentence in English.

Unlike Isabel and Sofia, Antonio was shy and withdrawn in speaking both his home language and English. However, his language scores on the ELDA were much higher than either Isabel or Sofia. Therefore, it took more time to work together through his quiet personality to cultivate his confidence in speaking with me. The first breakthrough moment occurred when Antonio corrected my pronunciation of the Spanish word huevos (eggs). On February 29, 2016, I noted in my field journal:

Antonio felt confident enough today to correct my pronunciation today with the word "huevos." I pronounced the word with a /v/ sound and he told me it was supposed to be a /b/ sound. He felt confident enough in our relationship and his language to point this out to me. I love it!

Antonio continued to help me with my Spanish as we worked together, including my pronunciation of words and translating words I did not know.

Learning behavior confidence in OLAI-2. Part of the OLAI-2 (Gentile, 2011) assessment is a notation of the students' learning behaviors as they complete each task. The choices are Flexible (the child interacts positively with the examiner and task), Fight (the child confronts or resists the examiner or task), and Flight (the child shuts down, appeals, and appears immobilized). Isabel, Sofia, and Antonio all scored in the Flexible category for the Repeated Sentences task in all administrations of the assessment. However, for the Story Retelling component, Isabel, Sofia, and Antonio showed Flight behaviors during their first administration of the assessment. After I showed the students 
the picture cards for the story and told them the story orally, I asked them to retell the story to me using the same cards. All three students appealed to me in one way or another. Sofia asked me, "But how I gonna do this? I no talk good," while Antonio sat silently and looked at the floor. In fact, Isabel replied to the request with, "Oh...I'm afraid." Even after I provided the students with support and encouragement and helped them begin their retelling, they still showed characteristics of the Flight learning behavior. However, by the time of their second OLAI-2 administration, all three students' learning behaviors were in the Flexible category for the Story Retelling component,as well as the Repeated Sentences task. Even though the story and picture cards were new to them, none of the students appealed to me for help, and all three participants readily engaged in the task of retelling the story to me. Below are each student's story retellings from both administrations of the OLAI-2.

[Isabel's story retelling- first administration]

Isabel: I'm afraid. I don't know.

Sarah: You can try your best. You can do it.

Isabel: Mario and...I don't know.

Sarah: Miguel.

Isabel: Mario and Miguel. They play in...want outside. And the Mom came and room is a mess. Mario and Miguel, they clean the mess. Mom said they can go play.

[Isabel's story retelling- second administration]

Isabel: One day, Popcorn was called Popcorn and he called Popcorn cause he got the spots and that's why he got...his name is Popcorn. Popcorn 
and...Mary loved to play every day. Popcorn loved to roll and kick his feet in the air. One day, Mary got her things and she..she said I am trying..I am going to try. Popcorn said Don't be afraid, said Popcorn. Mary didn't be afraid...Popcorn jumped and Mary didn't fall down and the rabbit and the bird were watching. The end.

[Sofia's story retelling- first administration]

Sofia: But how I gonna do this? I no talk good.

Sarah: You can do this. Use the pictures to help you.

Sofia:I see the tree. I see the girl. I see the horse. The next one I see the girl with the horse playing with the tree. Um...I see the horse and the... and the...the girl put her boot, her hat. The other one, she...she was on the top the horse and then she didn't fall. And then I see the rabbit coming.

[Sofia's story retelling- second administration]

Sofia: Popcorn had a friend. They are friends. Popcorn and the girl are laughing and they having fun. The girl get her hat, her boots, and she scared to ride. Popcorn say to her not worry, you not gonna fall. And the girl is up in back and the rabbit is looking at them. And she not scared.

[Antonio's story retelling- first administration]

Antonio: The...the boy..? (appeals)

Sarah: $\quad$ Go ahead.

Antonio: The boys are awake. Messy room. Mom came in the room...? (appeals) 
Sarah: You can do this.

Antonio: They clean it. It is clean.

[Antonio's story retelling- second administration]

Antonio: Popcorn and Mary...were having fun...having a great day. And Popcorn likes to puts his feet up in the sky and they have too much fun! Popcorn said, "Why do you never ride me?" Mary didn’t like to climb to have a ride with Popcorn. Then Mary try... She...put on her boots and her hat and her clothes. She just...she get on Popcorn's back. And she have a ride and she did not fall!

All three students' story retellings improved in their length and details. There were no signs of fear or appeals for help in the second administration of the OLAI-2.

Furthermore, when analyzing the sentence types (Gentile, 2003) used in the story retellings for both administrations, all three students showed improvement. In Isabel's first retelling, she used only simple sentences, although her word count and inclusion of story elements placed her at Stage II (see Table 4.1). Simple sentences usually include an article, a noun, a verb, and an object. Sofia's and Antonio's first retellings also used mostly simple sentences and one expanded simple sentence with a prepositional phrase, although they remained at Stage I because of the limited number of words they used and the lack of some story elements (see Table 4.1) (Gentile, 2003). However, for their second retelling, all three students used sentences that included two phrases linked by a conjunction (Gentile, 2013), instead of only simple sentences, and included the important story elements in their retelling. All three students were at Stage III for story elements in their second administration. Isabel moved to Stage III with the increase in her story 
retelling's word count, and Antonio moved to Stage II (see Table 4.2).

Confidence in reading. The first instances of confidence in reading came from the students' fluency. I wrote in my field journal on October 29, 2015: "Sofia's fluency is so much better when reading familiar books in Spanish versus English. I need to record her and let her listen to herself so that she can hear how smoothly she reads." I recorded Sofia the next day and then played the video so she could hear herself reading smoothly with intonation and expression. Sofia's reaction was one of surprise, embarrassment, and eventual confidence. She exclaimed, "I sound good!" after she watched the video. In later lessons, she asked me to record her again, this time reading one of her favorite English books about two dogs, Bella and Rosie. When she viewed this video, she noted, "I sound good with that book now too." She was exactly right. Her fluency improved drastically in the English texts as well as the weeks progressed. Sofia's confidence and resulting improved fluency encouraged me to record Antonio and Isabel as well. They both enjoyed listening to themselves read in both languages, and it was an effective teaching moment to hear the kind of fluent reading they could do in either language.

There were other instances of confidence in reading in both languages throughout our lessons. All three students expressed their love for the Spanish books and they boasted about their abilities to read those books and others. On November 11, 2015, Isabel asked if we could read another Spanish book. When I replied that we could, she exclaimed, "I know how to read all the books!" On April 20, 2016, I noted that Antonio had already chosen his familiar texts to begin our lesson before I even sat down. When I asked about his choices, he explained, "I am a good reader with this book. It is 8, but I can read it." Antonio had recently started to note the numbered levels written on the 
backs of the books in his classroom and in my room. The day before, his teacher had told him that level 8 books were too hard for him to read.

Many times, Sofia would display confidence in reading her texts by discouraging me from helping or prompting her. For example, I noted in my field journal on November 10, 2015:

When reading today, Sofia encountered a word with /ow/ in it and paused. I waited for about 10 seconds and as I got ready to prompt her, she interrupted me by shouting, "I know! I know! That word is like 'how.' I know that, Mrs. Catto. I do it." Then she broke the word into parts successfully and reread to regain the meaning of the sentence and to demonstrate greater fluency. She is doing this more and more. Her confidence in her own abilities is sky-rocketing.

Sofia wanted to do everything as independently as possible, which is one of the main goals of Reading Recovery lessons.

Confidence in writing. The students' confidence also shined in their conversations around their writing and in the process of writing their stories in either English or sometimes in Spanish. In the beginning of our lessons, I noted both Sofia and Antonio were very reluctant writers. In the first four weeks of lessons, Sofia appealed for assistance 27 times and Antonio did so 19 times. On April 12, 2015, Antonio flipped through his writing notebook, past some of his earlier entries of only a few words. He remarked, "That was when I did not know how (to) write. Now I know and I can write mucho (a lot)." I asked him what was different about him as a writer then and now, and he replied, "I used to not know words in the English, so it was hard como escribirlo (how to write it). I know lots of words in Spanish, so I can write a lot now. And in English 
too."

Sofia's confidence in her independent reading translated to her writing as well. She constantly insisted, "I do it," or "I know how to do that," when she was writing. I compared Sofia to a sponge in my field notes from October 26, 2015:

Sofia started out as such a reluctant writer. Now, just a month later, she soaks up anything I show her as a strategy and applies it immediately, even days later.

She is so sure of herself now when she writes. More so in Spanish writing at this point, but I can start to see it in her English writing too.

Sofia showed more confidence in how to spell words when she was writing about a book we had read. I noted Sofia's strong visual memory for words early in our lessons together. Once she saw a word in connected text, it only took two or three more exposures to the word before it was committed to her memory. She used this strength to build her "meagre knowledge of words" (Clay, 2005, p. 40), which is one of the areas in Reading Recovery in which Reading Recovery teachers spend time if it is needed. Together we used that bank of words to make analogies for similarly spelled words. While Sofia's spelling was strongest with words she had encountered in our books together, her confidence in the content of her writing was strongest when she was writing about a cultural experience with her family. Out of 74 writing entries in her writing notebook, 40 of them were about cultural experiences with her family, such as: breaking a piñata at a birthday party, cooking dinner for her extended family with the women in her neighborhood, or taking her little brother, Dylan, to watch her father play soccer. In these entries, Sofia's writing contained many details with rich content. 


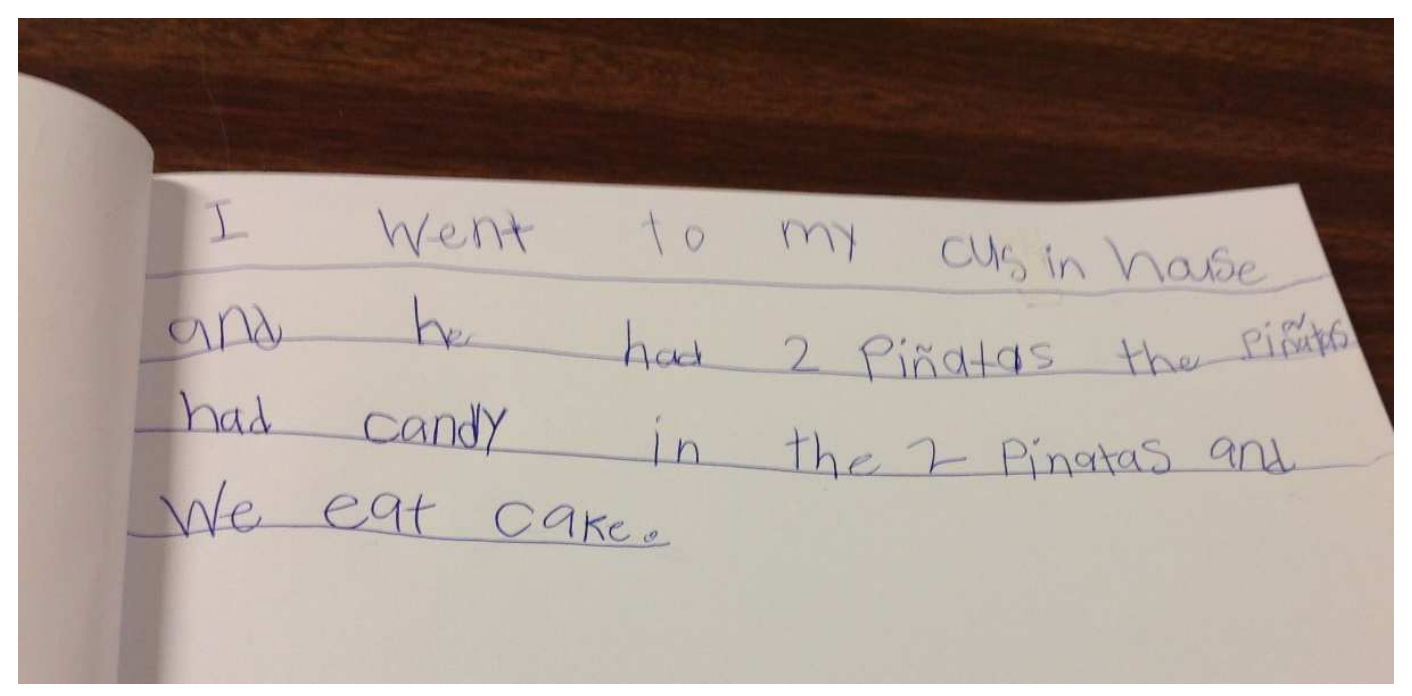

Figure 4.1 Sofia's story about a birthday party

The three participants entered our lessons with fear about their use of their home language in a school setting. They started building their confidence in the use of both languages in speaking, reading, and writing in our lessons. Welcoming the topic of their cultural experiences diversified their writing content, bolstered the development of both Spanish and English languages, and provided me the opportunity to know more about them and their families.

Students' gains in speaking, reading, and writing. I collected achievement data on the three participants using OLAI-2 (Gentile, 2011), Observation Survey (Clay, 2000), the Benchmark Assessment System (Fountas and Pinnell, 2010), and the Dominie Reading and Writing Assessment Portfolio (DeFord, 2004). All three participants showed growth in speaking, reading, and writing in both languages, based on the assessment measures used at the beginning, midterm, and ending points of their lessons with me. It is important to note that both Isabel and Sofia were in Reading Recovery for the full 20 weeks of lessons, from September until the beginning of February. Antonio, as a second round student, started Reading Recovery lessons in February and ended in 
May, totaling 13 weeks of lessons (which is the average number of weeks students generally remain in the program prior to having lessons discontinued). Tables 4.1 and 4.2 show the data for OLAI-2 (Gentile, 2011) assessments for all three participants.

\section{Table 4.1}

OLAI-2 Assessment Data (Beginning of Year)

\begin{tabular}{lccc} 
Student & $\begin{array}{c}\text { Repeated } \\
\text { Sentences }\end{array}$ & $\begin{array}{c}\text { Retelling } \\
\text { Word Count }\end{array}$ & $\begin{array}{c}\text { Retelling } \\
\text { Story Elements }\end{array}$ \\
\hline Isabel & $15 / 29$ & $46 \%$ & $3 / 4$ \\
& Stage I & Stage II & Stage II \\
Sofia & $10 / 29$ & $16 \%$ & $2 / 4$ \\
& Stage I & Stage I & Stage I \\
Antonio & $11 / 29$ & $17 \%$ & $2 / 4$ \\
& Stage I & Stage I & Stage I \\
\hline
\end{tabular}

Table 4.2

OLAI-2 Assessment Data (End of Year)

\begin{tabular}{lccc} 
Student & $\begin{array}{c}\text { Repeated } \\
\text { Sentences }\end{array}$ & $\begin{array}{c}\text { Retelling } \\
\text { Word Count }\end{array}$ & $\begin{array}{c}\text { Retelling } \\
\text { Story Elements }\end{array}$ \\
\hline Isabel & $18 / 29$ & $51 \%$ & $4 / 4$ \\
& Stage II & Stage III & Stage III \\
Sofia & $16 / 29$ & $27 \%$ & $4 / 4$ \\
& Stage I & Stage I & Stage III \\
Antonio & $19 / 29$ & $48 \%$ & $4 / 4$ \\
& Stage II & Stage II & Stage III \\
\hline
\end{tabular}

The stages of language development from OLAI-2 (Gentile, 2011) range from Stage I to Stage III. Students in Stage I use primarily single words and phrases and understand some simple exclamations, questions, commands, and negative statements (Gentile, 2003). Students in Stage II use longer complete sentences with afew prepositional phrases and both understand and use some simple exclamations, questions, 
commands, and negative statements (Gentile, 2003). Finally, in the OLAI-2 (Gentile, 2011) Stage III includes using complete sentences with a variety of prepositional phrases and the understanding and use of expanded exclamations, questions, commands, and negative statements (Gentile, 2003).

All three students made gains in both measurements, Repeated Sentences and Story Retelling. While Sofia's results did not move her to the next stage in two of the three measures, her gains in both were still impressive. With her bilateral hearing loss identified in late May, her ability to hear the sentences and repeat them may have been affected. Her retelling of the stories improved drastically between the two assessment points. In my log, I noted her first retelling did not have the elements of a retold story. Instead, she simply stated what she saw in each picture from the story cards: "I see the girl. I see the horse. I see the leaves." For the second retelling in May, Sofia retold the story with a beginning, middle, and end, including the characters, the problem, and the solution.

I also collected achievement data using the Observation Survey (Clay, 2000) at the beginning and end of our lessons, and a third administration at the end of the year. Tables 4.3A and 4.3B display the results. I used stanines to represent the data collected on these tasks. Scores in stanines 1, 2, and 3 are in the below average range, and scores in stanines 4,5 , and 6 are in the average range. Scores in stanines 7, 8, and 9 are in the above average range. 
Table 4.3A

Observation Survey Assessment Data

\begin{tabular}{|c|c|c|c|c|c|c|c|c|c|}
\hline Student & \multicolumn{3}{|c|}{ Letter ID } & \multicolumn{3}{|c|}{ CAP } & \multicolumn{3}{|c|}{ Word Reading } \\
\hline & $\underline{\mathrm{BOS}}^{\mathrm{a}}$ & $\underline{E O S}^{b}$ & $\underline{E O Y}^{c}$ & $\underline{\mathrm{BOS}}$ & EOS & EOY & $\underline{\mathrm{BOS}}$ & $\underline{\mathrm{EOS}}$ & EOY \\
\hline Isabel & 2 & 3 & 5 & 2 & 7 & 8 & 2 & 9 & 9 \\
\hline Sofia & 3 & 5 & 9 & 2 & 6 & 6 & 2 & 4 & 4 \\
\hline Antonio & 5 & - & 9 & 1 & - & 6 & 2 & - & 4 \\
\hline
\end{tabular}

Table 4.3B

Observation Survey Assessment Data

\begin{tabular}{|c|c|c|c|c|c|c|c|c|c|}
\hline \multirow[t]{2}{*}{ Student } & \multicolumn{3}{|c|}{ Writing Vocabulary } & \multicolumn{3}{|c|}{$\begin{array}{c}\text { Hearing } \\
\text { \&Recording } \\
\text { Sounds in Words }\end{array}$} & \multicolumn{3}{|c|}{ Text Level } \\
\hline & $\underline{\mathrm{BOS}}^{\mathrm{a}}$ & $\underline{\mathrm{EOS}}^{\mathrm{b}}$ & $\underline{E O Y}^{c}$ & $\underline{\mathrm{BOS}}$ & $\underline{\mathrm{EOS}}$ & $\underline{\mathrm{EOY}}$ & $\underline{\mathrm{BOS}}$ & $\underline{\text { EOS }}$ & $\underline{E O Y}$ \\
\hline Isabel & 3 & 5 & 6 & 3 & 9 & 9 & 2 & 5 & 5 \\
\hline Sofia & 2 & 5 & 6 & 1 & 9 & 9 & 1 & 5 & 5 \\
\hline Antonio & 2 & - & 5 & 2 & - & 8 & 1 & - & 4 \\
\hline
\end{tabular}

Note. Antonio's data do not include an End of Service score because as a second-round student who ended lessons in May. His End of Service testing coincided with End of Year testing.

${ }^{a}$ Beginning of Service. ${ }^{b}$ End of Service. ${ }^{c}$ End of Year

All participants' end of year scores placed them in the average or above average bands for all tasks. All three students showed strong improvements in their understanding of concepts about print, and the number of words they could write in 10 minutes (Writing Vocabulary). They also showed great progress in their ability to hear sounds and record them based on a dictated sentence (Hearing and Recording Sounds in 
Words). Both Isabel and Sofia discontinued from Reading Recovery lessons in early February. From their end of service testing until their end of year testing three months later, both girls maintained their gains by scoring in the same or higher stanines showing they had a "self-extending system" (Clay, 2001, p. 129) in both reading and writing that allowed them to continue learning independently without need of one-on-one intervention services. Although Antonio received only 13 weeks of lessons, which was seven weeks fewer than the girls, his scores placed him in the average or above average range for all tasks.

I used Fountas and Pinnell's (2010) Benchmark Assessment System to assess the participants' reading levels as well. The district's literacy intervention department uses the system as a monthly progress monitoring assessment for all students receiving interventions. Table 4.4 displays the reading levels for the three participants from the fall, mid-year, and year-end assessment points. Table 4.5 illustrates the reading levels for an anonymous comparison group of Spanish-speaking children who also received interventions in first grade but did not have the supports of their home language or culture in those lessons. For this district, expectations for this assessment are that students can read at an independent level I.

Table 4.4

Benchmark Assessment System Independent Reading Levels

\begin{tabular}{lccc} 
Student & Fall & Mid-year & Year-end \\
\hline Isabel & A & G & J \\
Sofia & A & G & J \\
Antonio & A & C & I \\
\hline
\end{tabular}


Table 4.5

Benchmark Assessment System Reading Levels (Comparison Group)

\begin{tabular}{lccc} 
Student & Fall & Mid-year & Year-end \\
\hline Student 1 & A & F & I \\
Student 2 & $<$ A & B & C \\
Student 3 & A & D & E \\
Student 4 & A & E & G \\
Student 5 & A & F & G \\
Student 6 & A & C & G \\
Student 7 & $<$ A & F & H \\
Student 8 & $<$ A & C & F \\
Student 9 & $<$ A & F & J \\
Student 10 & $<$ A & F & H \\
Student 11 & A & F & I \\
Student 12 & $<A$ & E & I \\
Student 13 & B & F & I \\
Student 14 & B & E & I \\
Student 15 & B & G & K \\
Student 16 & B & E & G \\
Student 17 & B & E & H \\
\hline
\end{tabular}

All three participants' beginning reading levels in the fall were below grade level for first grade. By mid-year, after 20 weeks of instruction, both Isabel and Sofia were reading above the grade level expectation for first grade (level F) at that time of the year. By the end of the year, both girls had continued their progress and were still reading above grade level (I), and this growth was happening without additional intervention services. After 12 weeks of instruction, Antonio's year-end reading level met grade-level expectations, illustrating rapid acceleration for him as well. It is interesting to note that his progress within the regular classroom setting prior to the onset of Reading Recovery services 
documents the need for heightened intervention services (he had advanced only from a level A to a level $\mathrm{C}$ in reading in the regular classroom, with mid-year expectations being a level $\mathrm{F}$ ) in order to address his learningneeds as a reader and writer.

Analyzing the comparison group's data, all 17 students' Fall reading levels were also below grade level for first grade, with six of these students below a level A at the beginning of the year, thus unable to read the lowest level DRA book. At the mid-year point, $41 \%$ of the comparison students were reading at the grade level expectation for first grade (level F). Unlike Sofia and Isabel, at that mid-year point, none of the comparison group students were reading above that grade level expectation. By the end of the year, $41 \%$ of the students were reading at grade level (level I) and only 2 were reading above grade level expectations ( $\mathrm{J}, \mathrm{K})$.

The Dominie Reading and Writing Assessment Portfolio (Spanish version) (DeFord, 2004) was the final achievement assessment used with the three participants. For the purposes of this study, I utilized the Show Me Book (El Libro Muestrame) task and the Text Reading task twice in my time with the participants, once at the beginning of our sessions together and once when our lessons ended. I used stanines to represent the data collected on the Show Me Book. Scores in stanines 1, 2, and 3 are in the below average range, and scores in stanines 4, 5, and 6 are in the average range. Scores in stanines 7,8 , and 9 are in the above average range. Since the Text Level portion of Dominie is a criterion-referenced assessment and compares students to a set standard, there are no stanines, but the end of grade criterion level for text reading for kindergarten is 3 and for first grade is a level 7. Table 4.6 illustrates the results of these assessments. 
Table 4.6

Dominie Assessment Data

\begin{tabular}{|c|c|c|c|c|c|c|}
\hline \multirow[t]{2}{*}{ Student } & \multicolumn{2}{|c|}{ El LibroMuestrame } & \multicolumn{2}{|c|}{ Text Level ${ }^{\mathrm{c}}$} & \multicolumn{2}{|c|}{ Fluency $^{\mathrm{d}}$} \\
\hline & $\underline{\mathrm{BOS}}^{\mathrm{a}}$ & $\underline{\mathrm{EOS}}^{\mathrm{b}}$ & $\underline{\mathrm{BOS}}$ & $\underline{\text { EOS }}$ & $\underline{\mathrm{BOS}}$ & EOS \\
\hline Isabel & 2 & 4 & $1 \mathrm{~A}$ & $2 \mathrm{~A}$ & 2 & $3 / 4$ \\
\hline Sofia & 1 & 4 & 1 & $2 \mathrm{~A}$ & 1 & $3 / 4$ \\
\hline Antonio & 2 & 5 & 1B & 3 & 1 & $2 / 4$ \\
\hline
\end{tabular}

${ }^{\mathrm{a} B e g i n n i n g}$ of Service. ${ }^{\mathrm{b}}$ End of Service. ${ }^{\mathrm{c}}$ The grade equivalency for the Dominie text

levels are: 1, 1A-B: Beginning Kindergarten, 2A-B, 3: End of Kindergarten, Beginning

First Grade. ${ }^{\mathrm{d}}$ The fluency scale is arranged from high fluency (4) to low fluency (1)

While all of the students showed progress on these tasks, they scored higher on the equivalent Observation Survey tasks in English (CAP and text level). However, all three participants improved their Spanish concepts about print stanines from below average to withinthe average band. On the English text level task, all three students ended the year reading on or above grade level. On the Spanish text level task, the yearend scores were equivalent to a beginning first grade student. It is worth noting the Writing Vocabulary portion of El Libro Muestrame, in which all three students progressed from only writing their name to independently writing between 14 and 18 Spanish words. These scores place the students within the average band for this task as well.

\section{Research Question Two}

What is the nature of the methods and materials used in the instructional intervention that best support the students' emerging bilingualism?

Throughout my analysis, students' connections between languages, texts, and cultural experiences emerged as a dominant theme in the data. I coded students' 
connections between languages in 112 instances. Connections between students' lives and cultural experiences and the texts they were writing and reading emerged in 72 instances.

As we started using students' home languages and cultural experiences in our conversations and reading and writing experiences, the participants made solid and useful connections between the languages, the texts, and their cultural experiences. The students applied reading and writing strategies that we practiced in the Spanish or bilingual texts to English texts and vice versa. They also made connections between their lives and texts, such as noticing books that featured characters that looked like them or writing about their cultural experiences. These connections strengthened their reading and writing strategies in both languages, and provided motivation for the students to read and write more texts.

Connections in reading strategies. Before our lessons began, I purchased a set of emergent level texts in Spanish from Reading Reading Books, the same publisher of some of the English texts that we used in Reading Recovery. I chose this publisher's texts because of the use of strong picture cues, appropriate size of the print on the page, and the number of words on the page. These features matched the same features found on the English texts of the same level. Unfortunately, the publisher only provided 12 texts in their Leo Libros Collection, ranging from level 1 through level 4. Nevertheless, this was better than nothing, which was what I had at the moment as far as Spanish emergent level texts. When the students read the Spanish texts, I noted the miscues just as I would in an English text. I provided the prompts necessary to move them forward in their use of strategies in the text, whether they were based on visual, structure, or 
meaning. I started to notice that the kinds of miscues the students made in the Spanish texts were replicated in the English texts as well.

Strategy work in reading Spanish texts. For example, in our lesson records for early October, I noted Isabel left off the plural -s ending in reading both the English and Spanish books. Therefore, I noted that I needed to focus in the strategy of looking to the end of a word in both languages (Personal Log Notes, 11-6-15, 11-10-15):

Isabel: $\quad$ Necesito una...luz. I need a...light. (Remains on page)

Sarah: $\quad$ It could be luz because it starts with 1.

Isabel: $\quad$ Lantierna...Lantern.

Sarah: How did you know that?

Isabel: $\quad$ Uh, cause it got all the letters.

Sarah: $\quad$ More than luz, right? This is what luz looks like. (Writes "luz" on whiteboard) You were looking all the way to the end of the word. Nice noticing. (Transcription 12-10-15)

The same kind of notes were made for Sofia as well, as I noticed we used her Spanish book to work on the same early kinds of reading activities I expected to see in her English text reading, including using picture cues and the initial letter of an unknown word to "get the word started" while maintaining the meaning of the text (Personal log notes, 10-20-15, 10-26-15, and 1-11-16). In the following example, I supported Sofia in using multiple sources of information to help herself as she read Soy Un Tigre.

Sofia: Me...gusta correr. Me gusta la agua. I like to run. I like the water.

Sarah: He does like the water, doesn't he? Can you read that again? Something tricked you. 
Sofia: $\quad$ Me gusta la agua. I like the water. No.

Sarah: What tricked you?

Sofia: $\quad$ This. (Points to nadar)

Sarah: You're exactly right. So let's use the story to help us and this time look closely at that word. ¿Que esta hacienda en la agua? What is he doing in the water?

Sarah: OK. So try it again.

Sofia: $\quad$ Me gusta...nadar. Me gusta nadar. I like to swim.

Sarah: Does that look right? Does it make sense?

Sofia: Sí. He swimming. (Transcription 11-12-15)

Sofia used the meaning of the text by using the picture of a tiger swimming in a river, as well as the visual information located in the word "nadar" and the structure of the Spanish language to identify her miscue and correct it.

Similarly, Antonio and I illustrated his use of meaning when reading with the Spanish book Soy Un Tigre:

Antonio: Me gusta...dormir? I like to...swim? (Student checks picture of tiger drinking water from a river) No. Me gusta....tomar? I like to...drink? (Appeals to teacher)

Sarah: What do you think? Is it tomar?

Antonio: No.

Sarah: How do you know?

Antonio: There no $t$ there. (Points to word "beber")

Sarah: OK. So you checked the picture and you can see the tiger is drinking. 
But the word can't be "tomar." What else could it be?

Antonio: ...beber?

Sarah: $\quad$ Check under it slowly and see.

Antonio: (Reading it slowly while dragging his finger under the word) Beber. Me gusta beber. I like to drink.

Sarah: Were you right?

Antonio: Yes! (Transcription 2-5-16)

The kinds of strategies I prompted for in this Spanish text with all three students are the same strategies I could prompt for in an English text. The more connections we could make between the kinds of strategies he needed, the better. And if those connections were in more than one language, it was even better for the participants. In the 137 coded instances that either I or the student mentioned a reading strategy in a Spanish text, 78\% of those instances included the child attempting the same reading strategy in the English text for that lesson.

Strategy work in writing Spanish texts. In addition to applying reading strategies in Spanish books, I wanted to "dig ditches" between the pools of resources in bothreading and writing (DeFord, 1994, p. 53) as students wrote in Spanish. One strategic action was using parts to help the participants write some unknown words. For example, Sofia wanted to write a story about a big brother letting her play inside.

Sarah: What would you like your story to say?

Sofia: $\quad$ Mi hermano grande deja mi jugar al dentro. My big brother let me play outside.

Sarah: $\quad$ OK. Get started. 
Sofia: Mi....hermano. I know that one from yesterday. Mi hermano grande...Grande?

Sarah: What can you do to help yourself?

Sofia: $\quad$ Say the parts.

Sarah: $\quad$ Try it.

Sofia: $\quad$ Gran. (writes gran). De...I know de! Like de mi mama!

Sarah: $\quad$ You already know that part, don't you?

Sofia: $\quad$ Yeah! D. E. (Writes de) (Transcription 1-11-16)

Sofia connected the word grande to the word de, as she thought of parts in words she already knew to help her. This is a skill she needed practice with in English also, using analogies and known parts within words to help her write unknown words. Similarly, Antonio noted the similarities between two words in his story about playing with his brother in the street when he fell down.

Antonio: Mi hermano y yo corrimos en la calle y yo me calli. Calli. My brother and I run in the street and I fall.

Sarah: Yes, what can you do to help yourself with calli?

Antonio: Say the sounds?

Sarah: You could. There's a word in your story that you've written already that could help you.

Antonio: (rereading his writing) Mi hermano y yo corrimos en la calle...Calle.

Calli.

Sarah: There you go.

Antonio: It's the same thing? 
Sarah: They look and sound the same, except their endings are different. Try it.

Antonio: C. A. L. L. E?

Sarah: That's an I at the end.

Antonio: Y yo me calli. They kinda look the same. This one has I.

Sarah: You're exactly right. So sometimes if you know how to spell one word, it can help you spell another word by changing it just a little bit. It's the same when we read. (Transcription 4-25-16)

In another instance, Antonio quickly made the connection between the Spanish words pelota and perros when writing about playing catch with his dog.

Sarah: Ok, let's clap pelota.

Antonio: Pe-lo-ta.

Sarah: Ok, pe...

Antonio: Pe...like perros.

Sarah: Exactly! Good listening. Just like perros. It has the same beginning part. Pe.

Antonio: (writing the sounds he hears): P. E. (Transcription 3-11-16)

Making connections between those words in Antonio's writing was an effective way to get the new word written in the most efficient way, when he wanted to try hearing and recording the sounds instead.

\section{Transfer of strategies in English and Spanish.}

Once the students were using strategies in their Spanish reading and writing work, it was not long before they started transferring the strategy work to their English reading 
and writing as well. In my research journal, I noted, "Once I started asking Isabel to find parts in Spanish words as we read, her success in using that strategy in English books skyrocketed" (1-11-16). For example, the same day Isabel found the parts in tortuga (tortu-ga), she used the same strategy in reading her English text with the word forgetful. Sofia started to show the same transfer in strategies in her reading and writing as well. The example below is the exchange that occurred when she tried to write the word "jugar."

Sofia: Ju...gar. Gar, like car? A.R!

Sarah: That's right! You used the English word "car" to help you spell "jugar."

Sofia would make similar connections between English and Spanish as we completed the Word Work portion of her lesson a week later. We were listing words that had the -ar ending. Sofia and I used magnetic letters to build words like car, far, and star. Suddenly, she exclaimed, "Hablar has -ar too! And jugar! Y nadar!” (Transcription 1211-15). We continued to make those words with magnetic letters as well, even though I had not planned on doing so in my lesson plans. It was a welcome adjustment to make.

Oftentimes, a strategy we focused on in a Spanish text in familiar rereading would reappear in the English text for the new book for the same lesson. The following excerpt is from Isabel's reading of a familiar Spanish book, Peligro en el Arbol.

Isabel: Uno? (Appeals to teacher)

Sarah: $\quad$ You tell me, is that una or un?

Isabel: Una.

Sarah: What would una have at the end of it? 
Isabel: $\quad$ Mmm...A?

Sarah: Does that word have an a at the end?

Isabel: No.

Sarah: So, what do you think it could be?

Isabel: $\quad$ Un...raton se...sube...el arbol. A rat climbs up the tree. Un gato se sube al arbol. A cat climbs up the tree. Sssss! El rata..no not rata. Raton!

Sarah: Raton. You looked all the way to the end of the word. So just like in our English books, we're looking all the way to the end in these books too. (Transcription 9-18-16)

Twenty minutes later in the same lesson, I introduced the new text for the lesson, Clever Seagull and reminded Isabel of the strategy of slow-checking to the end of a word.

Sarah: $\quad$ Ok, let's go back and look closely and slowly. You read, "Is Seagull eat the shellfish?" Which word tricked you? (Child points to eat).

Sarah: You're exactly right. That's it. Let's look again.

Isabel: $\quad$-ing?

Sarah: $\quad$ Say it again?

Isabel: The -ing.

Sarah: You're right, the -ing ending was left off. Let's try that again.

Isabel: Is Seagull eating the shellfish?

Sarah: What do you think?

Isabel: It's like my arbol book. I gotta look at the back of the word.

Sarah: Yes, and also listen to what sounds right. "Is Seagull eating the shellfish?" sounds better too. (Transcription 9-18-16) 
Isabel made connections between the strategies she used in both languages in both familiar and new texts.

As part of expanding the children's "meagre knowledge of words," (Clay, 2005, p. 40) each child had a box of cards with high frequency words. At first, these cards only had English words on them, words taken from familiar reading books, including phonetically irregular words that the child could easily learn. One day, Sofia asked if we could add Spanish words as well. Initially, we tried to write the Spanish translation on the back of each English high frequency word. However, because of the differences between the two languages, there was not always a 1:1 match between an English high frequency word and its Spanish counterpart. Therefore, we added the Spanish translation to the backs of some of the words, and then added separate Spanish word cards for Spanish high frequency words as well. I noted in my research journal that day, "Sofia wants to say Spanish HFW for English ones, so we tweaked some of her cards to have both. Such a great idea from her. She got very excited adding the Spanish word cards" (Research Journal Entry, 11-17-15).

The connections all three students made between their languages and their texts in reading and writing reinforced the strategies that propelled them forward as strategic readers and writers.

Connections between life and text. Along with making connections between strategic actions in reading and writing in both their home and school languages, the participants also made connections between their cultural experiences and the texts they wrote and read. For example, the students promptly noticed any texts that included Latino characters and compared those characters and events to themselves. In addition, 
the participants connected their life experiences to events in texts without any Latino characters. Furthermore, students had the choice to write about their home lives and cultural experiences during the writing portion of their lessons.

Books with Latino characters. The participants made connections between the texts and their own lives and cultural experiences with books that included Latino characters or families. For example, when Isabel chose the book El Gato Grande for one of her texts for familiar reading, she made the statement, "It's kinda like you're in Mexico in them!" (Transcription 11-12-15). When I asked her what she meant by that statement, she explained, "When I read it, it's like I'm back in Mexico with my family" (Transcription 11-12-15). Antonio made a similar statement about the book Dennis Rides His Bike, a book that tells the story of two Latino boys, Elzeare and Dennis, and their experience with Dennis learning to ride a bike:

Sarah: $\quad$ Yesterday we read a book with Dennis and Elzeare.

Antonio: It was easy. It had people like me.

Sarah: What do you mean?

Antonio: He look like me (points to Dennis). And my big brother (points to Elzeare).

Sarah: Ah, yes they do, don't they? What do you think about that?

Antonio: I like that. You have more? ¿Otros libros con estas personas? Other books with these people? (Transcription 4-19-16)

After reading the book Desayuno Con Mi Mama, Sofia noted the Latina girl and her mother were eating breakfast like she does with her mother. Sofia compared the characters to her family and said, "That girl and her mom like me and my mom. My 
mom make desayuno (breakfast) for me too en la mañana (in the morning). But no tocino (bacon)" (Transcription 10-5-15). The students could make connections between their lives and the people and experiences they read about in these books.

Connecting cultural experiences in book previews. The students continued to make connections between their life experiences and the books even if those books did not include Latino characters. As Isabel and I previewed the story The Little White Hen, Isabel wanted to share her experience with raising chickens at her home, connecting what she knew about protecting chicken eggs with the story's plot.

Sarah: And she wants to know where to lay it. Her friends tell her that she should lay it inside the hen house. On a farm, a hen house is where hens usually lay their eggs to keep them safe.

Isabel: I got...I got five...I got six of hens. And I got one dog. And I don't love him to chew her. And she could die.

Sarah: It's interesting you talk about a dog. Because there's a dog in this book too. So even though her friends tell her to lay the eggs inside the hen house, White Hen says no, I want to lay it outside.

Isabel: But the dog! The dog will eat the egg!

Sarah: Away she goes and just like you said...

Isabel: I said that! The dog will come and eat the....

Sarah: Is that a safe place for her to lay her egg?

Isabel: No. I have chickens and I never put them there. (Transcription 11-1315) 
Isabel made a strong connection to that book, especially to the part with the dog threatening the hen's eggs. Including her cultural experience in our preview of the text was essential to that connection, and selecting books that included experiences similar to her own supported her use of meaning cues as a reader and heightened her comprehension.

Sofia also connected her experiences with her baby brother to Emily Can't Sleep, an English text with a babysitter coming over to take care of a little girl. As we previewed the text together, Sofia made connections with the main character:

Sofia: $\quad$ My new story!

Sarah: That's right, your new story is Emily Can't Sleep. Emily's babysitter came to stay with her when her mom and dad went away.

Sofia: $\quad$ My...Dylan was sleeping. I stay with him. I'm babysitter for Dylan.

Sarah: It sounds like you take good care of him. Sometimes a babysitter is a friend of a mom or dad who comes over to stay with you.

Sofia: Yeah. I be his babysitter tonight. Sometime he go to sleep in my bed (laughs). (Transcription 12-1-15)

Sofia knew what it was like to take care of her younger brother when her parents were gone or busy. Our conversation before reading the book helped strengthen her understanding of a new vocabulary word (babysitter) and her comprehension of the story's plot.

Similarly, Antonio and I had a conversation as we previewed the book, At the Beach, a story where three dogs, Rosie, Bella, and their friend, Olive, search for clams at the beach. I asked Antonio if he knew what a clam was and said, "kind of." The 
following exchange continued as he described watching his mother make ceviche at home:

Sarah: What does she have in it again?

Antonio: She have some...lechuga lettuce...Limón lemon... She puts cebolla onion. She puts el...She puts the water...

Sarah: La agua in too? Ok, what else?

Antonio: She put cilantro.

Sarah: $\quad$ Ooo, I love cilantro.

Antonio: She puts like lemonade and she puts drinks with lemon and she put it and she sticks in the bottles.

Sarah: $\quad$ And then she puts what?

Antonio: The clam.

Sarah: She puts the clam in there? So you do know about clams.

Antonio: Yeah...

Sarah: It sounds like she was making ceviche. Do you think that's what it was called?

Antonio: Yeah. And it had jugo de tomate tomato juice.

Sarah: Oh, that sounds delicious. So now that you know what clams are, let's see if the dogs find any to eat on the beach. (Transcription 2-17-15)

Previewing texts was an important part of our daily lessons when introducing a new book. Including students' cultural experiences in those previews and conversations as well as in selecting books for lessons was essential in their understanding and connections to characters and plot events. 
Writing about cultural experiences. Approximately ten minutes of a Reading Recovery lesson are dedicated to writing a story. In our lessons, students would sometimes write about the story they read in that lesson or write about something happening in their lives. Both kinds of writing were motivating for the students at different times. If a student came to me bursting with excitement about the soccer game her father played in last night, that emotion transferred to her writing about that event. I found these moments supported the students in writing in both languages, as well as capitalize on using their cultural experiences in their stories.

When we first met, Antonio shared his experience of having some of his family still living in Guatemala while his mother worked three jobs in order to make enough money to try to transport more of his family members to the United States. One day, Antonio told me he wanted to write about his experience of sending toys to his brother who still lived in Guatemala. The following exchange shows our conversation prior to his writing:

Antonio: Mi hermano no tenía juguetes...y...yo tenía...mucho juguetes y no quería todos los juguetes My brother did not have toys... and...I had.. a lot of toys and I did not want all of my toys y..la...y la...y.......I send my toys in a box to Guatemala...to my hermano brother.

Sarah: That's so kind of you. Is that what you want your story to be about today?

Antonio: Sí. Mi hermano no tenía juguetes. Yes. My brother did not have toys. (Transcription 4-19-16)

Antonio continued to write about his experiences with having part of his family living in 
another country and the challenges he faced as his mother worked so hard to provide for both her family here and her family in Guatemala. Including his cultural experiences in his writing proved to be a way for me to learn more about his family and their successes and struggles and provided an outlet for him to release his feelings about the situation as well.

Student-made books. Many of the students' writings about their cultural experiences came in the form of student-made books that we made together. I attended a conference with Matt Glover in January 2016, and I was invigorated by his explanation of student-made books and their impact on student engagement and making meaning. I decided to introduce the idea to the students and see what they thought. According to my researcher log journal notes from the day I introduced the concept, the students "dove in" (Research Journal Notes, 1-15-16). All three students chose different topics for their books. Isabel wrote a story about her future trip to Mexico to see her grandmother. She chose to write in both Spanish and English in her book that she titled The Story of Isabel's Trip of Mexico. She wrote about spending time with her family in Mexico, especially her grandmother and her cousin, Pancico. 
tator going to mexico

to Sos bos grabre.

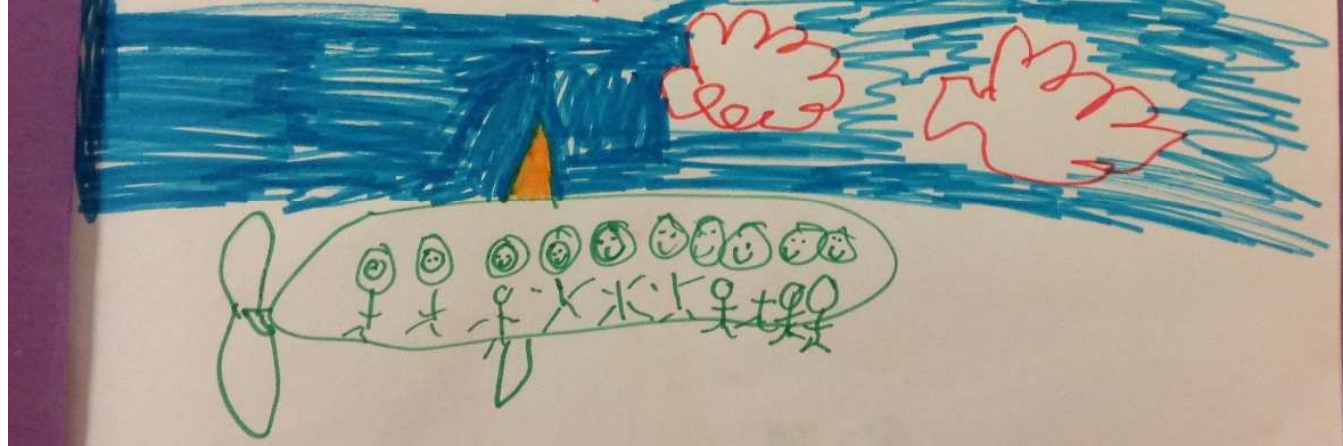

Figure 4.2 The first page of Isabel's book about her trip to Mexico

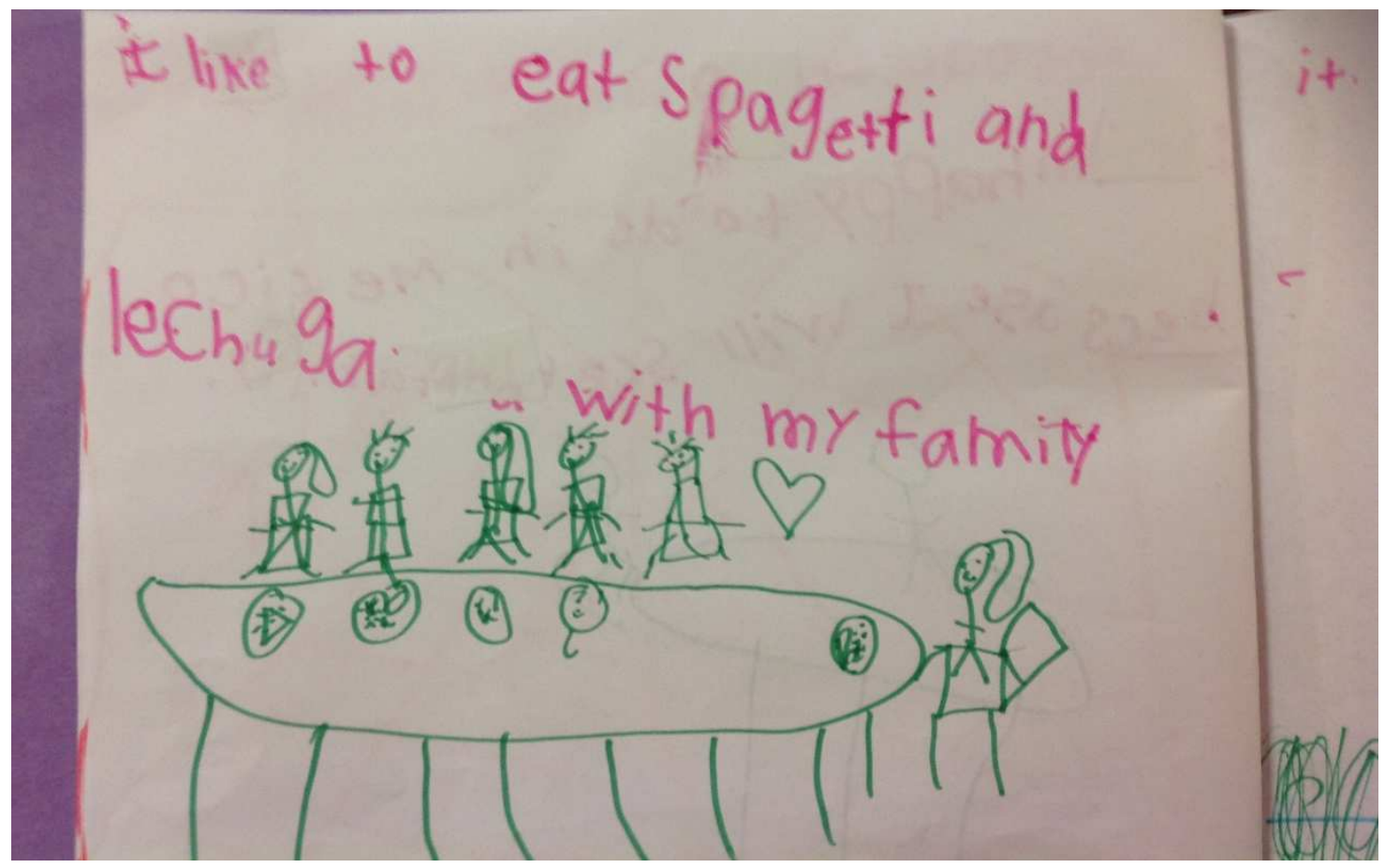

Figure 4.3Using Spanish and English, Isabel describes the food she will eat 
Sofia chose to write about her brother Dylan and his antics. Dylan was a favorite topic for Sofia to talk about, so writing about him was very motivating for her. The idea for her book was also based on an English book we read the previous week, My Big Brother. The book was about a boy (who looked Latino) and his big brother. When Sofia asked if I had the same book in Spanish, I told her no. She replied that she would make one for us, but about her little brother. She ended up wanting to write the book in English, but the inspiration was still there.

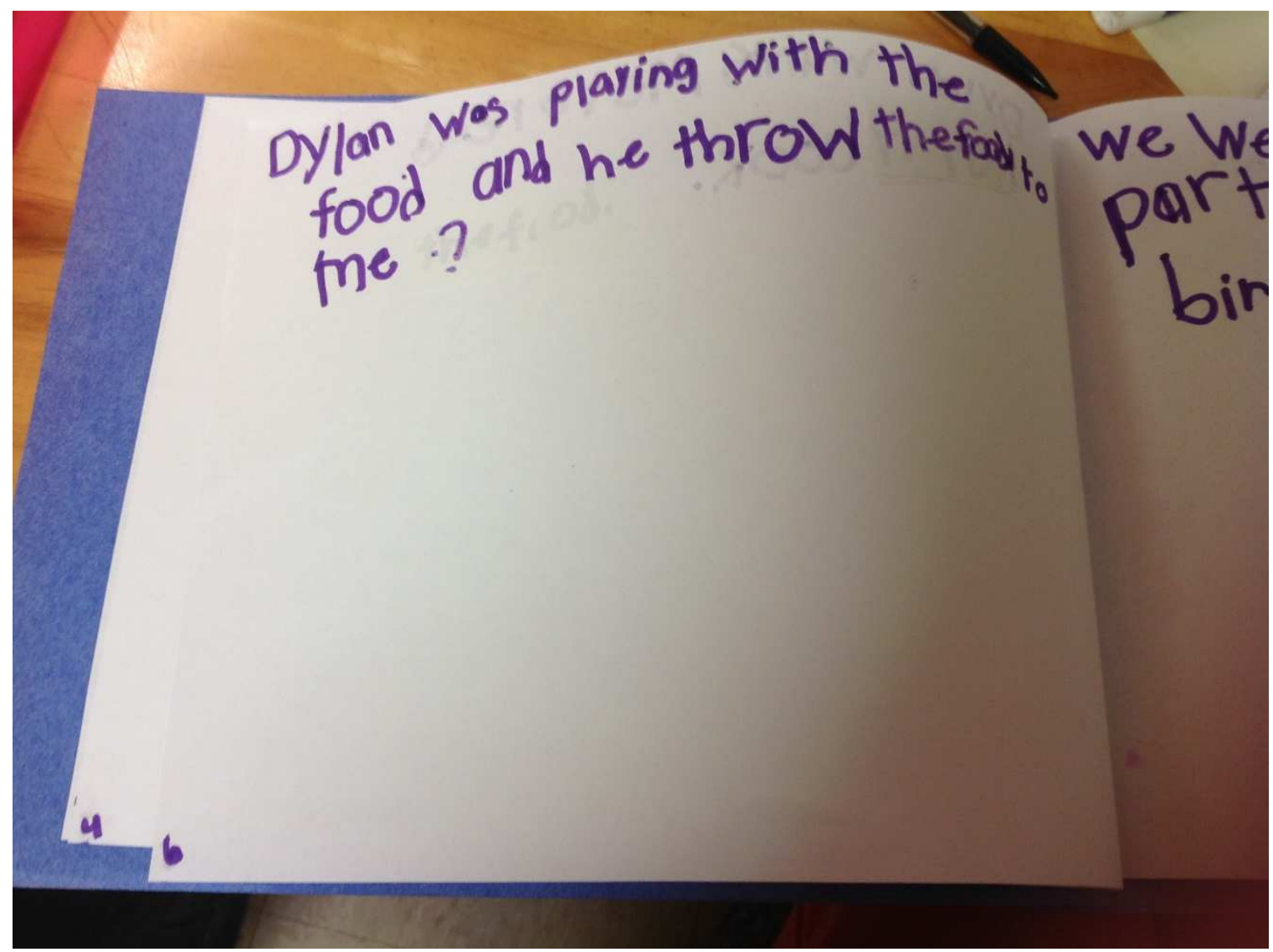

Figure 4.4 Sofia writes about her brother, Dylan, playing with his food

Antonio chose to write a book about eating breakfast with his mother after she cooked a variety of Guatemalan dishes. Similar to Sofia, we had read a Spanish book, Desayuno Con Mi Mama, a few weeks prior and it seemed to inspire him. When I asked 
him what kind of book he wanted to make, he grabbed the Spanish book and said, "Like this" (Researcher Journal 2-12-16).

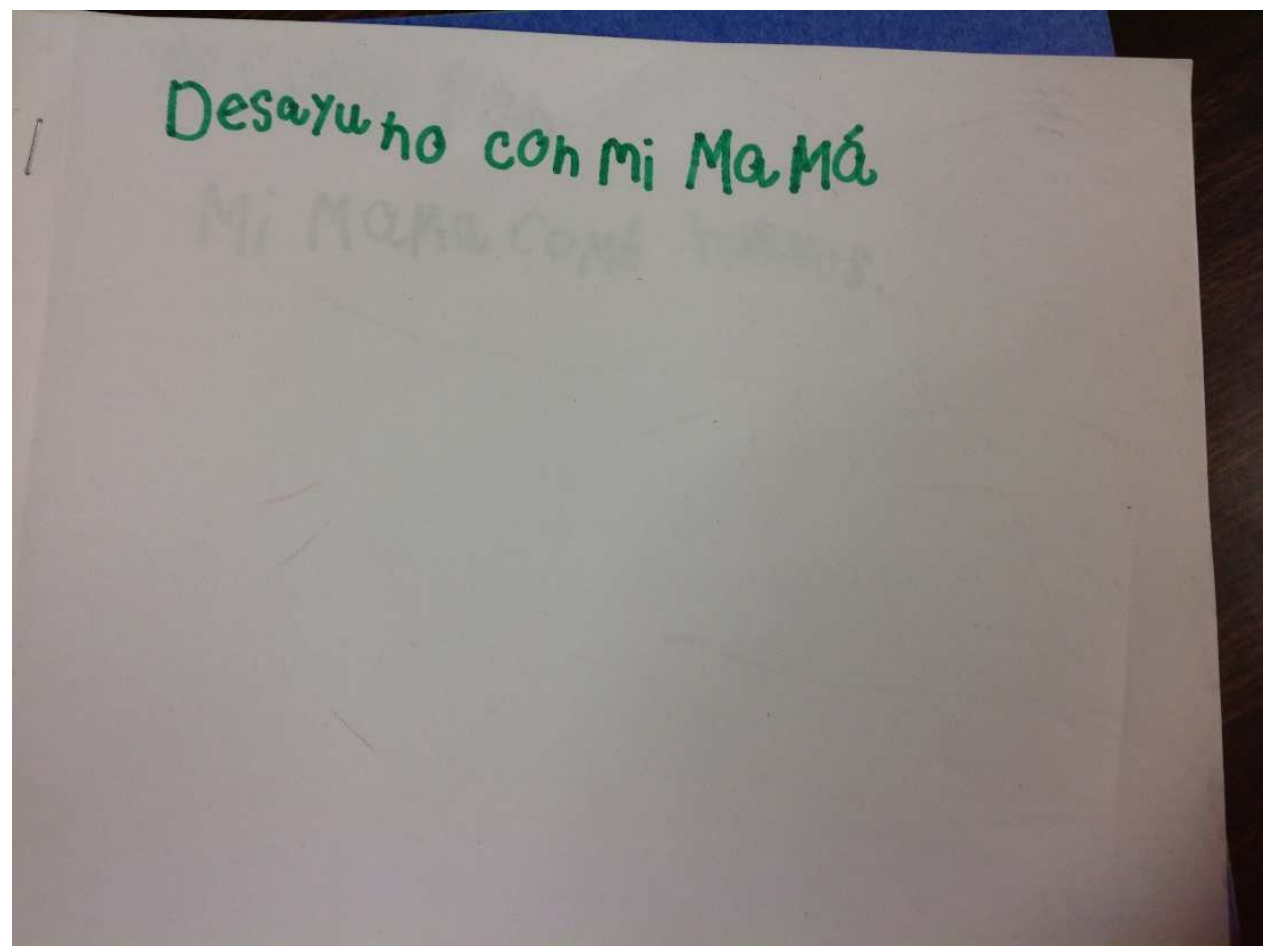

Figure 4.5 Antonio's front cover of his book

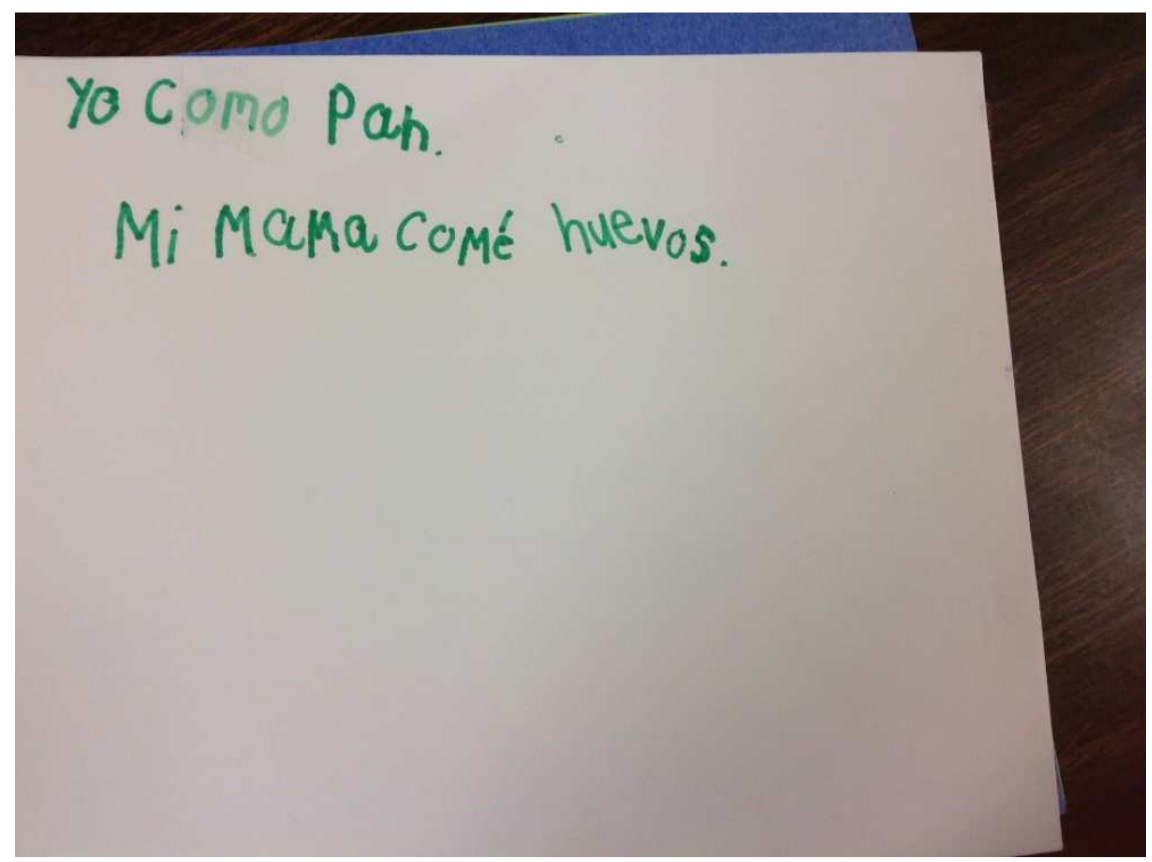

Figure 4.6 Antonio writes about the foods he and his mother eat at breakfast. 
Writing about their life events and connecting texts they could write and read with those cultural experiences motivated all three students.

The variety of connections made between the students' languages, the texts, and the students' cultural experiences were relevant and useful for each participant. These connections strengthened their reading and writing strategies in both languages, and provided motivation for the students to read and write more texts.

\section{Research Question 3}

\section{How can the involvement of students' families contribute to the utilization of students' home languages and cultural experiencesin school?}

Involving the participants' families in our lessons and activities at school, as well as reading and writing experiences at home, helped build relationships among participants, families, and school faculty. These relationships contributed to the utilization of the students' home languages and cultural experiences in school and the beginnings of new understandings on the part of Goodman teachers and administration.

As I mentioned earlier, issues of fear and power pervaded the school when discussing Latino students and their families. These feelings were not limited to Goodman Elementary. At one of our year-end meetings where all interventionists met together, one of the intervention program coordinators handed out a summer packet for parents that included ideas and activities to continue to support their children during the summer break. When some interventionists asked if we could have a Spanish version of the packet for those families who could not read English, the reply was, "No, there's no need to do that. If they can't read English, then they can't help their child read" (Researcher Log, 4-21-16). These kinds of opinions were prevalent throughout my 
experiences in the district, and my attempts to include the participants' families in their reading and writing experiences directly opposed this kind of thinking. The ways in which I tried to involve these families included lesson visits, support of home literacy experiences, focus groups, and other classroom and school activities that specifically focused on the Latino families and their contributions to their children's learning.

Lesson visits. The first step I took to involve the participants' families was an invitation to observe one of their children's lessons with me. I sent home a short Spanish letter to parents asking them to choose a day and time that worked best for them to observe a 30-minute lesson. I explained they could bring younger siblings to the lesson visit to alleviate any concerns about childcare. All three participants' parents observed one lesson, and Isabel's mother brought her little sister to her lesson visit as well. I found these lesson visits helped forge my relationships with the families, as they watched their children speak, read, and write in both English and Spanish with my support. They witnessed how we read bilingual and Spanish texts, wrote in both Spanish and English, created student-made books about cultural experiences in both Spanish and English, and used Spanish in our daily conversations. The lesson visits also gave the students an opportunity to proudly show their parents what they could do in reading and writing. After each lesson visit, the parents had the opportunity to ask me any questions or make comments about what they observed. Sofia's father commented, "Estamos muy orgullosos de ella. Y ella está orgullosa cuando está en casa con sus libros en español. We are very proud of her. And she is proud when she is in the house with her Spanish books. "(Personal communication, 12-7-15). During Isabel's mother's visit, her two-yearold sister remained directly beside Isabel, watching everything she did as she read and 
wrote. I asked her mother if this happened at home too, and she replied, "Yes. Sí. Isabel show her reading and writing. She like a teacher." (Personal communication, 1-8-16). In the same lesson, Isabel's mother started supporting her daughter as she read a bilingual book I Like Stripes, when Isabel read the word "caraterra" for the word "calle":

Isabel: [reading the text] A zebra has stripes. I like stripes. La zebra tienen rallas. Me gustan rallas. A street has stripes. I like stripes. El...la...caraterra tiene rallas. Me gustan ralles.

Mother: Calle. Esta palabra [pointing to word] es calle. ¿Lo ves? Mira toda la palabra. This word is calle. See it? Look at the whole word. (Transcription 1-8-16)

Her mother reminded Isabel of a strategy that Isabel and I worked on as well. Even though Isabel's mother admitted she did not know how to read and write in English, it did not prevent her from supporting her daughter in strategic reading activities. In addition, Isabel's mother co-composed Isabel's story with her in Spanish in the same lesson. Isabel chose to write in Spanish about going to Wal-Mart to buy clothes. As she started writing, her mother said the words slowly for Isabel and prompted her to listen to the parts in words.

Isabel: Fui a Wal-Mart para...I went to Wal-Mart to...

Mother: Comprar. To buy

Isabel: It's a c. O.

Mother: Commm...

Isabel: It's an $\mathrm{m}$ and a $\mathrm{p}$.

Mother: Com...prrrr... 
Isabel: Ar...A.R.

Mother: Ropa...¿las partes? Clothes. The parts?

Isabel: Ro...pa.

Sarah: Ro...pa. You got it!

[Mother smiled and laughed.] (Transcription 1-8-16)

When Isabel's mother and I debriefed after the lesson, she said it felt good to share that kind of literacy experience with her daughter, something she is not as confident doing in English. She said, "Isabel come home telling me what you do when read and write. She tell me find parts and say slow. She do it in Spanish and English" (Transcription 1-8-16). Isabel's mother paid attention to the strategies her daughter brought home from our lessons and supported her daughter in using them as well.

These lesson visits enriched the relationships between me and the participants' families. Because of these visits, I felt we started to understand each other a little more, including our goals for the students and their literacy growth. As a result, the students felt even more at ease with using their home languages and cultural experiences during our lessons. The participants knew they had my support in this endeavor, as well as the support of their families.

Home literacy experiences. Another part of families' involvement was their engagement in home literacy experiences with the students. As soon as I started sending home the Spanish and bilingual books with the student participants, they started telling me about how their families worked with them at home with those materials. Sofia constantly mentioned how she read both the Spanish and English books to her little brother, Dylan, and how her mother enjoyed reading the Spanish books with her. 
Sofia: $\quad$ My mom say that she like read it in Spanish that the baby not sleeping.

Sarah: Really?

Sofia: $\quad$ Um...

Sarah: This one? ¿El Bebe no Esta Dormido?

Sofia: Uh huh.

Sarah: That's the one I picked for you today! She likes to read that one?

Sofia: Yeah.

Sarah: Well, that's the one I'm going to send home with you today.

(Transcription 10-26-15)

Sofia's brother, Dylan, was “a major motivator for her reading at home in Spanish and English" (Researcher Journal 11-14-15). She expressed excitement whenever she got a new book sent home that she thought Dylan would enjoy. Both of her parents mentioned how grateful they were to have Spanish books in the home that Sofia could read on her own, to her brother, and that they could read as well. Before her lessons with me, the family had no Spanish books in the home for Sofia to read. Similarly, Isabel's mother mentioned how much Isabel enjoyed reading the Spanish books with her little sister and brother. Although Isabel's mother stated they did have other books in Spanish in the house, she was grateful for more. When we first started reading books in Spanish, Isabel even brought in the Spanish version of Goodnight Moon to show me another book her mother read to them.

Antonio's father seemed to be the main support for Antonio in his home literacy experiences in Spanish. Whenever Antonio talked about who read with him or other literacy activities, he always mentioned his father. With his mother working three jobs, 
she stated she wished she had more time to work with Antonio, but her schedule did not allow it. She was grateful Antonio had a supportive father to help. One of their favorite activities to do together involved the magnetic letters we used in each of our lessons during Word Work time and throughout other portions of the lesson. One day, Antonio asked if he could bring home some of the magnetic letters. His father had purchased a magnetic whiteboard the day before and Antonio wanted to practice making his last name at home. The next day on March 7, he made sure to show me how he could make his last name with the magnetic letters:

Antonio: I make it like this with my dad (spells last name with the magnetic letters). I did it!

Sarah: That's wonderful! I bet it feels good to be able to make your last name. You couldn't spell it last week. What a big change!

Antonio: I did it!

Sarah: Yes, you did.

Antonio: I want to make more words at home.

Sarah: Sounds good. Let's make a list.

After that lesson, we made a list of Spanish words Antonio wanted to make at home with his dad. The list included the names of his family members, as well as perro, gato, and color words. Another favorite activity was reading Antonio's cutup sentence every evening. After every lesson, the students had a cutup sentence from their written story from that lesson sent home. They were expected to reassemble it and glue it in their homework notebook and read it. Since some of Antonio's sentences were in Spanish or were about his cultural experiences, his father could participate in that activity with him. 
Antonio's father stated, "It felt good to help him. And he didn't need my help a lot. But I liked how he could read his words to me from the sentence and I felt like I was learning too" (Personal communication 2-13-16).

Families' involvement in the students' literacy experiences reinforced their use of their home language in their school lessons with me. The students and parents felt motivated and encouraged by having materials provided that they could use with confidence.

Parents' views. Another way in which I tried to involve the students' families more in their school experiences was through focus groups. In our focus groups, the students' parents had the opportunity to share their experiences at home and at school with their native language and what they observed concerning their children's experiences as well. They could also share their thoughts and feelings regarding their children's lessons, as well as any experiences from their home lives concerning their children's use of language and cultural experiences.

Parents' desires for more involvement. One finding from these focus groups was an overwhelming agreement that the parents wanted to be more involved in their children's school experiences. However, they also felt like their culture and language were barriers to that involvement. Sofia's mother shared, “I don't know how to be more part of the school. I come to PTA meetings. I come to parent conferences. I don't know what else. But I want to" (Focus group 10-23-16). Antonio's father expressed a similar feeling: "I feel you know Spanish and you like it. You like us and you want us here with our kids. But not other teachers" (Focus group 10-23-16). At the end of the first focus group meeting, I asked the parents to write down one idea that they would feel 
comfortable with doing to be more involved at Goodman Elementary. The ideas ranged from being a member of the School Improvement Council to having a day where they could make food from their cultures for the teachers and children to try.

Parent's views on biliteracy. Another finding from our focus group discussions was the parents' views on their children being able to speak, read, and write in Spanish at school versus at home. Sofia's mother and father shared their feelings:

Sarah: And what are your thoughts on the books I'm sending home? In Spanish? And sometimes her writing is in Spanish too? ¿Le gustan los libros que ella está recibiendo? Do you like the books she is getting?

Father: ¡Sí! Esta bien. Sí porque... Yes! It’s good! Yes, because...

Mother: Sí porque a mi importante a los dos linguas. Yes, because bothlanguages are important to me.

Sarah: Ok, then I'm going to continue to send more home with her every day. Because I agree. I think it's very important that both her English and her Spanish both become strong in her reading and writing. (Focus group 2-3-16)

Isabel's mother agreed and said, "Yo creo es muy importante leer y escribir en ingles y español. Español es la lengua de mi casa. Necesita los dos. I think it's very important to read and write in English and Spanish. Spanish is our home language. She needs both" (Focus group 2-3-16). The students' parents and I agreed on the importance of using both languages in their speaking, reading, and writing, which further reinforced the children's use of their home language and cultural experiences in their lessons with me. 
Other classroom and school experiences. As the students, their parents, and I continued to work together to strengthen the use of the students' home languages and cultural experiences in our lessons, our work started to spill over into other classrooms and settings in the school. One of these experiences included instructional changes in the classroom setting, and the other change came about in a school-wide manner.

Student-authored books. One example of this "spillover" was the writing of student-authored books in the regular classroom setting. Isabel took one of her authored books from our lessons and chose to share it with the rest of her class, with no prompting from me to do so. Isabel explained to me, "I read the book to my class! My friends think it was cool. I just wanted to share it with my class" (Transcription 1-28-16). After that, Isabel's teacher and other first grade teachers came to me to inquire about the process of student-authored books in English and Spanish, as well as the use of the students' cultural experiences in those books. After a few meetings together and my commitment to support the teachers in this new endeavor, two of those teachers then started the process with their students, including both home and school languages and students' cultural experiences in the writing process.

Parent-authored books. As those two classroom teachers became more comfortable with the idea of student-authored books, planning for the annual first grade Reading Picnic came up. In the past, teachers invited parents to come in and bring a blanket so they could read with their children while we provided a hot dog lunch. In addition, there were several literacy games and stations for the parents and children throughout the afternoon. During this year's planning process, I suggested asking parents if they would be willing to author a book in Spanish to share for our Read Aloud station. 
The other teachers agreed and we made sure the note sent home was in both English and Spanish. We had an overwhelming response from over 30 of our parents, which was many more parents than we needed for the Reading Picnic. We decided to include some of the parents as weekly read aloud authors to the first grade classrooms as well. Three of the six Latino parents who agreed to author a book in Spanish were Antonio's, Isabel's and Sofia's parents. Antonio's father wrote about his job as a painter and read it aloud at the Reading Picnic. Isabel's mother wrote about their latest visit to Mexico to see their family, and Sofia's father wrote about the neighborhood soccer team that he plays with every weekend. The children and parents were extremely proud of their accomplishment. Antonio said, "My dad was like an author like we learn. Like Mo Willems!" (Transcription 5-13-16). Isabel's mother told me, "Isabel (was) so happy when I start reading it. It was surprise for her" (Research journal 5-11-16). All the teachers unanimously agreed that parent-authored books should be a staple in our first grade literacy planning for the following year, whether in Spanish or English.

It is important to note that inviting Spanish-speaking parents to read their own authored books in Spanish to a class of children is a process that began months before the Reading Picnic event. Inviting the parents to first come and observe some of our Reading Recovery lessons was a first step that broke down initial barriers between home and school. Part of those observations included the parents watching their children write and illustrate a book in Spanish. Then, those books went home with the students, and the parents helped the students add even more pages. By the time I asked the parents if they would be willing to create their own short book to read to children, the idea of creating books in Spanish at home and at school was a familiar one. In addition, I provided all of 
the supplies the parents might need to create their book. The students were more than happy to deliver these materials to their parents and excitedly watch them begin the bookmaking process as well.

The involvement of the participants' families in our lessons and activities at school, as well as reading and writing experiences at home, helped build relationships among participants, families, and school faculty members. The students' support systems were varied and strong as they utilized their home languages and cultural experiences in school. Students felt stronger in their use of their cultural experiences and home languages in school settings, and their parents began to experience this confidence as well as they brought in their own literacy experiences to their children's school. This process also started to address the parents' concerns about their lack of involvement and the school's limited acceptance of their language and culture. Although they were small steps, the intentional actions of both parents and faculty members began to lessen the parents' overwhelming sense of division between their home lives and their children's school lives. 


\section{CHAPTER 5}

\section{DISCUSSION AND IMPLICATIONS}

In this chapter, I provide a discussion of the major findings related to this study of the impact of providing support for Spanish and English language and culture within Reading Recovery with emergent bilingual children while including their parents in that support network.I also discuss the implications of these findings for teachers, educational leaders, and future research. Given the restriction or outright exclusion of students' home languages and cultural experiences in their education, and teachers' uncertainty of the best ways to implement literacy instruction for emergent bilingual children, or how to include their parents in meaningful ways within the life of the school, I hoped to explore how students' home languages and cultural experiences affected reading and writing instruction and achievement in a literacy intervention setting, specifically in Reading Recovery lessons. I wanted to gain a better understanding of the impact of students' home languages and aspects of cultural diversity that influence reading and writing instruction. I also wanted to explore the instructional methods and materials used in the lessons that best supported these students' emerging bilingualism and the contribution of their families' involvement. I focused on gaining insights about three emergent bilingual children's ways of using their home languages and cultural experiences in conversation, reading, and writing during their instruction.

I organized this discussion of my findings by connecting them to my conceptual and theoretical framework, as well as theexisting literature. I present implications for 
both practice and future research, and these implications are developed as only a partial response to the problems addressed in this study.

\section{Discussion of the Findings}

Connection to conceptual/theoretical framework. My findings confirmed the tenets of my conceptual and theoretical framework: learning is a sociocultural process; reading and writing are socially constructed, meaning-making tools; and culturally relevant practices support the needs of all students.

Learning is a sociocultural process. The utilization of students' cultural experiences in their reading and writing, as well as the inclusion of their families in their literacy experiences, resulted in three students who were more confident in their abilities as readers and writers. The use of their home language encouraged them to take risks in their learning and motivated them. Because the students could use their home language to articulate their thoughts, ask questions, and clarify misconceptions, their abilities to read, write, and converse in English improved. They had multiple tools at their disposal to expand and deepen their learning as a result of including their home language and the use of their cultural and family experiences within Reading Recovery lessons. In essence, the support of their greater language facility in Spanish served through analogy, metaphor and example as a tool to better understand English as a language that was similar to and different from their mother tongue. This finding ties directly to Cummins (2000) and his belief in common underlying proficiency (CUP). Instead of believing all

languages are learned separately, the theory of common underlying proficiencies believes there are common skills and knowledge that a child acquires through the course of learning, and children can draw upon these skills when they work in other languages 
(Cummins, 2000). Similarly, Bialystok (2002) noted that children learning languages with similar phonologies have a greater likelihood of transferring phonological awareness skills between the two languages. Since children already have experience with manipulating the sounds and patterns in their native language, children are more adept with transferring those skills to another language that is similar. The data from this study clearly draws upon these theories. Although there are differences between the two languages, both Spanish and English are alphabetic languages with similar phonologies. Because of the commonality among the languages, the students transferred strategies between the languages and used what they knew in one language to help themselves in another.

This transfer of strategies between languages also reinforced my belief that learning takes place in cultural contexts and relies on the interdependence of individual and social processes in the construction of knowledge (Vygotsky, 1978). The social processes in this study were present in my interactions with the students, our conversations in both languages, as well as their construction of knowledge with their parents. The parents and the children had an intense desire to make sense of their new world, expand their own capabilities, and interact with others. Learning was and continues to be a sociocultural process for these three students and their families.

Reading and writing are socially constructed, meaning-making tools. Within the sociocultural contexts inside and outside of school, these three students used reading and writing to learn. I believe both are socially constructed, meaning-making processes. In this study, the more meaningful the reading and writing experiences were, the more authentic they were to the students. Seeing characters in books that looked like them and 
their families, connecting the plot of a book to their own lives, or writing about cultural experiences such as an upcoming trip to Mexico buoyed these students' motivation to read and write and to become more proficient as readers and writers.

The students in this study were constantly in a state of learning alongside their classmates, their family members, and other peers in their life. The more knowledgeable people were not always the teachers of the classroom. Oftentimes, Isabel, Sofia, and Antonio were the "more knowledgeable others" (Vygotsky, 1978) as I learned about their language and cultural experiences. The students' parents had the opportunities to be part of the scaffolding process for their children's literacy experiences as they read and wrote with themin their home language. The parents seized the opportunity to extend that knowledge through their participation in the school's evening with parents, the Reading Picnic event, where they shared their parent-produced books during the evening's read aloud experience. Within these sociocultural contexts of home and school, the children's peers and families supported their understanding that reading and writing are meaningful processes.

Culturally relevant practices support the needs of all students. Finally, the findings of this study confirmed my belief that instruction should be culturally relevant. In this study, the culturally relevant practices began with the utilization of the students' home languages and cultural experiences in their reading and writing instruction. I endeavored to make my classroom and lessons safe places for the students' language and experiences, and, as a result, they felt successful in their learningand grew in competence as readers and writers. The students' resulting confidence and their gains made in speaking, reading, and writing in both their home and school languages were evidence of 
how successful culturally relevant practices are for emergent bilingual children. There are certain aspects of Reading Recovery lessons that reflect culturally relevant pedagogy, including the identification and utilization of students' strengths, the focus on students' independence in reading and writing, and the building of a relationship between the Reading Recovery teacher and student. I believe this is one of the reasons why the Reading Recovery framework fit so well with the goals of the study.

Connection to existing literature themes.My findings also confirmed and extended existing studies and practices regarding the utilization of students' home languages and cultural experiences in reading and writing.

Aspects of literacy are interrelated and develop concurrently. The emergent literacy perspective considers all of a child's interactions with texts, print, reading, writing, and language as steps to becoming an independent reader and writer (Teale \& Sulzby, 1986). Through data analysis, I concluded all of these aspects of literacy were essential in Isabel's, Sofia's, and Antonio's journeys to literacy independence. For example, many of the strategic actions the students utilized in reading texts translated into similar processes in their writing. This kind of connection strengthened their understanding that a written message must convey meaning. Underlying both texts in reading and writing was the children's use of both English and their home languages. Every text the children wrote or read was cross-checked against the child's knowledge of the structure of the language of the texts, with varying levels of support from me or their parents.This principle thus supports the learning of multiple languages and language processes. As the children began to notice, many of the language concepts that exist in Spanish also exist in English; noticing how certain concepts operate in one language 
helped them notice specific similarities in the other language, which propelled their learning forward at a greater pace (Bialystok, 2002; Cummins, 2000).

Clay (2010) stressed the importance of the interrelatedness of writing, reading, and speaking, "As they write their earliest messages, children gradually begin to make links between speaking, reading, and writing. They may discover that: What I can say, I can write. And, what I can write, I can read" (p. 7). These connections were essential in this study as students used both their home and school languages in their reading and writing. The connections the students made between their home and school languages, the texts they read and wrote, and their cultural experiences confirmed this interrelatedness of reading, writing, speaking, and listening. When the OLAI-2 (Gentile, 2011) results showed a lack of past tense usage in Sofia's repeated sentences, my notes on her use of the past tense in her reading and writing reflected the same. However, once the past tense forms became a part of Sofia's oral communication, the use of past tense verbs soared in both reading and writing. What she could say, she could write. And what she could write, she could read (Clay, 2010).

Critical literacy theories have implications in pedagogy and learning. The view of literacy as power is a central tenet of critical theory. Freire (1970) believed literacy as power is literacy as a critical and transformative tool for changing existing social structures of oppression. While Isabel, Sofia, and Antonio did not specifically question why their culture and home language were not privileged in the school setting, there was an obvious disconnect between what they lived in the larger school setting and what they experienced in my classroom. They were able to articulate the fact that Spanish was not allowed in their classrooms, and they were at first surprised, then relieved, that Spanish 
as well as English could be freely used in my classroom. For their parents, our informal conversations and focus groups started to address the culture of silence (Edelsky, 1991) they experienced on a daily basis. The beginnings of trust and relationships between me, the students, and their families, slowly began to spread to the school community, and this challenged the fear of the unknown that pervaded Goodman Elementary. The students started using more than one language as an expression of their growing literacy, which transformed their stance from often-silenced or left out voices to children with a voice to share and new ways to celebrate their own growth and experiences.

Research has documented there arecommonly accepted assumptions about poor and diverse parents and the effect these beliefs can have on educators' treatment of these families and the children in their classroom (Compton-Lilly, 2004; Taylor\& DorseyGaines, 1988). I experienced the assumption that parents who cannot speak or read English cannot help their children with reading, a direct quote stated within a districtlevel May teacher meeting (see Chapter 4). There was clear evidence within the findings in this study that the parents did indeed read to their children, and did so using the bilingual books I sent home - they became part of the family literacy practices, shared by parents and children alike.

Research studies also stress that building relationships with families can help dispel these myths, realizing that "simplistic explanations that focus on negligence and incompetence are generally inaccurate and incomplete" (Compton-Lilly, 2004, p. 10). This study involved the students' parents in a variety of ways: inviting them to observe lessons, providing the resources to help their children read and write in their home language at home, reading their children's written stories about their cultural experiences, 
and inviting them as guest authors for the school-wide Reading Picnic event. The involvement of these emergent bilingual students' parents in the child's classroom or academic endeavors supported the families' home knowledge and encouraged bilingualism for all children. The process also highlighted the literacy strengths of the parents, which are typically undervalued or ignored in the school setting. We presented emergent bilingualism as helping, instead of hindering, the students' learning, and the inclusion of parents more openly in the life of the school began to have an impact on teachers' beliefs and practices.

Literacy education can fully support both native and nonnative languages. The findings of this study confirmed the body of literature that indicated developing literacy in a child's home language is a very important resource to students' reading and writing development in English (Calkins, 2003; Cummins, 2000; Fu, 2009; García \& Kleifgen, 2010; Hudelson, 1989; Samway, 2006). Additive bilingualism is an approach that supports all languages for students (Cummins, 2000), and this method resulted in studentsshowing a more developed awareness of language, which enhanced their academic resources, helped them communicate with their families, and created advantages in learning additional languages.For example, Antonio shared the magnetic letters from our lessons with his father at home. In turn, his father took action and supported his son's learning through those materials and the instructional techniques Antonio shared with him. Multiple researchers (Manyak, 2002; Samway, 2006; SolteroGonzalez, 2008) found significant advantages in the goal of children reading and writing in both languages. These practices support both students' native and nonnative languages and affirm the experiences and cultures of the students and communities who speak those 
languages. In my data analysis, I found the students' use of their home language supported both their reading and writing in that language as well as English. Many instances in the video transcriptions illustrated the children's use of one strategic reading or writing action in their home language and then the transfer of that same process to an English text. The children used their common underlying proficiencies (Cummins, 2000) in language to assist their transfer of strategic reading and writing action. Because the two languages are alphabetic and phonologically similar, the transfers between those languages were more easily facilitated (Bialystok, 2002). The students showed gains in the speaking, reading, and writing of both languages, which supported their creation of connections between these strategies in their spoken languages and the texts in which they were used.

Utilizing native languages in reading and writing. Related studies of the use of native language in students' reading or writing experiences and assessments (Butvilofsky \& Sparrow, 2012; Escamilla \& Coady, 2001; Cuero, 2010; De la Luz Reyes, 2012; Escamilla, 2007; Vaughn, Linan-Thompson, Mathes, Cirino, Carlson, Pollard-Durodola, Cardenas-Hagen \& Francis, 2006) stressed the benefits of students using what they know in one language to enhance understandings about literacy in another language. All three students in this study switched from English to their L1 and back throughout their conversations with me and across their reading and writing experiences. In doing this, their language resources were expanded in both languages, providing clear evidence for each of the three key ways language supports learning that Halliday (1975) discussed: 1) Learning language, 2) Learning through language, and 3) Learning about language. When these children had an insight about "language" in their home language, it served as a 
window through which to look at English, and significantly changed their ability to be more strategic as language learners. For example, when the students used a reading strategy in a Spanish text, they utilized the same strategy in the English text over $75 \%$ of the time. When Sofia and I used magnetic letters to build words like car, far, and star, she connected it to Spanish words with the same ending, "Hablar has -ar too! And jugar! Y nadar!” (Transcription12-11-15).

In multiple instances in the data, the students alsoused their home language to express themselves more clearly in conversations, and this helped them clarify their thoughts in their writing as well. Antonio especially used Spanish to articulate experiences or ideas that were more difficult to convey using English only. Other times, he would use Spanish to begin the idea and then quickly switch back to English. These instances led to more vivid and complex written stories. This finding confirms several researchers' recommendations to encourage students to use their L1 in their writing, increasing the amount and specificity in their stories, and clearer expressions of their writing voices (Cuero, 2010; Fu, 2009; Gort, 2006/2012; Hudelson, 1989; Samway, 2006).

Similarly, once the students had the freedom to use their home language in the reading of Spanish texts, they began using the strategic actions in those texts as they read the English texts as well. Having the Spanish texts to practice the application of reading strategies helped the students connect those same strategies to English reading. In the beginning, I was the one who prompted for these connections.However, as we continued to work in each child's zone of proximal development (Vygotsky, 1978), the students became the ones noticing the similarities and making the connections between what they 
were learning to do in both languages when reading. As the "noticing teacher" (Clay, 1991), I highlighted how each child could extend their own reading process and strategies. Opening this door led to the children going even further than my expectations with amazingly new responses, such as translating entire passages into Spanish without prompting or transferring reading and writing strategies independently between the two languages. Throughout our time learning together, I had to ensure I stayed open to surprises (Clay, 1998), instead of falling into the trap of my own expectations for the children.

Reading Recovery and Descubriendo la Lectura. The gains made by the students in this study confirmed the findings of multiple researchers who investigated the success emergent bilingual children experienced in Reading Recovery (Ashdown \& Simic, 2000; Hobsbaum, 1995; Neal \& Kelly, 1999). This study utilized students' home languages and cultural experiences to help them learn both their home language and the English language as they engaged in reading and writing. However, my main goal was the same goal for all Reading Recovery students: acceleration of their learning so that they could successfully discontinue Reading Recovery services when they were reading and writing at or above grade level in English. All three of the students achieved that goal in their English reading and writing. While their Spanish reading and writing data did not show the same amount of growth as their English, all three students still grew in their knowledge of how to read and write in Spanish simultaneously while they were learning how to read and write in English. These students were not in a school where their classroom literacy instruction was in Spanish; therefore, DLL was not a choice for their literacy intervention. Instead, I chose to use what they already knew from their home 
language and cultural experiences to support their learning as they read and wrotein English. This served to increase their confidence in reading and writing and impact their gains in reading and writing in both languages. I did not favor one language over another. Rather, I treated the two languages as equals, welcoming both for their unique utility in achieving the ultimate goal: strategic readers and writers who confidently developed a self-extending system (Clay, 2005) in their literacy learning. This method was a valuable extension of DLL, and welcoming both languages as equal resources in learning can also be utilized in the contexts of the classroom setting and other literacy interventions.

There was clear evidence that even when Reading Recovery services were discontinued early in the second half of the school year Sophia and Isabel continued to make impressive progress without need of additional intervention services. Antonio made very rapid progress when he began Reading Recovery lessons in the middle of the year, when he had made little progress prior to beginning intervention services, and he was reading at the average of his class at the end of the year. He, too, showed evidence of a self-extending system in his last weeks of instruction.

\section{Implications for Practice}

This study's findings suggest implications for practice for a variety of audiences: classroom teachers, interventionists, literacy coaches, administrators, and parents of emergent bilingual children. The kinds of support I offered to the students in the form of reading and writing bilingual and Spanish texts, writing about cultural experiences, and providing a space for the students to feel comfortable having conversations in their home language can all be replicated in other educational settings. 
Students' home languages and cultural experiences. Fear of the unknown has pervaded various areas of our lives. Teachers and administrators who are unfamiliar with emergent bilingual students' languages or their families' cultural experiences should open themselves to learning more about what is unfamiliar. Viewing emergent bilingual students' languages and experiences as additional helpful tools to expand their learning is an essential first step for teachers and educational leaders. Classroom teachers, even those who are unfamiliar with the students' home languages, can still provide the space for their students to use those languages, instead of punishing them for using their home language in the classroom. Making connections is an essential part of learning. Emergent bilingual students can make even more connections in their conversations and reading and writing experiences if they have the support to use all of what they know in the academic setting and their first language offers a valuable resource through which to clarify meanings, extend their ability to communicate more clearly, and as a window through which to gain insight through language about language. Their first language is a rich resource; to limit their use of such a great resource is to hold them back rather than help them leap forward!

Methods and materials. The kinds of methods and materials that best supported the students in this study were processes and products embedded in continuous texts used in authentic reading and writing experiences. In fact, the more authentic the continuous text, the more engaged the students were. Authenticity was defined by these students as Spanish books, Spanish writing, texts with characters that looked like them and their families, texts written by them about important family experiences, or texts written that expanded on a book with which they felt a strong connection. These kinds of experiences 
were not found in a basal reader, or a set of phonics flashcards,or materials created for a one-size-fits-all curriculum. Based on the findings of this study, I advocate the use of reading continuous texts while integrating strategic problem-solving within those texts (Clay, 2005). I was fortunate enough to have a large amount of texts provided by my Reading Recovery teacher leader, as well as an additional stipend from my principal to purchase Spanish texts. I am aware that not all districts or teachers have the opportunity to implement Reading Recovery in their schools. In those instances, I suggest enlisting the help of students and their families. Some of the best books I read through the duration of this study were written by Isabel, Sofia, Antonio, and their families. The ESOL teachers at Goodman were another resource for materials. They provided handouts with Spanish words and phrases for classroom teachers at their request, as well as online resources for free, printable bilingual books for the students to keep at home.

Family involvement. The involvement of the students' families in their literacy experiences and school activities contributed to their utilization of their home languages and cultural experiences in school. The connection between the parents and myself was an additional pillar of support for these students. School teachers and administrators need to explore more ways to include all families' viewpoints and opinions more consistently. No Spanish-speaking family members were on the Goodman Elementary School Improvement Council, Parent Teacher Association, or Leadership Team at the time of this study. The parents in this study expressed the need for more Spanish-speaking families' input in the daily operations of the school and ways to provide more space for their children's home languages and experiences. While the inclusion of Spanishspeaking parents and their self-authored books at the Reading Picnic event was a solid 
first step, the inclusion of these families in a more purposeful and systemic way needs to be a priority. Opening the space for these families to voice their needs and opinions while including their languages and cultures in the school settingwill bring about better results for emergent bilingual children and foster cross-cultural understandings across all stakeholders (teachers, parents, support staff, and administrators).

\section{Implications for Future Research}

I interacted with three students and their families in one school for a relatively short amount of time. While this research added to the existing literature on the utilization of students' home languages and cultural experiences in literacy practices, the findings from my case study may have differed had I spent time with different students in another setting for a longer period of time. However, an important aspect of this study was my belief that these students and families deserved to have the space to use their home languages and cultural experiences in a school setting. I viewed their home language as equally as important as English and their cultural experiences as rich "funds of knowledge" (Moll et al., 2005). Throughout this study, I met some opposition and many questions about my beliefs and the effect of those beliefs on the students' literacy experiences. Although these children were viewed through a deficit lens by many, the data and findings from this study provide a counter argument to this view. Regardless of their proficiency in the English language, these children showed skill in their ability to learn and apply that new learning in language, reading, and writing experiences. I expected something amazing from them, and they rose to that expectation and exceeded it many times. This resistance I encountered stemmed not only from other teachers and school leaders, but was also something with which I personally grappled. Themes of 
fear, power, and permission permeated this study, even in my personal notes and interactions with the students. I doubted my beliefs and actions more times than I ever thought I would. Therefore, I believe further research should be conducted on teachers' beliefs about emergent bilingual students' home languages and cultures and the significance of those beliefs on their interactions with students and parents.

Even though the students in this study spoke Spanish, they did not receive literacy instruction in Spanish in their homeroom. I did not use Descubriendo la Lectura (DLL) for these Spanish-speaking students. Instead, I incorporated their language within some of our conversations, some of our reading and writing experiences, and supported their writing about their cultural experiences within the Reading Recovery framework. It felt like a hybrid model between Reading Recovery and DLL, which, in turn, made me wonder about the gray space between DLL and Reading Recovery. Future research could continue to explore Reading Recovery lessons with emergent bilingual students and how their home languages and cultural experiences can be embedded throughout.

My case study involved three students whose home language was Spanish. I believe future research should continue to explore the issues of emergent bilingual students of other languages and backgrounds and their utilization of their home languages and cultural experiences in school settings. These future research studies could include a greater number of students or could follow these students for a longer period of time than my resources allowed.

\section{Conclusion}

Throughout the course of this study, I had the opportunity to study my own practice, learn about myself as a learner and teacher, and gain some insights. Antonio, 
Isabel, Sofia, and I were from very different cultural and linguistic backgrounds. However, that did not stop me from creating the space they needed to help them use every tool at their disposal to move them forward in their reading, writing, and language skills. The support I provided through Spanish and bilingual books, student-created books in the language of their choice, and the consistent invitation to speak in the language that best fit their needs can be offered by any educator, regardless of their background or language knowledge. Inviting the students to utilize their home languages and cultural experiences in our time together greatly enriched our lessons and our relationships. I believe the same effect would follow other classroom teachers, interventionists, or educational leaders who care enough to open the doors for these students. I also learned that even with the confidence I had in what I was doing for these children, I still felt fear and doubt during the times when I forgot to trust them. These children surprised me on a regular basis with what they could do in reading and writing in both languages. They made thoughtful connections that I, a veteran teacher, would never think to make. However, the times when I doubted them and their abilities is when we both faltered. Whenever I let my own expectations impede their progress, I had to right the course and place my confidence in the children and the work we can do together.

The restriction or exclusion of students' home languages and cultural experiences in their education motivated this study. Including students' home languages and cultural experiences in their reading and writing is not a universal solution for eradicating all narrow visions of language in classrooms. However, opening the classroom spaces in this way is an essential first step. Understanding students from diverse groups involves taking a risk outside the safety of our classrooms and inviting families from cultures 
different from our own to collaborate with us in the education of their children. Each community "has its own strengths and style of discourse, stories, symbols, rituals, and routines that can inform educators" (Boutte \& Hill, 2006). Unfortunately, all schools are not actively taking the necessary steps to learn from these familiesor capitalize upon the support they offer in their children's learning in the home.

At the conclusion of this case study, questions still remain that extend into other classrooms at other schools with other children. One of those lingering questions looks beyond the literacy experiences and focuses on the connections between home and school: How can we further bridge the gap between home and school? Another question asks: What are the long-term impacts on students when we silence their voices and essentially eradicate their home languages and cultures through shaming, exclusion, or neglect? Before this case study, these three children were fearful of their own language. Their identity at home and their identity at school were two disparate personalities. It seemed natural to them to forge a link between the two languages they speak and their school and home experiences. Instead of severing the ties between home and school, thereby silencing a multitude of voices and experiences, we must support children and their families in the building of these connections between learning contexts, languages, and people. 


\section{REFERENCES}

Adams, G.N. \& Brown, S.M. (2007). The six-minute solution: A reading fluency program. Longmont, CO: Sopris West.

Adichie, C. (2009, July). The danger of a single story. [Video File]. Retrieved from https://www.ted.com/talks/chimamanda_adichie_the_danger_of_a_single_story?1 anguage $=$ en .

Andrade, A.M., Basurto, A.G.M., Clay, M.M., Ruiz, O.A., Escamilla, K. (1995). Instrumento de observación de loslogros de la lecto-esciturainicial. Portsmouth, NH: Heinemann.

Ashdown, J.\&Simic, O. (2000). Is early literacy intervention effective for English language learners? Evidence from reading recovery. Literacy Teaching and Learning: An International Journal of Early Reading and Writing, 5 (1), 27-42.

Batalova, J., Fix, M. \& Murray, J. (2007). Measures of changes: The demography and literacy of adolescent English learners. Washington, DC: Migration Policy Institute.

Beaver, J. (2006). Developmental reading assessment. New York, NY: Pearson.

Bialystok, E. (2002). Acquisition of literacy in bilingual children: A framework for research. Language Learning, 52(1), 159-199.

Bissex, G. L. (1980). GNYS AT WRK: A child learns to write and read. Cambridge, MA: Harvard University Press.

Boutte, G.S. \& Hill, E.L. (2006). African American communities: Implications for 
culturally relevant teaching. New Educator, 2(4), 311-329.

Brock, C., McVee, M., Shojgreen-Downer, A. \& Flores Dueñas, L. (1998). No hablainglés: Critically exploring the construction of an English language learner's access to classroom discourse in a predominantly English-speaking classroom. The Bilingual Research Journal, 22, 175-200.

Browne, A. (2001). Voices in the park. London: DK Children.

Butler, D. (1980). Cushla and her books. Boston, MA: Horn Book.

Butvilofsky, S., Sparrow, W. (2012). Training teachers to evaluate emerging bilingual students' biliterate writing. Language and Education, 26 (5), 383-403.

Calkins, L. (2003). The nuts and bolts of teaching writing. Portsmouth, NH: Heinemann.

Canagarajah, A. S. (2011). Codemeshing in academic writing: Identifying teachable strategies of translanguaging. The Modern Language Journal, 95, 401-417.

Chasnoff, D., Cohen, H. S. (1996). It's elementary: Talking about gay issues in school. Harriman, N.Y.: New Day Films.

Clark, L.W. \& Whitney, E. (2009). Walking in their shoes: Using multiple-perspective texts as a bridge to critical literacy. The Reading Tacher, 62 (6), 530-534.

Clay, M.M. (1966). Emergent reading behavior. Unpublished doctoral dissertation. University of Auckland, New Zealand.

Clay, M.M. (1975). What did I write? Beginning writing behaviour. Auckland, NZ: Heinemann.

Clay, M.M. (1979). Reading: The patterning of complex behavior. Portsmouth, NH: Heinemann.

Clay, M.M. (1982). Observing young readers. Exeter, NH: Heinemann. 
Clay, M.M. (1991). Becoming literate: The construction of inner control. Auckland, New Zealand: Heinemann.

Clay, M.M. (1993). Reading Recovery: A guidebook for teachers in training. Portsmouth, NH: Heinemann.

Clay, M.M. (1998). By different paths to common outcomes. Portland, ME: Stenhouse. Clay, M.M. (2000). Concepts about print. Portsmouth, NH: Heinemann.

Clay, M.M. (2001). Change over time in children's literacy development. Portsmouth, NH: Heinemann.

Clay, M.M. (2005). Literacy lessons designed for individuals part one: Why? When? And how? Portsmouth, NH:Heinemann.

Clay, M.M. (2010). The puzzling code. Portsmouth, NH: Heinemann.

Clay, M.M. (2013). An observation survey of early literacy achievement. Portsmouth, NH: Heinemann.

Coady, M. \& Escamilla, K. (2005). Audible voices, visible tongues: Using Spanish speaking students' writing to explore social realities and inequities. Language Arts, 82 (6).

Compton-Lilly, C. (2004). Confronting racism, poverty, and power. Portsmouth, NH: Heinemann.

Compton-Lilly, C., \& Green, S. (2010). Bedtime stories and book reports: Connecting parent involvement in family literacy. New York, NY: Teachers College Press.

Crawford, J. (2004). Educating English learners: Language diversity in the classroom. Los Angeles: Bilingual Educational Services Inc.

Cuero, K. (2010). Artisan with words: Transnational funds of knowledge in a bilingual 
Latina's narratives. Language Arts, 87 (6), 427-436.

Cummins, J. (2000). Languages, power, and pedagogy: Bilingual children in the crossfire. Clevedon, England: Multilingual Matters.

DeFord, D. (2004). Programa de evaluacion de lectura y escritura Dominie K-3. New York:Pearson.

DeNicolo, C. (2010). What language counts in literature discussion? Exploring linguistic mediation in an English language arts classroom. Bilingual Research Journal, $33(2), 220-240$.

De Gaetano, Y. (2007). The role of culture in engaging Latino parents' involvement in school. Urban Education 42(2), 145-162.

De la Luz Reyes, M. (2012). Spontaneous biliteracy: Examining Latino students' untapped potential. Theory Into Practice, 51 (4), 248-255.

Delgado Gaitan, C. (1991). Involving parents in the schools: A process of change for involving parents. American Educational Research Journal, 100(1), 20-46.

Delgado Gaitan, C. (1992). School matters in the Mexican-American home: Socializing children to education. American Educational Research Journal, 29(3), 495-513.

Delgado Gaitan, C. (2004). Involving Latino families in schools. Thousand Oaks: Corwin Press.

Delpit, L. (1988) The silenced dialogue: Power and pedagogy in educating other people's children. Harvard Educational Review, 58 (3), 280-299.

Donaldson, M. (1978). Children's minds. New York, NY: WW Norton.

Dyson, A.H. (1991). The word and the world: A reconceptualization of written language development. Research in the Teaching of English, 25. 
Edelsky, C. (1991) With literacy and justice for all. London and Bristol, PA: Taylor \& Francis.

Escamilla, K. (1994). Descubriendo la Lectura: An early intervention literacy program in Spanish. Literacy, Teaching, and Learning, 1(1), 57.

Escamilla, K. (2007) The role of code-switching in the written expression of early elementary simultaneous bilinguals. Paper presented at the Annual Conference of the American Education Research Association, Chicago, IL.

Escamilla, K., Andrade, A., Basurto, A. and Ruiz, O. (1996) Instrumento de observación de loslogros de la lecto-escriturainicial. Portsmouth, NH: Heinemann.

Escamilla, K. \&Coady, M. (2001). Assessing the writing of Spanish speaking students: Issues and suggestions. In J. Tinajero and S. Hurley (eds.), Handbook for Literacy Assessment for Bilingual Learners. Boston: Allyn \& Bacon, 43-63.

Escamilla, K., Loera, M., Ruiz, O., \& Rodríguez, Y. (1998). An examination of sustaining effects in Descubriendo La Lectura programs. Literacy Teaching and Learning: An International Journal of Early Reading and Writing, 3(2),59-81.

Escamilla, K., Loera, M., Ruiz, O. \& Rodriguez, Y. (2003). An examination of sustaining effects in Descubriendo La Lectura programs. In Forbes, S. \& Briggs, C. (Eds.) Research in Reading Recovery Volume Two. Portsmouth, NH: Heinemann.

Ferreiro, E. \&Teberosky, A. (1982). Literacy before schooling. Exeter, NH: Heinemann.

Fountas, I. \&Pinnell, G. (2009). Leveled literacy intervention. Portsmouth, NH: Heinemann.

Fountas, I. \&Pinnell, G. (2010). Benchmark assessment system. Portsmouth, NH: Heinemann. 
Freire, P. (1970). Pedagogy of the oppressed (M. B. Ramos, trans.). New York:

Continuum.

Fu, D. (2009). Writing between languages: How English Language Learners make the transition to fluency. Portsmouth, NH: Heinemann.

García, O. (2012). Theorizing translanguaging for educators. In C. Celic\& K. Seltzer (Eds.) Translanguaging: A CUNY-NYSIEB guide for educators (1-6). New York: The City University of New York.

García, O. \&Kleifgen, J.A. (2010). Educating emergent bilinguals: Policies, programs, and practices for English Language Learners. New York: Teachers College Press.

García, O., Kleifgen, J. \&Falchi, L. (2008). From English language learners to emergent bilinguals. New York: Teachers College.

Garcia Coll, C. T., Akiba, D., Palacios, N., Bailey, B., Silver, R., DiMartino, L., Bailey, B. (2002). Parental involvement in children's education: Lessons from three immigrant groups. Parenting: Science and Practice, 2, 303-324.

Gay, G. (2010). Culturally responsive teaching: Theory, research, and practice. New York: Teachers College Press.

Gentile, L. M. (2003). The research base for the oral language acquisition inventory and oracy instructional guide. Carlsbad, CA: Dominie Press.

Gentile, L.M. (2004). Oracy instructional guide linking research and theory to assessment and instruction. Carlsbad, CA: Dominie Press.

Gentile, L.M. (2011). Oral language acquisition inventory (2nd ed). Bloomington, MN: Pearson. 
Gillanders, C. \& Jimenez, R.T. (2004). Reaching for success: A close-up of Mexican immigrant parents in the USA who foster literacy success for their kindergarten children. Journal of Early Childhood Literacy, 4(3), 243-269.

Glesne, C. (2011). Becoming qualitative researchers: An introduction (4 ${ }^{\text {th }}$ ed.). Boston, MA: Pearson Education, Inc.

Goldenberg, C., Gallimore, R., Reese, L., \&Garnier, H. (2001). Cause or effect? A longitudinal study of immigrant Latino parents' aspirations and expectations of their children's school performance.American Educational Research Journal, $38(3), 547-582$.

Gonzalez-DeHass, A. \& Willems, P. (2003). Examining the underutilization of parent involvement in the schools. The School Community Journal, 13, 85-99.

Goodman, Y. (1997). Multiple roads to literacy. In D. Taylor (Ed.) Many families, many literacies: An international declaration of principles (56-62). Portsmouth, NH: Heinemann.

Gort, M. (2006). Strategic code-switching, interliteracy, and other phenomena of emergent bilingual writing: Lessons from first grade dual language classrooms. Journal of Early Childhood Literacy, 6 (3).

Green, C.L., Walker, J.M.T., Hoover-Dempsey, K.V., Sandler, H.M. (2007). Parents' motivations for involvement in children's education: An empirical test of a theoretical model of parental involvement. Journal of Educational Psychology, 99, 532-544.

Greene, J.P. (1998). A meta-analysis of the effectiveness of bilingual education. Tomas Rivera Policy Institute. 
Gregory, E., Long, S., \& Volk, D. (Eds.). (2004). Many pathways to literacy: Young children learning with siblings, grandparents, peers, and communities. New York: Routledge.

Guitierez, K. (1995). Developing a sociocritical literacy in the third space. Reading Research Quarterly, 43 (2), 148-164.

Halliday, M.A.K. (1975). Learning how to mean: Explorations in the development of language. London: Edward Arnold.

Hankins, K.H. (2003). Teaching through the storm: A journal of hope. New York, NY: Teacher's College Press.

Harcourt Assessment (1994). Aprenda®: La prueba de logrosenespañol, Terceraedición. San Diego, CA: Harcourt Brace.

Heath, S.B. (1983). Ways with words. New York: Cambridge University Press.

Hernandez, A. (2001). The expected and unexpected literacy outcomes of bilingual students. Bilingual Research Journal (25), 3, 301-326.

Hobsbaum, A. (1995). Reading recovery in England. Literacy Teaching and Learning: An International Journal of Early Reading and Writing, 1, 21-39.

Hoover-Dempsey, K.V., Bassler, O.C., \&Brissie, J.S. (1992). Explorations in parentschool relations. Journal of Educational Research, 85, 287-294.

Hoover-Dempsey, K. V., Walker, J. M.T., Sandler, H. M., Whetsel, D., Green, C. L., Wilkins, A. S., \&Closson, K. (2005). Why do parents become involved? Research findings and implications. Elementary School Journal (106), 105-130.

Horner, B., Lu, M., Royster, J., \&Trimbur, J. (2011). Language difference in writing: Toward a translingual approach. College English, 73 (3), 303-321. 
Hudelson, S. (1989). Write on: Children writing in ESL. New Jersey: Prentice Hall.

Jones, S. (2013). Critical literacies in the making: Social class and identities in the early reading classroom. Journal of Early Childhood Literacy, 13 (2), 197-224.

Kinloch, V. (2009). Harlem on our minds: Place, race, and the literacies of urban youth. New York, NY: Teachers College Press.

Krashen, S. (2004). Under attack: The case against bilingual education. Culver City, CA: Language Education Associates.

Ladson-Billings, G. (2009). The dreamkeepers: Successful teachers of African American children. San Francisco, CA: Jossey-Bass.

Lankshear, C. \&McClaren, P., eds. (1993). Critical literacy: Radical and postmodernist perspectives. Albany, NY: SUNY Press.

Manyak, P. (2002). "Welcome to Salon 110": The consequences of hybrid literacy practices in a primary-grade English immersion class. Bilingual Research Journal, 6 (2), 421-442.

Mapp, K. L. (2003). Having their say: Parents describe why and how they are engaged in their children's learning. School Community Journal, 13(1), 35-64.

Marinez-Lora, A.M. \& Quintana, S.M. (2009). Low-income urban African American and Latino parents' school involvement: Testing a theoretical model. School Mental Health, 1(4), 212-228.

Martens, P. (1996). I already know how to read: A child's view of literacy. Portsmouth, NH: Heinemann.

Moll, L.C., Amanti, C. \& Gonzalez, N. (2005). Funds of knowledge: Theorizing practices in households and classrooms. Mahwah, NJ: Lawrence Erlbaum Associates. 
Murillo, L. (2012). Learning from bilingual family literacies. Language Arts, 90 (1), 1829.

National Center for Education Statistics (2001). Condition of education. Jessup, MD: U.S. Department of Education.

National Center for Education Statistics (2006). Characteristics of schools, districts, teachers, principals, and school libraries in the United States: 2003-04 Schools and staffing survey. Jessup, MD: U.S. Department of Education.

Neal, J., \& Kelly, P. (1999). The success of Reading Recovery for English language learners and Descubriendo la Lectura for bilingual students in California. Literacy Teaching and Learning: An International Journal of Early Reading and Writing, 4(2), 81-108.

Newkirk, T. (1989). More than stories: The range of children's writing. Portsmouth, NH: Heinemann.

Nieto, D. (2009). A brief history of bilingual education in the United States. Perspectives on Urban Education (Spring 2009), pg. 61-72.

Nieto, S. (1992). Affirming diversity: The socio-political context of multicultural education. In Fraser, J. (Ed.) (2000). The school in the United States: A documentary history. Boston: McGraw-Hill.

Nieto, S. (2009). The light in their eyes: Creating multicultural learning communities. New York: Teachers College Press.

Pahl, K., \&Rowsell, J. (2010). Artifactual literacies: Every object tells a story. New York: Teachers College Press.

Patton, M. (1980). Qualitative evaluation methods. New York, NY: Sage Publications. 
Patton, M. (2002). Qualitative research and evaluation methods. New York, NY: Sage Publications.

Ray, K. W. \& Glover, M. (2008). Already ready: Nurturing writers in preschool and kindergarten. Portsmouth, NY: Heinemann.

Read, C. (1971). Preschool children's knowledge of English phonology. Harvard Educational Review, 41, 1-34.

Read, C. (1986). Children's creative spelling. Routledge.

Rodriguez, Y. (2001). Descubriendo la Lectura in the United States. Journal of Reading Recovery, 1(1), 27-34.

Rodriguez-Valles, F. (2011). Coexisting languages: Reading bilingual books with biliterate eyes. Bilingual Research Journal (34), 19-37.

Rogoff, B. (2003). The cultural nature of human development. New York: Oxford University Press USA.

Romeo, K., Gentile, L., Bernhardt, E. (2008). Sentence repetition and story retelling as indicators of language proficiency in young bilingual children. $57^{\text {th }}$ Yearbook of the National Reading Conference. Oak Creek, WI: National Reading Conference.

Ruiz, R. (1984). Orientations in language planning. The Journal for the National Association for Bilingual Education, 8 (2), 15-34.

Samway, K.D. (2006). When English Language Learners write: Connecting research to practice, $K-8$. Portsmouth, NH: Heinemann.

Schram, T.H. (2006). Conceptualizing and proposing qualitative research. Boston, MA: Pearson Education, Inc.

Smith, F. (2005). Reading without nonsense. New York: Teachers College Press. 
Smith, F. (2013). Writing and the writer. London: Routledge.

Soltero-Gonzalez, L. (2008). The hybrid literacy practices of young immigrant children: Lessons learned from an English-only preschool classroom. Bilingual Research Journal, 31, 75-93.

Southern Education Foundation (2010). The new diverse majority report. Atlanta, GA: Southern Education Foundation Inc.

Souto-Manning, M. (2009). Negotiating culturally responsive pedagogy through multicultural children's literature: Towards critical democratic literacy practices in a first grade classroom. Journal of Early Childhood Literacy, 9(1), 50-74.

Sprick, M. (2007). Read Well@ Longmont, CO: Sopris West.

Taylor, D. (Ed.). (1997) Many families, many literacies: An international declaration of principles. Portsmouth, NH: Heinemann.

Taylor, D. \& Dorsey-Gaines, C. (1988). Growing Up Literate. Portsmouth, NH: Heinemann.

Teale, W. H.\&Sulzby, E. (1986). Emergent literacy: Writing and reading. Norwood, NJ: Ablex.

Trevino, R. E. (2004). Against all odds: Lessons from parents of migrant high-achievers. In C. Salinas \& M. E. Fra'nquiz (Eds.), Scholars in the field: The challenges of migrant education. Charleston, WV: AEL.

Trumbull, E., Rothstein-Fisch, C. \& Hernandez, E. (2003) Parent involvement in schooling: According to whose values? The School Community Journal, 13(2),45-72.

Valdés, G. (1996). Con Respeto: Bridging the Distances Between Culturally Diverse 
Families \& Schools. New York, NY: Teachers College Press.

Vaughn, S., Linan-Thompson, S., Mathes, P., Cirino, P., Carlson, D., Pollard-Durodola, S., Cardenas-Hagen, E., Francis, D. (2006). Effectiveness of Spanish intervention for first-grade English language learners at risk for reading difficulties. Journal of Learning Disabilities (39), 1, 56-73.

Vygotsky, L. (1978). Mind in society: The development of higher psychological processes. Cambridge, UK: Cambridge University Press.

Walker, J.M.T, Ice, C. L., Hoover-Dempsey, K.V., \& Sandier, H. M. (2011). Latino parents' motivations for involvement in their children's schooling: An exploratory study. Elementary School Journal (111), 409-429.

Wells, G. (1999). Dialogic inquiry: Towards a sociocultural practice and theory of education. Cambridge, UK: Cambridge University Press.

Wertsch, J. (1985). Vygotsky and the social formation of the mind. Cambridge, MA: Harvard University Press.

Wiley, T. (1999). What happens after English is declared the official language of the United States? In: Kibbee, D.A. (ed) (1998) Language Legislation and Linguistic Rights. Selected Proceedings of the Language Legislation and Linguistic Rights Conference, the University of Illinois at Urbana-Champaign, March 1996. Philadelphia, PA: John Benjamins Publishing Company.

World Class Instructional Design and Assessment Consortium. (2012). The English language development standards. University of Wisconsin-Madison, WI: WIDA.

World Class Instructional Design and Assessment Consortium. (2013). ACCESS for ELLs. University of Wisconsin-Madison, WI: WIDA. 
Yin, R. (2014). Case study research: Design and methods. Thousand Oaks, CA:

Sage Publications. 


\section{APPENDIX A}

\section{INVITATION LETTER AND PERMISSION FORM (ENGLISH)}

Dear

My name is Sarah Catto. I am a doctoral candidate in the Department of Instruction and Teacher Education at the University of South Carolina. I am conducting a research study as part of the requirements of my degree in Language and Literacy, and I would like to invite your child to participate.

I am studying the effects of children using their home languages while being served in literacy interventions. If you decide to allow your child to participate, your child will be asked to complete some surveys about what they think about reading and writing and meet with me for an interview about using their home language. These surveys and interviews will take place at the school during the school day and should last about 15 minutes. The interview, as well as the instruction your child receives in literacy interventions, will be videotaped so that I can accurately reflect on what is discussed. Only I will review the recordings to transcribe and analyze them. The recordings will then be deleted.

Participation is confidential. Study information will be kept in a secure location at the University of South Carolina. The results of the study may be published or presented at professional meetings, but your identity will not be revealed.

Allowing your child to take part in the study is your decision. Your child does not have to be in this study if you do not your child to take part. Your child may also quit being in the study at any time or decide not to answer any question your child is not comfortable answering.

I am happy to answer any questions you have about the study. If you have any questions about your child's rights as a research participant, you may contact the Office of Research Compliance at the University of South Carolina at 803-777-7095.

Thank you for your consideration. If you would like to participate, please complete the consent form attached to this letter. When you are done, please return it to your child's classroom teacher. 


\section{Parental Permission Form}

\section{Researcher: Sarah Catto}

I have read the information contained in the letter/memo about the above titled study, which describes what my child will be asked to do if (s)he wants to participate in the study; and,

$\square \quad$ Yes - I give permission for my child to participate in the study.

-OR-

$\square \quad$ No - I do not give permission for my child to participate in the study. 


\section{APPENDIX B}

\section{INVITATION LETTER AND PERMISSION FORM (SPANISH)}

\section{Estimado}

Mi nombre es Sarah Catto. Soy un candidato doctoral en el Departamento de Instrucción y Formación del Profesorado en la Universidad de Carolina del Sur. Estoy llevando a cabo un estudio de investigación como parte de los requisitos de licenciatura en lenguaje, y me gustaría invitar a su niño a participar.

Estoy estudiando los efectos de los niños mediante sus lenguas mientras se sirve en las intervenciones del leyendo y escribiendo. Si usted decide permitir que sus hijos participen, se pedirá su hijo a completer algunas encuestas sobre lo que piensan sobre la lectura y la escritura y reunirse conmigo para una entrevista sobre el uso de su lengua. Estas encuestas y entre vistas se llevará a cabo en la escuela durante el día escolar y debe durar unos 15 minutos. La entrevista, así como la instrucción de que su hijo recibeen las intervenciones del leyendo y escribiendo será video grabado para que exactamente puedo reflexionar en lo que se discute. Sólo los miembros del equipo de investigación revisará las grabaciones para transcribir y analizarlos. Luego se eliminarán las grabaciones.

La participación es confidencial. Información del estudio se mantendrá en un lugar segur o en la Universidad de Carolina del Sur. Los resultados del studio pueden ser publicados o presentados en reunions profesionales, pero no se revelará su identidad.

Permitir que su niño a participar en el studio es su decisión. Su hijo no tiene que participar en este estudio, si lo hace no a su hijo para participar. Su niño también puede dejar de estar en el studio en cualquier momento o decidir no responder cualquier pregunta que su hijo no es cómodo de responder.

Estoy feliz de contester cualquier pregunta que tenga sobre el estudio. Si usted tiene alguna pregunta sobre los derechos de su hijo como un participante de la investigación, pued ecomunicarse con la oficina de cumplimiento de la investigación en la Universidad de Carolina del Sur al 803-777-7095.

Gracias por su consideración. Si desea participar, por favor complete el formulario de consentimiento que se adjunta a esta carta. Cuando termines, devuelva al maestro de su hijo. 
Forma de Permiso de Los Padres

Investigador: Sarah Catto

He leído la información contenida en la carta/nota sobre el studio titulado, que describe lo que mi hijo se va a pedir a si quiere participaren el estudio; y,

$\square \quad$ Sí, doy mi consentimiento para que mi hijo/a participar en el estudio.

$-\mathrm{O}-$

$\square \quad$ No, no se la doy permiso para que mi hijo a participar en el estudio.

Firma del Padre/guardián

Fecha

Firma del Padre/guardian

(2)

